\title{
Infection Models of Intracellular Staphylococcus aureus and The Impact of Interleukin 12 on Macrophage Killing Activity
}

Therwa Hamza

West Virginia University

Follow this and additional works at: https://researchrepository.wvu.edu/etd

\section{Recommended Citation}

Hamza, Therwa, "Infection Models of Intracellular Staphylococcus aureus and The Impact of Interleukin 12 on Macrophage Killing Activity" (2012). Graduate Theses, Dissertations, and Problem Reports. 4862. https://researchrepository.wvu.edu/etd/4862

This Dissertation is protected by copyright and/or related rights. It has been brought to you by the The Research Repository @ WVU with permission from the rights-holder(s). You are free to use this Dissertation in any way that is permitted by the copyright and related rights legislation that applies to your use. For other uses you must obtain permission from the rights-holder(s) directly, unless additional rights are indicated by a Creative Commons license in the record and/ or on the work itself. This Dissertation has been accepted for inclusion in WVU Graduate Theses, Dissertations, and Problem Reports collection by an authorized administrator of The Research Repository @ WVU.

For more information, please contact researchrepository@mail.wvu.edu. 


\title{
Infection Models of Intracellular Staphylococcus aureus and The Impact of Interleukin 12 on Macrophage Killing Activity
}

\author{
Therwa Hamza
}

Dissertation submitted to the School of Pharmacy at West Virginia University in partial fulfillment of the requirements for the degree of

\author{
Doctor of Philosophy
}

In

Pharmaceutical and Pharmacological Sciences Program

\author{
Bingyun Li, Ph.D., Chair/Mentor \\ Patrick Callery, Ph.D. \\ Peter Gannett, Ph.D. \\ Yon Rojanasakul, Ph.D. \\ Kathleen Brundage, Ph.D., External \\ Department of Pharmaceutical and Pharmacological Sciences Program
}

Morgantown, West Virginia

Fall 2012

Keywords: osteomyelitis, Staphylococcus aureus, infection, interleukin 12, cytokine, osteoblast, macrophage, rat, intracellular S. aureus. Copyright 2012 Therwa Hamza. 


\section{$\underline{\text { ABSTRACT }}$ \\ Infection Models of Intracellular Staphylococcus aureus and the Impact of Interleukin 12 on Macrophage Killing Activity}

\section{Therwa Hamza}

Staphylococcus aureus (S. aureus) is the predominant cause of bone and joint infections worldwide. These infections may lead to severe bone and joint destruction and high mortality. Treatment of bone infections frequently requires long-term hospitalization for repeated debridement and prolonged antibiotic treatment. Bacteria including S. aureus, however, are often surprisingly successful in overcoming both host defense mechanisms and antibiotic treatments resulting in chronic and recurrent bone infections. Indeed, a high rate of recurrence or relapse of bone infections has been reported where $\sim 17 \%$ of infections related to traumatic extremity injuries recur or relapse. One thought is that bacteria like $S$. aureus used to elude host defenses and antibiotic treatments are able to "hide" themselves intracellularly within host cells.

S. aureus has conventionally been considered as an extracellular pathogen, but there is growing evidence showing that it can survive intracellularly within host cells. Once internalized into host cells, S. aureus may elicit a pro-inflammatory response often characterized by the secretion of interleukin $1 \beta$ (IL-1 $\beta$ ), IL-6, IL-12p70 (IL-12), and tumor necrosis factor- $\alpha$ (TNF- $\alpha$ ) among other cytokines. Production of pro-inflammatory cytokines from infected osteoblasts may disrupt the balance of the immune system thereby leading to uncontrolled inflammation and bone destruction. On the other hand, IL-12 is released primarily by antigen-presenting cells and acts as a link between innate 
and acquired immunities by inducing the differentiation of the $\mathrm{T}$ helper 1 (Th1) phenotype and the release of interferon gamma (IFN- $\gamma$ ) from activated T-cells as well as natural killer cells. T-cell-derived IFN- $\gamma$ is considered crucial to the activation of macrophages, the ultimate effector cells in host defense against intracellular infection. Studies have shown that both IL-12 and IFN- $\gamma$ are up-regulated in infection models of other bacteria, parasites, and viruses but little is known about how they may contribute to the outcome of infection.

The overall goal of this dissertation is to develop in vitro and in vivo infection models of intracellular $S$. aureus that can aid in understanding the pathogenesis of chronic and recurrent infections and to develop effective immunotherapy regimens to prevent or treat such infections. This dissertation starts with an overall literature review in Chapter 1 about the bacterium $S$. aureus, implant-associated infection, and finally IL12 as a potential therapeutic agent against infections. Chapter 2 establishes and compares two $S$. aureus infection models utilizing a non-phagocytic cell (osteoblast) and a phagocyte (macrophage) and the corresponding cellular responses of each cell type upon infection. In Chapter 3, S. aureus within osteoblasts is used to infect an open femur fracture rat model. We have presented the first direct in vivo evidence that intracellular $S$. aureus could be sufficient to induce bone infection in animals and intracellular S. aureus could play an important role in the pathogenesis of S. aureus infections. Finally, a potential approach using IL-12 as a therapeutic agent to improve macrophage killing activities against intracellular S. aureus is investigated in Chapter 4.

Keywords: osteomyelitis, Staphylococcus aureus, infection, interleukin 12, cytokine, osteoblast, macrophage, rat, intracellular S. aureus. 


\title{
DEDICATION
}

To my family:

\author{
Mohammad Riyad Hamza \\ Neeran Al-Taiyar \\ Raniya Hamza \\ Bashar Hamza \\ Sarah Hamza
}




\section{ACKNOWLEDGMENTS}

Science is not an individual pursuit; it is a team effort, a significant collaboration in which we learn something wonderful, not only about the world around us, but also about ourselves as human beings in that world. The work presented here would never have been possible without the help and support of a large community of family, friends, and colleagues.

My dissertation committee (Drs. Li, Brundage, Callery, Gannett, and Rojanasakul) has been a substantial source of support for me during my time as a graduate student. Thank you all for encouraging me, for pushing me, and for all the discussions and ideas which we generated together. This work could never have come to fruition without your help and dedication.

In my more than five years at WVU, there have been a number of staff and students in the Department of Orthopaedics who have been, truly, a family to me. Each one of you has helped and supported me, and my deepest appreciation goes out to one and all. Andrea Armstead, Nina Clovis, Suzanne Danley, Bingbing Jiang, Vince Kish, Jingting Li, Jabeen Noore, Sheila Rye, Xianfeng Wang, and Ying Zhang.

Graduate school is not only a time for learning and working on experiments, but also a time for making new friends, and I have been fortunate to meet some wonderful people in my time here at WVU. I could never have guessed I would make so many great friends. There are too many of you to thank individually here, but my time here was infinitely better because it was spent with all of you. To Sun Hee Park, my best friend, and lunch buddy; thank you so much for all that you are and all that you have given me.

My wonderful family has been my biggest cheering section through the last five years. My greatest thanks go to my parents for inspiring me through the path of my graduate career. I am also so very thankful for my sisters, Raniya and Sarah, and brother, Bashar, for cheering me through this wild adventure. You always believed in me and told me how proud you were of me, even when I wasn't sure of myself.

I would like to acknowledge the support and guidance of the Pharmaceutical and Pharmacological Sciences Program and the Biomedical Sciences Graduate Program. 


\section{TABLE OF CONTENTS}

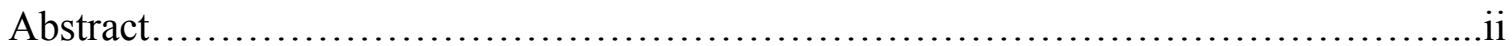

Dedication..................................................................

Acknowledgments................................................................

Table of Contents..............................................................

Specific Aims.................................................................

Chapter 1: Literature Review..............................................1

1.1 Staphylococcus aureus....................................................

1.1.1. Biology and virulence factors

1.1.2. Intracellular S. aureus

1.1.3. Host immune response

1.1.4. Treatment for $S$. aureus infections

1.2 Implant-Associated Infections and Osteomyelitis...........................

1.2.1. General concepts

1.2.2. Pathogenesis

1.2.3. Therapy

1.3 Interleukin 12: a Key Immunoregulatory Cytokine in Infection Applications....12

1.3.1. IL-12 Molecular structure

1.3.2. IL-12 Receptor and signaling pathway

1.3.3. IL-12 Family members

1.3.4. IL-12 Biological activities

1.3.5. IL-12 Therapeutic applications in infections

1.4 References

Chapter 2: Staphylococcus aureus Internalization and Associated Biological Responses of Osteoblasts and Macrophages.

2.1 Abstract

2.2 Materials and Methods

2.2.1 Reagents

2.2.2 Bacteria

2.2.3 Infection of osteoblasts with S. aureus

2.2.4 Infection of macrophages with $S$. aureus

2.2.5 Inhibition of $S$. aureus internalization in osteoblasts 
2.2.6 Survival of S. aureus within osteoblasts or macrophages

2.2.7 Confocal microscopy

2.2.8 Transmission electron microscopy (TEM)

2.2.9 Reactive oxygen species production

2.2.10 Osteoblast alkaline phosphatase (ALP) activity

2.2.11 Macrophage phagocytosis assay

2.3 Results

2.3.1 Characterization of $S$. aureus infection of osteoblasts and macrophages

2.3.2 Biological responses of osteoblasts and macrophages upon $S$. aureus infection

2.4 Discussion

2.5 Conclusion

2.6 References

Chapter 3: Intracellular Staphylococcus aureus Alone Causes Infection: In vivo

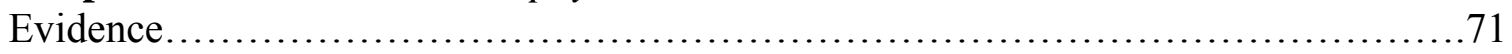

3.1 Abstract

3.2 Materials and Methods

3.2.1 Reagents

3.2.2 Preparation of osteoblasts with intracellular S. aureus via co-culturing osteoblast-S. aureus

3.2.3 Animal groups and open fracture infection procedure

3.2.4 Microbiological and radiographic evaluations

3.2.5 Body weight and complete blood count

3.3 Results

3.3.1 Intracellular S. aureus causes high bacterial burden in bone and muscle tissues

3.3.2 Radiographic assessment of bone infection

3.3.3 Body weight and complete blood counts

3.4 Discussion

3.5 Conclusion

3.6 References 
Chapter 4: Effect of Interleukin 12 on the Killing of Intracellular Staphylococcus

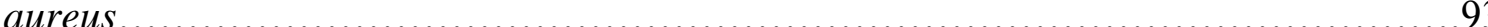

4.1 Abstract

4.2 Materials and Methods

4.2.1 Reagents

4.2.2 IL-12 bioactivity

4.2.3 Bacterial culture

4.2.4 Splenic macrophage isolation and culture

4.2.5 Splenic macrophage infection and IL-12 treatment

4.2.6 IL-12 action specificity

4.2.7 Reactive oxygen species detection

4.3 Results

4.3.1 Effect of IL-12 treatment on the survival of $S$. aureus within infected splenic macrophages

4.3.2 Effect of IL-12 treatment on cytokine production in infected splenic macrophages

4.3.3 Effect of IL-12 treatment on reactive oxygen species production in splenic macrophages

\subsection{Discussion}

\subsection{References}

Chapter 5: General Discussion............................................ 112

Curriculum Vita......................................................... 114 


\section{SPECIFIC AIMS}

For decades, S. aureus has been recognized as one of the most important leading cause of hospital- and community-acquired infections worldwide. Controlling S. aureus infections, especially chronic and recurrent infections, is a growing clinical challenge, and a better understanding of $S$. aureus pathogenesis and development of new therapeutic strategies are of importance. To achieve this long-term goal, my project has three specific aims:

1) Establish and compare in vitro S. aureus infection models using phagocytic (macrophage) and non-phagocytic cells (osteoblast)

2) Determine whether intracellular S. aureus can induce bone infection in vivo

3) Introduce IL-12 as a therapeutic agent to improve the killing efficacy of macrophages against intracellular S. aureus 


\section{CHAPTER 1}

\section{Literature Review}

\subsection{Staphylococcus aureus}

\subsubsection{Biology and Virulence Factors}

Staphylococcus aureus (S. aureus) is a Gram-positive spherical bacterium, between 0.5 to $1.7 \mu \mathrm{m}$ in diameter, non-motile, facultative anaerobic, catalase and coagulase positive that is able to induce ß-haemolysis [1]. Traditionally, S. aureus is considered to be an extracellular pathogen $[2,3]$, but increasing evidence indicates that $S$. aureus might be a facultative intracellular pathogen [4-9]. The species name "aureus", which means "golden" in Latin, is due to the yellow-golden color of the colonies. The color is imparted by carotenoid pigments that support the bacteria in the prevention of oxidant killing by phagocytes. Approximately, 20-30\% of human beings are persistently colonized with $S$. aureus in the nose, skin, mucosa, the axilla region, or gastrointestinal tract [10].

The remarkable success of $S$. aureus as a pathogen is due to the expression of a wide array of virulence factors including a capsule as well as surface-exposed and secreted proteins $[11,12]$. A schematic representation of $S$. aureus virulence factors is illustrated in Figure 1. Protein A is the hallmark of $S$. aureus which is able to bind immunoglobulins through their fragment crystallizable region $(\mathrm{Fc})$ thereby hampering $\mathrm{Fc}$ receptor-mediated opsonophagocytosis [13, 14]. Protein A can also induce T-cellindependent proliferation and apoptosis of B cells [15]. Coagulase is an extracellular protein that results in clotting of the blood that might protect the bacterium from 


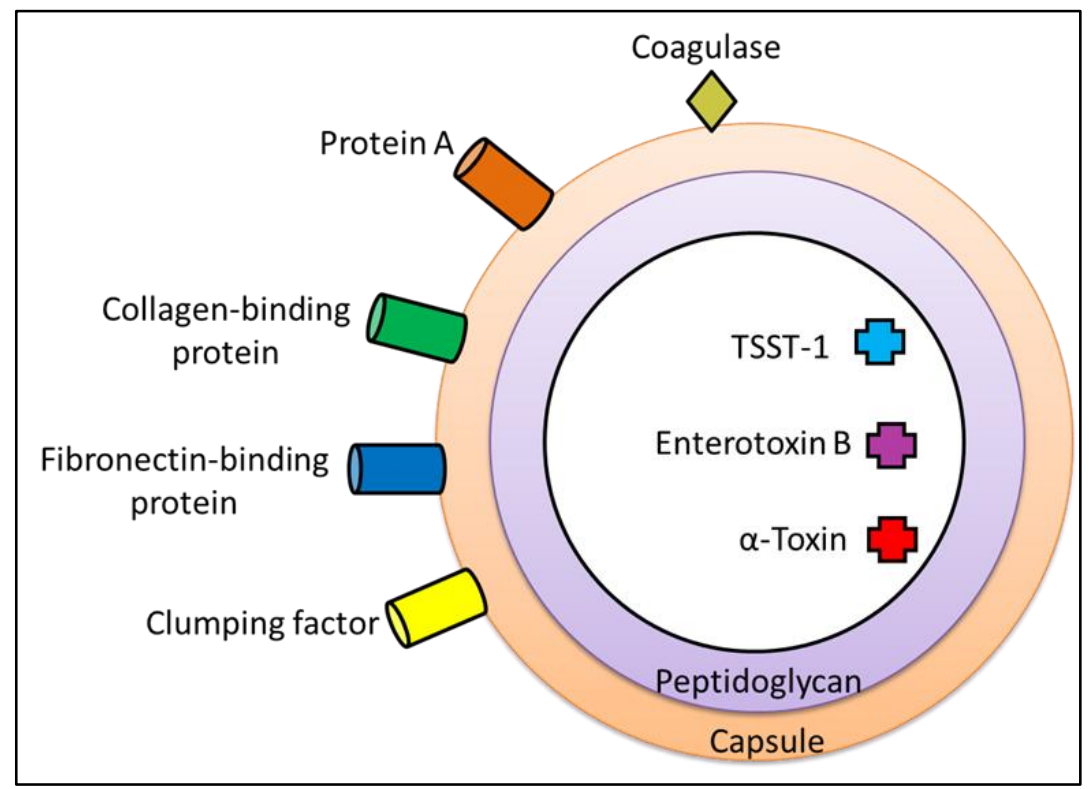

Figure 1. Pathogenic factors of Staphylococcus aureus, with structural and secreted products both playing roles as virulence factors.

phagocytic uptake by immune cells [16]. The clumping factor $\mathrm{A}$ and $\mathrm{B}$ bind serum fibrin/fibrinogen and reduce the activity of phagocytic immune cells [17]. The collagenbinding and fibronectin-binding proteins support the adhesion of $S$. aureus to connective tissue, cartilage, and extracellular matrix [18, 19]. Enterotoxin B and toxic-shocksyndrome-toxin 1 (TSST-1) are bacterial superantigens that bind major histocompatibility complex II (MHC II) complexes on antigen-presenting cells leading to immunosuppression [20-22]. The $\alpha$-toxin is the best-characterized and more potent cytotoxin of $S$. aureus. It binds to cell surface receptors and lipid bilayers on host cells and forms pores that eventually cause cell death $[23,24]$. 


\subsubsection{Intracellular S. aureus}

S. aureus has long been considered an extracellular pathogen [5]. However, many studies have demonstrated its remarkable ability to survive and replicate intracellularly [25]. The ability of $S$. aureus to escape host immunity and then establish a cell-niche are actually crucial steps in its pathogenesis $[3,5]$.

S. aureus possesses several cell-surface adhesion molecules that facilitate its binding to extracellular matrix components. Binding involves a family of adhesins known as microbial surface components recognizing adhesive matrix molecules (MSCRAMMs). MSCRAMMs recognize proteins such as fibronectin, collagen, and fibrinogen to mediate adherence of $S$. aureus to epithelium, endothelium, bone, and biomaterials coated with host proteins [26]. Among all MSCRAMMs, fibronectin-binding proteins (FnBPs) are the most critical for adherence and internalization of $S$. aureus. The schematic representation in Figure 2 shows $S$. aureus attached to $\alpha_{5} \beta_{1}$-integrins on the surface of a non-phagocytic cells, such as epithelial cells, endothelial cells, or osteoblasts, via fibronectin fibrils that are bound to FnBP (attachment). The host cell integrins are associated with myosin bound tensins, and by contraction of the myosin, the bacteria are transported toward the cell center. The uptake is performed by tensin-mediated actin reorganization $[27,28]$.

Currently, the mechanisms allowing for the intracellular survival of $S$. aureus have not yet been fully understood $[5,29]$. In some non-phagocytic cells, S. aureus is able to escape from phagolysosomes and multiply in the cytosol. It also leads to the death 


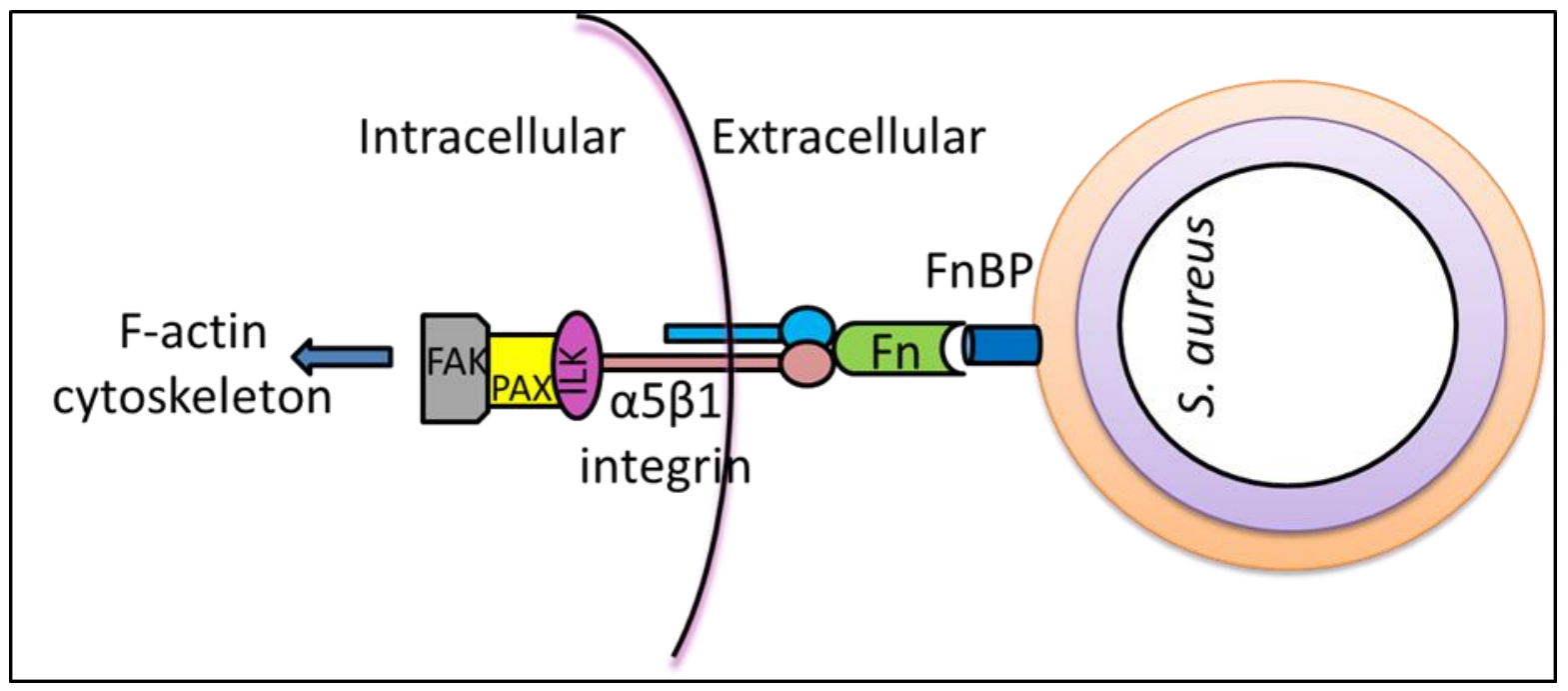

Figure 2. Schematic diagram of some of the signaling events involved in invasion of 'non-professional phagocytic' host cells by $S$. aureus. Adapted from Wright and Nair (28).

of these cells by apoptosis [30-32]. In contrast, in phagocytic cells, S. aureus seems to remain trapped within vacuoles $[33,34]$ where its multiplication is slowed down but not impaired by the acidic $\mathrm{pH}$ [35]. S. aureus is also known to produce enzyme degrading oxidant species (catalase, hydroperoxide reductase, and superoxide dismutase) [36], which may contribute to protecting it intracellularly.

Within the cell, $S$. aureus can switch to a phenotype known as small-colony variants (SCVs) that provides several advantages for its intracellular survival, among which are smaller colony size and reduced growth rate [37-39, 5]. SCVs demonstrate a number of characteristics that are different from $S$. aureus and are linked to interruption of electron transport [40]; they also present an altered antibiotic sensitivity [38], being most notably resistant to aminoglycosides [41]. SCVs are auxotrophic and can revert to 
normal growth and morphology in the presence of menadione and hemin, thiamine, or $\mathrm{CO}_{2}$-rich culture medium [42].

\subsubsection{Host Immune Response}

Normally, macrophages and other leukocytes in the host eliminate invading bacteria by a process called phagocytosis. Bacteria are engulfed into phagosomes and eventually fuse with lysosomes forming a phagolysosome where the microorganisms are destined for destruction. There, the bacteria are exposed to a number of toxic chemicals and enzymatic agents, some of which are reactive oxidative species such as superoxide anions and hydrogen peroxide, acidic $\mathrm{pH}$, and degradative proteases. The pathogenicity of $S$. aureus is mainly mediated by a variety of secreted enzymes, adhesins, immunomodulating proteins, and the presence of cell wall compounds [43]. Recognition of $S$. aureus components by innate immune cells is the first step of host defense. Toll-like receptors (TLRs) are a class of receptors that recognize pathogen-associated molecular patterns (PAMPs) such as LPS, peptidoglycan, and lipoprotein [44, 45]. TLRs that are involved in the recognition of $S$. aureus include TLR2 which binds bacterial peptidoglycan and TLR9 which binds bacterial CpG DNA. Triggering of TLR signaling after pathogen recognition leads to the activation of transcription factors that induce transcription of genes coding for various proteins including cytokines and inflammatory mediators [46]. This process results in a massive invasion of immune cells to the site of infection. Several studies using knockout mice have shown that TLRs play a critical role in the innate immune response to Staphylococcal infections as mice deficient in the expression of myeloid differentiation factor 88 (MyD88), a cytoplasmic adaptor molecule 
essential for the signaling of IL-1R/TLR family, are highly susceptible to this pathogen [47].

An effective immune response against $S$. aureus involves polymorphonuclear cell (PMN) recruitment such as neutrophils $[48,49]$. The importance of neutrophils in host defense against $S$. aureus infection has been demonstrated by recurrent $S$. aureus infections in patients with chronic granulomatous disease, who have a defect in the NADPH oxidase and respiratory burst $[48,50]$.

\subsubsection{Treatment for S. aureus Infections}

Despite increasing knowledge on this bacterium, it is still difficult to prevent or effectively treat Staphylococcal infections in many cases. Developing new therapeutic strategies (including antibiotic and alternative therapies) as well as prophylaxis strategies, which are important for patients before invasive medical procedures, is an essential topic in research [51-54].

Treatment of $S$. aureus infections is commonly done using antibiotics, especially $\beta$-lactams [55]. The hospital-acquired strain of methicillin-resistant $S$. aureus can be susceptible to rifampicin, fusidic acid, and co-trimoxazole but they are rarely used because this strain can easily acquire resistance [56].

Cationic antimicrobial peptides (CAMPs) such as defensins, cathelicidin, and thrombocidins are positively charged $(+2$ to +7$)$ amphipathic molecules with antibacterial properties [57-59]. Produced by the innate immune system, they protect the skin and epithelia from bacterial invasion [60]. 
There is still a problem with the introduction of an efficient vaccine in the prevention of infections caused by $S$. aureus. This can be associated with the fact that, throughout its life, a human organism is in contact with this bacterium as many people are constant or transient carriers of $S$. aureus on the mucus of the nasal or oral cavity. Earlier, the whole bacterial cell was used as an antigen, but recent research is aimed at obtaining antibodies against specific virulence factors such as adhesins, toxins, or invasins [61].

FnBPs are responsible for adherence of $S$. aureus to and subsequent internalization by phagocytes. Intramuscular application of a recombinant fragment of the fibronectin-binding domain $(\mathrm{rFnBF})$, which potentially inhibits the entrance of $S$. aureus to host cells, counteracted the formation of abscesses in guinea pigs. The protective effect was dose-dependent and increased the efficacy of preventive treatment if applied simultaneously with cefazolin. The efficacy of this method relies on competition in the adhesion of exogenic S. aureus $\mathrm{rFnBF}$ with FnBP, which causes infection [62].

\subsection{Implant-Associated Infections and Osteomyelitis}

\subsubsection{General Concepts}

Bone turnover is a highly regulated process. New bone is formed by osteoblasts, which are cells of mesenchymal lineage derived from osteoprogenitor cells located in the periosteum or bone marrow. Osteoblasts form new bone matrix, called osteoid, which is later mineralized as osteoblasts mature. When osteoblasts become surrounded by mineralized matrix, they become osteocytes. Old or damaged bone is resorbed by osteoclasts via a process called bone resorption. Osteoclasts are large multinucleated cells 
of hematopoietic lineage derived from the fusion of monocytes and macrophages. Osteoclasts are activated and recruited to sites of microfracture by factors such as macrophage colony stimulating factor (M-CSF) and receptor activator of nuclear factor $\kappa \beta$ ligand (RANKL). The balance in osteoblast and osteoclast activities is critical for healthy bone environment and successful implant procedures.

Orthopaedic implants are commonly used in treating patients with pain and compromised mobility or for fracture fixation. The risk of infection is increased by the presence of foreign materials in the body. The most commonly cultured pathogens isolated from prosthetic implant-associated infections are S. epidermidis (30 to 43\%) and S. aureus (12 to $23 \%$ ), followed by mixed bacterial flora (10 to $11 \%$ ), streptococci (9 to $10 \%$ ), Gram-negative bacilli (3 to $6 \%$ ), enterococci (3 to $7 \%$ ), and anaerobes ( 2 to $4 \%$ ) [63]. Recently, S. aureus SCVs, which have a slower metabolism, do not produce toxins, and are more resistant to antibiotics, have been isolated from implant-associated infections and represent a risk factor for treatment failure, and persistence and recurrence of infection [64].

Implant-associated infections occur by bacterial contamination of the surgical site during surgery or immediately after, or they result from haematogenous spreading from distinct infections in the nose or on the skin. The resulting infection of the bone and soft tissue is called osteomyelitis, which is an inflammatory process characterized by massive bone destruction, or osteolysis (5). The disease can be acute or chronic with periodic recurrence $[65,66]$. Chronic osteomyelitis is usually defined as osteomyelitis occurring in a patient who cannot be cured by medical means within six weeks [67]. The hallmarks 
of chronic osteomyelitis include the presence of pus, persisting microorganisms, lowgrade inflammation, and dead bone without a blood supply (sequestra) [68].

There are three types of osteomyelitis: haematogenous osteomyelitis which is commonly found in children and in elderly patients, osteomyelitis secondary to diabetic foot infection, and osteomyelitis caused by local spread from an adjacent infection after trauma, surgery, or joint replacement, while the incidence of the latter is the highest [5].

\subsubsection{Pathogenesis}

Staphylococci have a strong ability to adhere to plastic surfaces, a fact that has been used in basic in vitro assays. However, during colonization on medical devices, the additional interaction of MSCRAMMs and host proteins most likely cause a stronger attachment $(61,69]$. This bacterial colonization forms what is called a biofilm, which is a microbial community covered by a thin three-dimensional structure matrix $[70,71]$. The host immune system responds to foreign bodies with a localized inflammation leading first to the formation of a capsule-like membrane of fibrinogen, fibronectin, and collagen on the surface [72]. Extracellular proteins such as fibronectin and fibrinogen mediate bacterial adhesion to medical devices and host tissue. The localized inflammation causes a secondary phenomenon known as "frustrated phagocytosis", which results from granulocyte contact with the foreign body and causes a functional granulocyte defect with reduced oxygen burst and chemotaxis in the presence of foreign bodies (Figure 3). This process may be partly responsible for the high susceptibility of implants to infections [74]. 


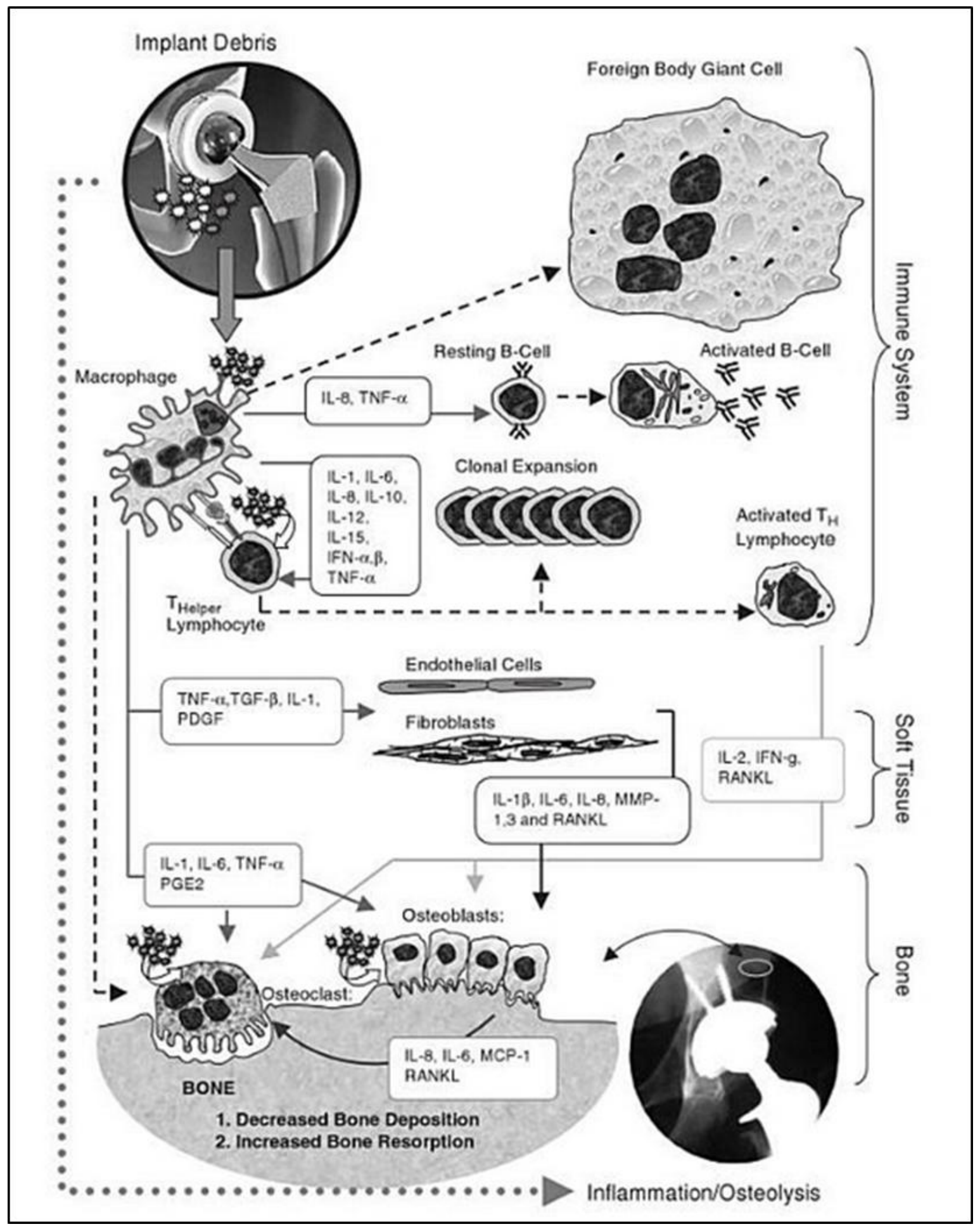

Figure 3. Pathogenesis of implant-associated infection. Adapted from Biomaterials (Biomaterials Science: An Introduction to Materials in Medicine, $2^{\text {nd }}$ edition). 


\subsubsection{Therapy}

The goal of implant-associated infection therapy is a long-term application and functional joint and is achieved by elimination of the infection. But, implant-associated infections are difficult to treat due to lack of microcirculation, which is crucial for host defense and for the delivery of antibiotics. Five treatment approaches utilizing appropriate surgical treatment and antimicrobial therapy are available. (I) Long-term antimicrobial therapy alone does not eradicate the infection. Additionally, clinical symptoms re-appear during or after antimicrobial breaks. (II) Debridement with retention of the prosthesis means removal of tissue around a stable implant for patients with an early postoperative or acute haematogenous infection $(<3$ weeks). Furthermore, an agent with activity against biofilm bacteria should be available. (III) and (IV) One- or two-stage revision includes removal of all devices, debridement, and replacement of a new prosthesis during the same procedure or after a period of time, respectively. (V) Finally, resection is defined as permanent removal and debridement without replacement [74, 63].

Surgical intervention as well as antibiotic therapy using cephalosporins and penicillins remains the most effective means of treatment for osteomyelitis [75]. However, osteomyelitis cases caused by $S$. aureus are especially chronic in nature and recalcitrant to therapy. In addition, the effectiveness of traditional antibacterial agents is becoming increasingly limited as the incidence of methicillin-resistant S. aureus (MRSA) has increased sharply in recent years. The wide array of virulence factors in S. aureus, including secreted products for host damage and immune evasion, coupled with its ability to invade and reside inside host cells using cell surface adherence factors, can protect 
these bacteria from host defense mechanisms and antibiotics which can account for the persistence of disease despite what may be considered adequate surgical and antibiotic management [76].

\subsection{Interleukin 12: a Key Immunoregulatory Cytokine in Infection Applications}

It is well-established that $\mathrm{CD}^{+} \mathrm{T}$ helper (Th) cells can be divided, besides $\mathrm{T}$ regulatory and Th17, into two major subsets: Th1 and Th2, based on their patterns of cytokine production. Th1 cells mainly secret interleukin 2 (IL-2), IFN- $\gamma$, and IL-12, whereas Th2 cells secret IL-4, IL-5, and IL-10 [77]. Functionally, Th1 cells predominantly promote cell-mediated immunity and help in clearance of intracellular pathogens, whereas Th2 cells are responsible for humoral immunity protecting against extracellular invaders. The balance between IL-12, favoring Th1 responses, and IL-4, favoring Th2 responses, determines the early preference expressed in the immune response.

IL-12 has multiple biological functions; importantly, it bridges the early nonspecific innate resistance and subsequent antigen-specific adaptive immunity [78]. IL12 was first identified as a product of Epstein-Barr virus (EBV)-transformed human B cell lines. IL-12 was previously known as T-cell differentiation factor (TCDF), or natural killer cell stimulatory factor (NKSF). IL-12 was used to be the only known heterodimeric cytokine, but it is now part of a family consisting of several other members including IL23, IL-27, and the recently identified IL-35. These new molecules have been found to play distinct cellular and functional roles in Th1 development [79]. 


\subsubsection{IL-12 Molecular Structure}

IL-12 is a key immunoregulatory cytokine $[78,80,81]$ with a molecular weight of $70 \mathrm{kDa}$; it is composed of two covalently-linked subunits, IL-12p35 (35 kDa) and IL$12 \mathrm{p} 40(40 \mathrm{kDa})$, each of which is expressed on different chromosomes. The sequence of the p35 gene is homologous similar to that of IL-6 and granulocyte-colony stimulating factor [82]. The sequence of the $\mathrm{p} 40$ chain has a homology to the extracellular domain of IL-6 receptor (IL-6R) $\alpha$-chain and the ciliary neurotropic factor [83]. This homology explains some of the redundant actions applied by these cytokines.

Although p35 transcripts are found in many cell types, free p35 is not secreted without the $\mathrm{p} 40$ subunit. IL-12p40 is produced predominantly by activated monocytes, macrophages (MФs), neutrophils, and dendritic cells (DCs). It has been suggested that in mice, but not in humans, IL-12p40 homodimers antagonize IL-12p70 activity by binding to the $\beta 1$ subunit of the IL-12 receptor [84-86]. Also, IL-12p40 has been shown to act as a chemoattractant for MФs and promotes the migration of stimulated dendritic cells [87]. The p40 subunit is associated with several pathogenic inflammatory responses such as silicosis, graft rejection, and asthma, but it is also found to be protective in a mycobacterial infection model [87].

\subsubsection{IL-12 Receptor and Signaling Pathway}

The biological activities of IL-12 are mediated via binding to a membrane receptor complex which is also composed of two subunits: IL-12R $\beta 1$ and IL-12R $\beta 2$. Both of the subunits are members of the class I cytokine receptor family, which includes IL-6, IL-11, and leukocyte inhibitory factor related to glycoprotein gp130 [88, 89]. There 


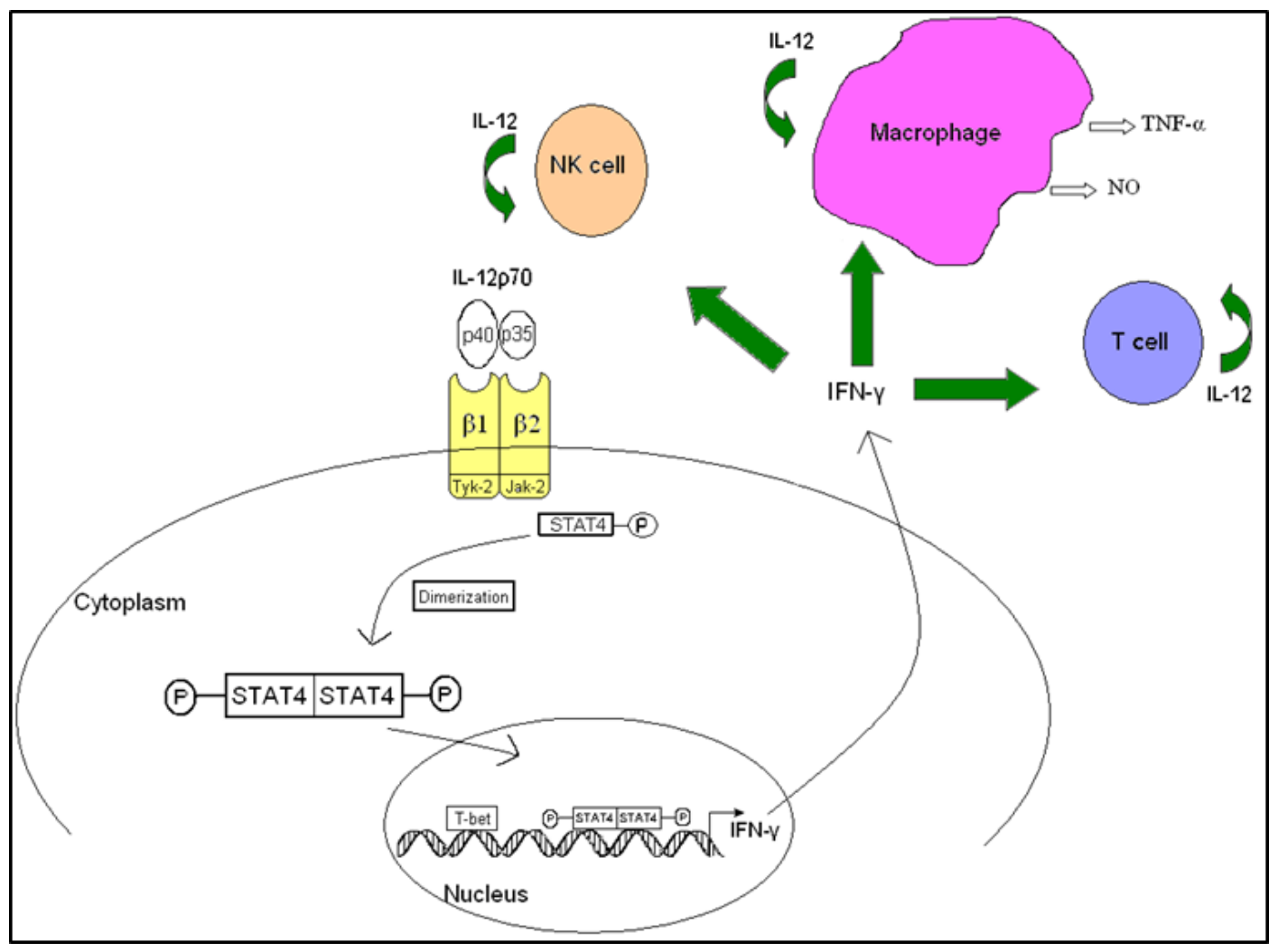

Figure 4. IL-12 signaling pathway. IL-12 activates the Jak/STAT pathway. Following binding of IL-12p40 and IL-12p35 to IL-12R $\beta 1$ and IL-12R $\beta 2$, respectively, Jak-2 and Tyk-2 get transphosphorylated. Phosphorylated IL-12R $\beta 2$ binds to STAT4 which will then dimerize with another STAT4 molecule. STAT4 homodimers translocate to the nucleus and promote IFN- $\gamma$ gene transcription. T-bet is another transcription factor that plays a role in Th1 development and IFN- $\gamma$ production. The IL-12 and IFN- $\gamma$ produced induce the activity and proliferation of MФs, NK cells, and T-cells, which also secrete IL-12. Modified from [97]. Reprinted from Cytokine \& Growth Factor Rev., 14(5), Watford, W.T.; Moriguchi, M.; Morinobu, A.; O'Shea, J.J. The biology of IL-12: coordinating innate and adaptive immune responses, 361-368, Copyright (2003), with permission from Elsevier.

is a high level of conservation, with a $68 \%$ amino acid sequence homology, between mouse and human IL-12R $\beta 2$ proteins, and a 54\% sequence identity homology between the mouse and human IL-12R $\beta 1$ [88]. Both receptor chains are required to mediate maximal signaling; however, the two chains have independent roles. IL-12R $\beta 1$ is required for high-affinity binding to the IL-12p40 subunit and is associated with the 
Janus kinase (Jak) family member Tyk-2. The IL-12R $\beta 2$ chain mediates signal transduction via three tyrosine residues that act as a docking site for STAT4; it is associated with Jak-2 (Figure 4). IL-12R $\beta 2$ recognizes either the heterodimer IL-12 or IL-12p35 subunit and is expressed, not on naive T-cells, at low levels after T-cell receptor stimulation. Expression of this receptor subunit is critically influenced by IL-12 and type 1 IFNs [81]. The initial expression of functional IL-12Rs is further enhanced when IL-12 is present at the time of priming, working as a positive feedback loop regulator [90].

The signaling pathway of IL-12 is described in Figure 4. On binding of IL-12 to the IL-12R complex, activation of Jak kinases (Tyk-2 and Jak-2) occurs, leading to phosphorylation of the receptor, which becomes a binding site for STAT4 proteins that are rapidly recruited to the receptor and phosphorylated on their tyrosine residues by the Jak kinases. Tyrosine phosphorylation of STAT4 proteins induces their homodimerization and translocation to the nucleus where they bind to specific sequences and regulate gene transcription (Figure 4). In Th1 and NK cells, IL-12 mainly induces STAT4 activation. In addition, STAT1, STAT3, and STAT5 can also be activated by IL12 signaling $[89,91]$. Studies have shown that IFN- $\gamma$ increases the transcription factor Tbet activity, which was originally shown to be induced in Th1 cells [92]. T-bet response to IFN- $\gamma$ leads to the up-regulation of IL-12R $\beta 2$ surface expression and allows for Th1 cell responsiveness to IL-12 [92, 93]. More recent studies showed that T-bet negatively regulates GATA-3 expression, the main regulator of Th2 cell axis [94]. In contrast, the Th2 cytokine IL-4 reduces IL-12R $\beta 2$ expression and thus leaves Th2 cells nonresponsive [95]. The opposite effects of IFN- $\gamma$ and IL-4 on IL-12R $\beta 2$ expression may 
contribute to the commitment of Th1/Th2 differentiation. Priming of macrophages with IFN- $\gamma$ increases cellular responsiveness to inflammatory stimuli, including IFN- $\gamma$ itself, which activates direct microbicidal functions including the production of reactive oxygen species and TNF- $\alpha$ and promotes the Ag processing and presentation capacities of macrophages. Also, IFN- $\gamma$ plays a role in the regulation of T-cell proliferation and activity [96].

\subsubsection{IL-12 Family Members}

The IL-12 family has expanded recently to include members including IL-23, IL27, and IL-35. IL-12 and these new family members play critical roles in Th1 cell development $[80,98]$. Table 1 summarizes the structure and biological properties of these major IL-12 family members.

\section{A. Interleukin 23}

IL-23 is a proinflammatory cytokine that is closely related to IL-12 in structure; they both share the p40 subunit that is able to build a disulfide bridge complex with the p19 subunit to form the biologically active molecule. The p40-p19 complex is mainly secreted by activated intestinal antigen presenting cells, such as DCs and monocytes [98]. Similar to IL-12 signaling, IL-12R $\beta$ 1 is required for high affinity binding to $\mathrm{p} 40$, whereas IL-23R has a cytoplasmic STAT4 binding domain for signal transduction. However, STAT3/STAT4 heterodimers in IL-23 instead of STAT4 homodimers in IL-12 are translocated to the nucleus to induce specific gene expression [99]. 


\begin{tabular}{|c|c|c|c|c|}
\hline & IL-12 & IL-23 & IL-27 & IL-35 \\
\hline Cytokines & & & & \\
\hline Receptors & $2 R$ & & p130 & $?$ \\
\hline Kinases & & & & \\
\hline $\begin{array}{l}\text { Vital } \\
\text { STATs }\end{array}$ & $\begin{array}{c}\text { STAT } \\
4\end{array}$ & $\begin{array}{c}\text { STAT } \\
3\end{array}$ & $\begin{array}{c}\text { STAT } \\
1\end{array}$ & $?$ \\
\hline $\begin{array}{l}\text { Also phos- } \\
\text { phorylated }\end{array}$ & STAT $1 / 3 / 5$ & STAT $1 / 5$ & STAT $4 / 5$ & $?$ \\
\hline $\begin{array}{l}\text { Cells that } \\
\text { Produce }\end{array}$ & $\begin{array}{c}\text { DCs, monocytes } \\
\text { macrophages, } \\
\text { B cells }\end{array}$ & $\begin{array}{c}\text { DCs, monocytes } \\
\text { macrophages, } \\
\text { B cells }\end{array}$ & $\begin{array}{c}\text { DCs, monocytes } \\
\text { macrophages, } \\
\text { B cells }\end{array}$ & $\begin{array}{c}\text { Foxp3 }{ }^{*} T_{\text {regs }} \\
\text { Others? }\end{array}$ \\
\hline $\begin{array}{l}\text { Cells that } \\
\text { Respond }\end{array}$ & $\begin{array}{l}\text { Naïve T cells } \\
\text { Th1 cells } \\
\text { NK cells }\end{array}$ & $\begin{array}{l}\text { Memory T cells } \\
\text { Th1 \& Th17 cells } \\
\text { NK cells }\end{array}$ & $\begin{array}{l}\text { T cells } \\
\text { Th1 cells } \\
\text { NK cells }\end{array}$ & $\begin{array}{l}\text { T cells, } \\
\text { Others? }\end{array}$ \\
\hline Function & $\begin{array}{l}\text { Th1 activation } \\
\text { Th1 maintenance } \\
\text { Blocks Th2 }\end{array}$ & $\begin{array}{l}\text { Th1 activation } \\
\text { Th17 polarization } \\
\& \text { proliferation }\end{array}$ & $\begin{array}{c}\text { Th1 cell } \\
\text { proliferation } \\
\text { Skewing effector T } \\
\text { cell lineages } \\
\text { Blocks Th17 }\end{array}$ & $\begin{array}{c}\text { Inhibits T cell } \\
\text { proliferation } \\
\text { Additional? }\end{array}$ \\
\hline
\end{tabular}

Table 1. The IL-12 cytokine family; structural and biological characteristics.

The main role of IL-23 involves the stimulation of Th17 cells to produce IL-17 [79] and it induces the proliferation of memory T-cells [100]. Unlike IL-12, IL-23 does not induce significant production of IFN- $\gamma$, and in the absence of IL-23, IFN- $\gamma$ production and Th1 differentiation are still found to be normal [98]. 


\section{B. Interleukin 27}

IL-27 is another heterodimeric cytokine composed of the p28 subunit and the p40related protein Epstein-Barr virus-induced gene 3 (EBi3). IL-27 activities are driven via one receptor that was described recently with some homology to gp130, known as TCCR or WSX-1 [101]. Signaling through TCCR or WSX-1 is required for the early initiation of a Th1 response, but not necessary for the maintenance of Th1 responses [101]. The signaling pathway initiated by IL-27 activates Jak-1 and Jak-2 molecules. However, only STAT1 and STAT3 are critical to IL-27 bioactivities, and STAT3 rather than STAT1 is required for IL-27-induced proliferation [102].

IL-27 is rapidly produced by human phagocytic cells and DCs after their activation [101]. IL-27 is involved in early Th1 initiation, is able to induce proliferation of naive but not memory T-cells, and can synergize with IL-12 in IFN- $\gamma$ production [102].

\section{Interleukin 35}

IL-35 was discovered very recently [103]; this heterodimeric cytokine is composed of the p35 subunit and the p40-related protein EBi3. IL-35R complex has not been characterized yet, but it is possible that it may be composed of the receptors known for IL-27 and IL-12, either gp130 or WSX-1 and IL-12R $\beta 2$.

Within the $\mathrm{CD}^{+}$T-cell population, IL-35 is expressed by resting and activated $\mathrm{T}$ regulatory cells (Tregs) but not activated T-cells. Loss of IL-35 expression results in reduced immune suppression by Tregs. IL-35 appears to function as an anti-inflammatory molecule by inhibiting T-cell proliferation. It is suggested that IL-35 can suppress Th17 
development in vivo [104]; however, further studies are required to fully understand the exact mechanism behind these functions.

\subsubsection{IL-12 Biological Activities}

IL-12 is produced mainly by DCs, MФs, monocytes, neutrophils, microglia cells, and, to a lesser extent, B-cells (Figure 5); human but not murine B cells were found to produce IL-12 following CD40 ligation [105]. Non-immune cells such as infectedkeratinocytes and osteoblasts, epithelial, and endothelial cells have also been shown to produce some amounts of this cytokine [106, 107]. Pathogen-associated molecular patterns such as LPS, teichoic acid, peptidoglycan, and bacterial CpG DNA, can induce IL-12 production. The production of IL-12 is regulated by positive and negative feedback mechanisms involving Th1 cytokines (e.g. IFN- $\gamma$ ), Th2 cytokines (e.g. IL-10), and type 1 IFN (Figure 5) [108, 109].

IL-12 has multiple biological functions (Table 2) and it bridges innate and adaptive immunity. IL-12 induces differentiation of naive $\mathrm{CD}^{+} \mathrm{T}$-cells to Th1 cells and activates NK cells. Upon activation, these cells produce IFN- $\gamma$ and other type-1 cytokines [110]. IL-12 also protects $\mathrm{CD}^{+}{ }^{+}$Th1 cells from antigen-induced apoptotic death [111]. IL-12 was found to have synergistic effects with IL-18 in developing Th1 cells, and IL-12 and IL-18 reciprocally upregulate each other's receptors [81]. In addition, IL-12 plays a role in T-cell trafficking and migration by inducing functional adhesion molecules such as Pand E-selectin ligand expression on Th1 cells but not Th2 cells; therefore, these cells are selectively recruited to sites where Th1 immune responses are needed [112]. Studies also reported selective expression of CCR5 and CXCR3 when naive T-cells were primed in 
the presence of IL-12 [110, 113]. Stimulation of MФ-derived IL-12 also plays a major role in the induction of resistance in parasitic infestation [114].

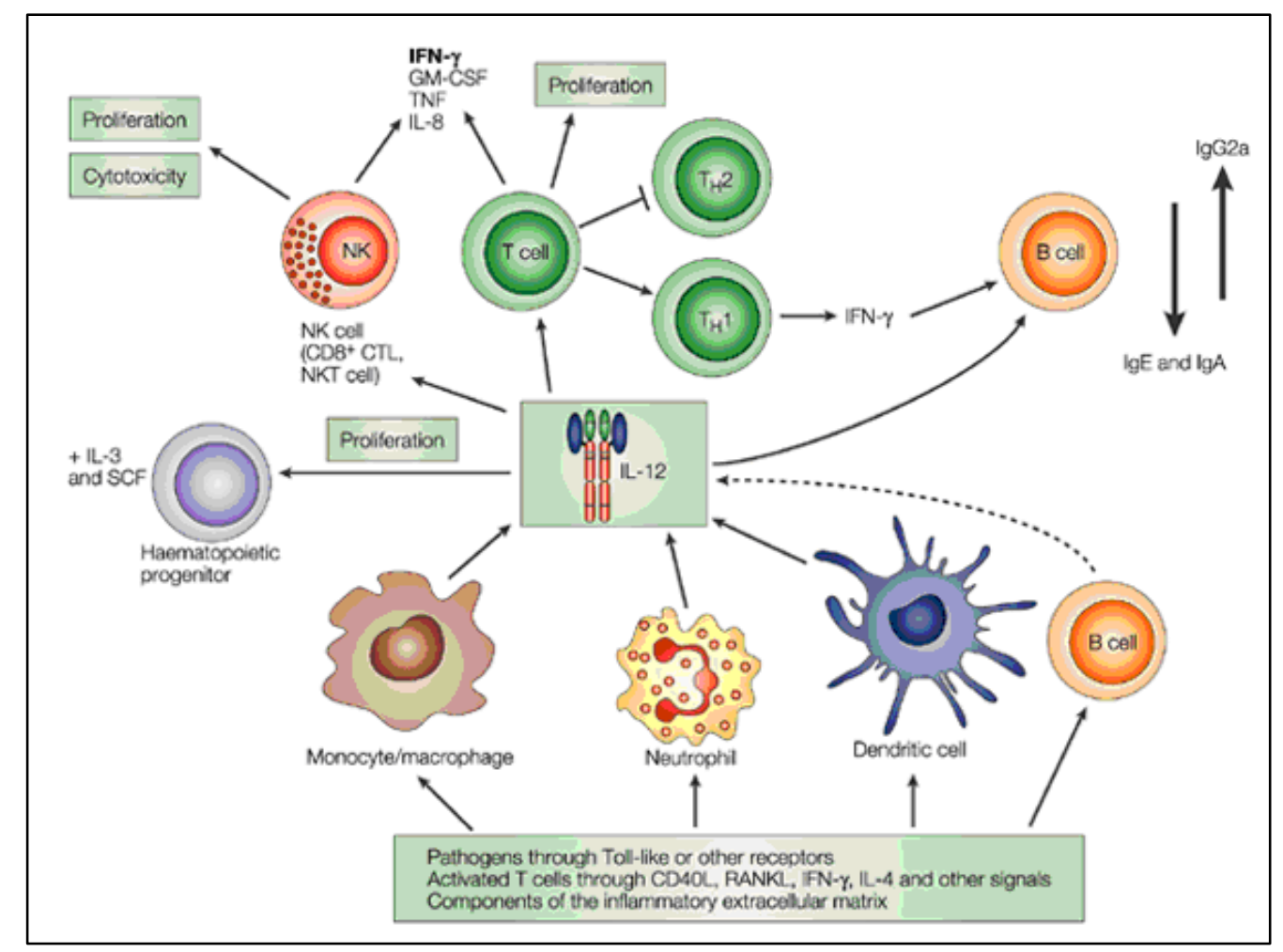

Figure 5. Summary of the biology of IL-12 [90]. Reprinted by permission from Macmillan Publishers Ltd: Nat Rev Immunol., 3, Trinchieri, G. Interleukin-12 and the regulation of innate resistance and adaptive immunity, 133-146, Copyright (2003).

- Promote naive $\mathrm{CD} 4^{+} \mathrm{T}$-cells to differentiate into Th1

- Enhance the generation and activity of cytotoxic T lymphocytes

- Induce IFN- $\gamma$ production by (i) NK cell, T-cell, DC, and MФ, (ii) cooperating with B7/CD28 interaction, and (iii) synergizing with IL-18

- Increase МФ antimicrobial activity

- Prime DC activation to induce more IL-12 production

- Induce functional adhesion molecule expression on Th1 cells and influence T-cell trafficking

Table 2. Main immunological functions of IL-12. 
The biological activity and quantity of IL-12 can be determined using molecular approaches. One of the first approaches for quantifying IL-12 was based on IL-12induced proliferation of phytoheagglutinin (PHA)-stimulated lymphocytes [115]. Peripheral blood mononuclear cells activated with PHA along with IL-2 proliferate in response to IL-12. Enzyme-linked immunosorbent assay (ELISA) was also applied to quantify specifically IL-12p40 and IL-12p70 [116]. In combination with ELISA, another approach, based on the ability of IL-12 to induce IFN- $\gamma$ secretion from activated Tlymphoblasts, was developed and has been used to measure the biological activity of IL$12[117,118]$.

\subsubsection{IL-12 Therapeutic Applications in Infections}

IL-12 holds considerable promise as an immunotherapeutic agent because it plays a central role in regulating innate and adaptive immune responses and synergizes with several other cytokines for increased immunoregulatory activities. Animal and human studies have shown improved outcomes in treating or preventing infections based on the mechanisms of IL-12-dependent therapies.

\subsubsection{Viral Infections}

The role of IL-12 in promoting endogenous protective immune responses to viral infections has been attracting more attention with time. Many experimental models have been developed to test the potential effects of IL-12 and other immune mediators on herpes simplex virus, influenza virus, human immunodeficiency virus (HIV), lymphocytic choriomeningitis virus, mouse cytomegalovirus, and many others [119]. 


\section{A. Herpes simplex virus}

In an in vivo herpes simplex virus-1 (HSV-1) mouse model, sustained expression of IL-12 was induced by the virus. This local IL-12 production was considered to cause an immunopathological response in the mouse eye environment due to Th1 immunity [120]. However, exogenous IL-12 showed a protective role and increased the resistance to infection in HSV-1-thermally injured mice, possibly resulting from the activation of viral-specific Th1 immunity [121]. Also, IL-12 and IL-18 were shown to play an important role in innate immunity against genital HSV-2 infection in a mouse model; the protection was mainly mediated by IFN- $\gamma$ production [122].

\section{B. Influenza virus}

$\mathrm{CD} 4^{+} \mathrm{T}$-cells are important in controlling influenza A virus infection. $\mathrm{CD}^{+} \mathrm{T}$ cells drive the induction and expansion of cytotoxic T lymphocyte (CTL) against such viral pathogens. Earlier studies using the influenza virus system as a model showed that DCs induced effective CTL response without increasing endogenous IL-12 levels. Exogenous application of IL-12 was found to significantly enhance CTL activity [123]. Studies also demonstrated a combined effective role of IL-12 and DCs together in enhancing CTL immunity to viral infection [123]. The influenza virus vaccination effectively protects individuals against serious complications through induction of humoral and cellular responses [124]. Interestingly, patients identified with genetic IL$12 / 23 \mathrm{R} \beta 1$ or IFN- $\gamma \mathrm{R}$ deficiencies were found to develop immune responses to childhood vaccination [123]. Also, influenza vaccination could induce humoral immunity and IFN- $\gamma$ production in IL-12/23R $\beta 1$ deficient patients [125]. These studies may imply that both IL-12 and IFN- $\gamma$ play a significant role in fighting viral infections. 


\section{Human immunodeficiency virus (HIV)}

HIV infection mainly induces Th2 immunity which is unable to clear the viral infection most of the time. Glycoprotein gp120 of HIV has been shown to induce IFN- $\gamma$ dependent production of IL-12 in cultured MФs. The use of IL-12 production and Th1 activation might contribute to decreasing viral load and increasing clearance of the infection [126]. However, phase I trials in HIV patients have shown moderate effects accompanied by some toxic responses [127].

\subsubsection{Bacterial Infections}

As a potent inducer of Th1 immune response and an important mediator between innate and adaptive immunity, IL-12 has potential clinical uses in treating and preventing bacterial infections.

\section{A. Bone infection}

Osteomyelitis is a bone infection characterized by the presence of necrotic bone tissue and increased osteoclast activity. It is commonly caused by Staphylococcus aureus (S. aureus), which is traditionally known as an extracellular pathogen; however, it has been shown that $S$. aureus can be internalized and live within a variety of host cells $[128$, 129]. Internalization of $S$. aureus into the host cells could be an important pathogenicity factor for escaping the host immune system leading to persistence of infection [130]. It was reported that in vitro mouse and human osteoblasts infected with $S$. aureus express high levels of IL-12 [107]; IL-12 and/or IL-23 knockout mice showed an increased susceptibility to bacterial, parasitic, and fungal infections [131]. Therefore, IL-12 may play a critical role in the downregulation of $S$. aureus growth in vivo [132]. 


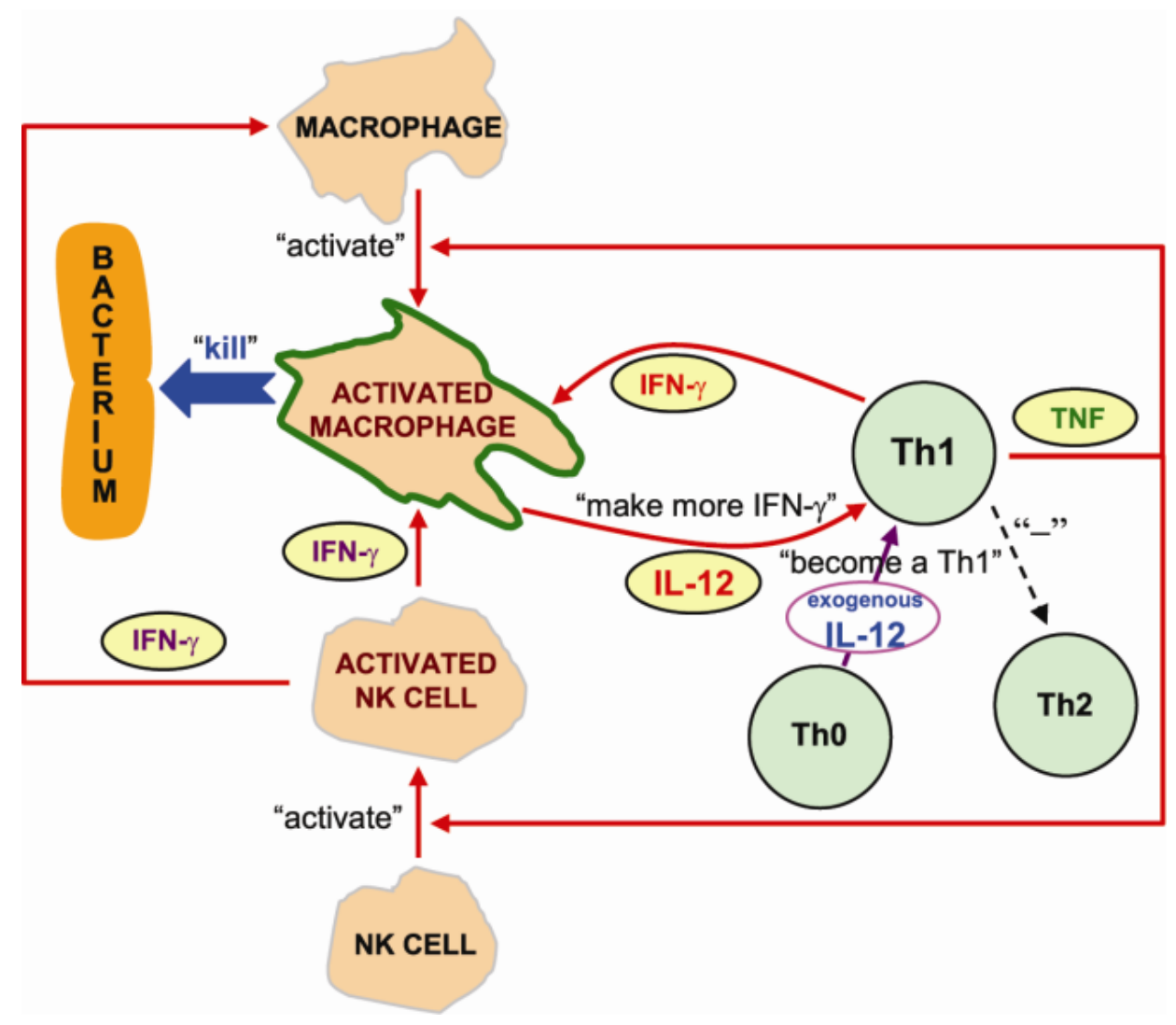

Figure 6. Local IL-12 therapy stimulates Th cells to secrete Th1 cytokines [63]. Exogenous IL-12 application creates an environment rich in IL-12 around the infection site. In such a local environment, newly activated Th cells, responding to the presence of bacteria, exit the blood and are influenced to become Th1 cells and secrete more Th1 cytokines and activate macrophages and NK cells. Activated macrophages will produce more IL-12 via a positive feedback; cell-mediated immunity can be promoted to battle bacteria thereby leading to the prevention of infection. Reprinted from Biomaterials, 30, Li, B.; Jiang, B.; Boyce, B.M.; Lindsey, B.A. Multilayer polypeptide nanoscale coatings incorporating IL-12 for the prevention of biomedical device-associated infections, 25522558, Copyright (2009), with permission from Elsevier.

More recently, studies have shown that IL-12 may play a significant role in preventing osteomyelitis. A decrease in IL-12 production was observed upon pathogenmediated ligation of MФ Fc $\gamma$ or complement receptors $[133,134]$. This finding may indicate that there are cases in which regulation of IL-12 production can be affected by 
pathogens. Perhaps down-regulation of IL-12 has the potential of providing pathogens with a means of suppressing cell-mediated immunity which would make pathogen clearance takes longer and increase the risk of bacterial infections. Meanwhile, IL-12 production was shown to decrease following trauma or major burn resulting in decreased or delayed cell-mediated immune response and decreased resistance to infection [135138]. Exogenous application of IL-12, combined with nanotechnology drug delivery systems, may have restored the decreased IL-12 level and recovered the host's cellmediated immune response; the combination has been found to be effective in preventing open fracture-associated osteomyelitis $[139,140]$. The mechanism of protection is related to the enhancement of Th1 reactivity and activation of MФs at an early stage following surgery (Figure 6) [139]. The activation of MФs may lead to enhanced antigen presentation, phagocytosis, Fc receptor expression, and nitric oxide and superoxide production [141]. As a result, these changes may substantially increase the ability of MФs to kill a wide variety of intracellular and extracellular bacteria and enhance the development of long-term immunity to those pathogens [141].

\section{B. Tuberculosis}

Tuberculosis (TB) is a common and often deadly infectious disease caused by mycobacteria including Mycobacterium tuberculosis, Mycobacterium bovis, Mycobacterium africanum, Mycobacterium canetti, and others. The chronic nature of Mycobacterium tuberculosis (Mtb) infection has led researchers to investigate the host's immunity to respond to and control this disease. Previous reports involving TB infection models showed that the development of Th1 cells in response to IL-12 production and 
subsequent induction of IFN- $\gamma$ are key players in immunity to TB [142]. Exogenous IL12 application was found to result in lower bacterial load and increased incidence of survival [143]. DC and Th1 activation and migration to the infected lungs were shown to control bacterial growth via IFN- $\gamma$-induced activation of phagocytes [144]. This immune response, however, may not be solely mediated by IL-12, as the other IL-12 family members (IL-23, IL-27, and IL-35) may also participate as well [87]. 


\section{References}

[1] Ryan KJ, Ray CG, ed. (2004). Sherris Medical Microbiology (4th ed.). McGraw Hill.

[2] Boyce JM, Potter-Bynoe G, Chenevert C, King T. Environmental contamination due to methicillin-resistant Staphylococcus aureus: possible infection control implications. Infect Control Hosp Epidemiol. 1997 Sep;18(9):622-7.

[3] Lowy FD. Staphylococcus aureus infections. N Engl J Med. 1998 Aug 20;339(8):520-32.

[4] Hudson MC, Ramp WK, Nicholson NC, Williams AS, Nousiainen MT. Internalization of Staphylococcus aureus by cultured osteoblasts. Microb Pathog. 1995 Dec;19(6):409-19.

[5] Lowy FD. Is Staphylococcus aureus an intracellular pathogen? Trends Microbiol. 2000 Aug;8(8):341-3.

[6] Clement S, Vaudaux P, Francois P, Schrenzel J, Huggler E, Kampf S, Chaponnier C, Lew D, Lacroix JS. Evidence of an intracellular reservoir in the nasal mucosa of patients with recurrent Staphylococcus aureus rhinosinusitis. J Infect Dis. 2005 Sep 15;192(6):1023-8. Epub 2005 Aug 9.

[7] Sendi P, Proctor RA. Staphylococcus aureus as an intracellular pathogen: the role of small colony variants. Trends Microbiol. 2009 Feb;17(2):54-8. Epub 2009 Jan 21.

[8] Zautner AE, Krause M, Stropahl G, Holtfreter S, Frickmann H, Maletzki C, Kreikemeyer B, Pau HW, Podbielski A. Intracellular persisting Staphylococcus aureus is the major pathogen in recurrent tonsillitis. PLoS One. 2010 Mar $1 ; 5(3): \mathrm{e} 9452$.

[9] Tuchscherr L, Medina E, Hussain M, Völker W, Heitmann V, Niemann S, Holzinger D, Roth J, Proctor RA, Becker K, Peters G, Löffler B. Staphylococcus aureus phenotype switching: an effective bacterial strategy to escape host immune response and establish a chronic infection. EMBO Mol Med. 2011 Mar;3(3):12941.

[10] Gordon RJ, Lowy FD. Pathogenesis of methicillin-resistant Staphylococcus aureus infection. Clin Infect Dis. 2008 Jun 1;46 Suppl 5:S350-9.

[11] Foster TJ, Höök M. Surface protein adhesins of Staphylococcus aureus. Trends Microbiol. 1998 Dec;6(12):484-8.

[12] Archer GL. Staphylococcus aureus: a well-armed pathogen. Clin Infect Dis. 1998 May;26(5):1179-81.

[13] Deisenhofer J. Crystallographic refinement and atomic models of a human Fc fragment and its complex with fragment B of protein A from Staphylococcus aureus at 2.9- and 2.8-A resolution. Biochemistry. 1981 Apr 28;20(9):2361-70.

[14] Nilsson B, Moks T, Jansson B, Abrahmsén L, Elmblad A, Holmgren E, Henrichson C, Jones TA, Uhlén M. A synthetic IgG-binding domain based on staphylococcal protein A. Protein Eng. 1987 Feb-Mar;1(2):107-13.

[15] Goodyear CS, Silverman GJ. Death by a B cell superantigen: In vivo VH-targeted apoptotic supraclonal B cell deletion by a Staphylococcal Toxin. J Exp Med. 2003 May 5;197(9):1125-39. 
[16] Bodén MK, Flock JI. Fibrinogen-binding protein/clumping factor from Staphylococcus aureus. Infect Immun. 1989 Aug;57(8):2358-63.

[17] Palmqvist N, Patti JM, Tarkowski A, Josefsson E. Expression of staphylococcal clumping factor A impedes macrophage phagocytosis. Microbes Infect. 2004 Feb;6(2):188-95.

[18] Hienz SA, Schennings T, Heimdahl A, Flock JI. Collagen binding of Staphylococcus aureus is a virulence factor in experimental endocarditis. J Infect Dis. 1996 Jul;174(1):83-8.

[19] Ganesh VK, Rivera JJ, Smeds E, Ko YP, Bowden MG, Wann ER, Gurusiddappa S, Fitzgerald JR, Höök M. A structural model of the Staphylococcus aureus ClfAfibrinogen interaction opens new avenues for the design of anti-staphylococcal therapeutics. PLoS Pathog. 2008 Nov

[20] Bhakdi S, Tranum-Jensen J. Alpha-toxin of Staphylococcus aureus. Microbiol Rev. 1991 Dec;55(4):733-51.

[21] Muraille E, De Smedt T, Andris F, Pajak B, Armant M, Urbain J, Moser M, Leo O. Staphylococcal enterotoxin B induces an early and transient state of immunosuppression characterized by $\mathrm{V}$ beta-unrestricted $\mathrm{T}$-cell unresponsiveness and defective antigen-presenting cell functions. J Immunol. 1997 Mar 15;158(6):2638-47.

[22] Wahlsten JL, Ramakrishnan S. Separation of function between the domains of toxic shock syndrome toxin-1. J Immunol. 1998 Jan 15;160(2):854-9.

[23] Bantel H, Sinha B, Domschke W, Peters G, Schulze-Osthoff K, Jänicke RU. alpha-Toxin is a mediator of Staphylococcus aureus-induced cell death and activates caspases via the intrinsic death pathway independently of death receptor signaling. J Cell Biol. 2001 Nov 12;155(4):637-48.

[24] Speziale P, Pietrocola G, Rindi S, Provenzano M, Provenza G, Di Poto A, Visai L, Arciola CR. Structural and functional role of Staphylococcus aureus surface components recognizing adhesive matrix molecules of the host. Future Microbiol. 2009 Dec;4(10):1337-52.

[25] Brouillette E, Grondin G, Shkreta L, Lacasse P, Talbot BG. In vivo and in vitro demonstration that Staphylococcus aureus is an intracellular pathogen in the presence or absence of fibronectin-binding proteins. Microb Pathog. 2003 Oct;35(4):159-68.

[26] Garzoni C, Kelley WL. Staphylococcus aureus: new evidence for intracellular persistence. Trends Microbiol. 2009 Feb;17(2):59-65.

[27] Schröder A, Schröder B, Roppenser B, Linder S, Sinha B, Fässler R, Aepfelbacher M. Staphylococcus aureus fibronectin binding protein-A induces motile attachment sites and complex actin remodeling in living endothelial cells. Mol Biol Cell. 2006 Dec;17(12):5198-210.

[28] Wright JA, Nair SP. Interaction of staphylococci with bone. Int J Med Microbiol. 2010 Feb;300(2-3):193-204.

[29] Foster TJ. Immune evasion by staphylococci. Nat Rev Microbiol. 2005 Dec;3(12):948-58.

[30] Bayles KW, Wesson CA, Liou LE, Fox LK, Bohach GA, Trumble WR. Intracellular Staphylococcus aureus escapes the endosome and induces apoptosis in epithelial cells. Infect Immun. 1998 Jan;66(1):336-42. 
[31] Menzies BE, Kourteva I. Internalization of Staphylococcus aureus by endothelial cells induces apoptosis. Infect Immun. 1998 Dec;66(12):5994-8.

[32] Alexander EH, Rivera FA, Marriott I, Anguita J, Bost KL, Hudson MC. Staphylococcus aureus - induced tumor necrosis factor - related apoptosis inducing ligand expression mediates apoptosis and caspase- 8 activation in infected osteoblasts. BMC Microbiol. 2003 Apr 2;3:5.

[33] Gresham HD, Lowrance JH, Caver TE, Wilson BS, Cheung AL, Lindberg FP. Survival of Staphylococcus aureus inside neutrophils contributes to infection. J Immunol. 2000 Apr 1;164(7):3713-22.

[34] Räisänen SR, Halleen J, Parikka V, Väänänen HK. Tartrate-resistant acid phosphatase facilitates hydroxyl radical formation and colocalizes with phagocytosed Staphylococcus aureus in alveolar macrophages. Biochem Biophys Res Commun. 2001 Oct 19;288(1):142-50.

[35] Courvalin P. Antibiotic resistance: the pros and cons of probiotics. Dig Liver Dis. 2006 Dec;38 Suppl 2:S261-5.

[36] Clements MO, Foster SJ. Stress resistance in Staphylococcus aureus. Trends Microbiol. 1999 Nov;7(11):458-62.

[37] Acar JF, Goldstein FW, Lagrange P. Human infections caused by thiamine- or menadione-requiring Staphylococcus aureus. J Clin Microbiol. 1978 Aug;8(2):142-7.

[38] Chuard C, Vaudaux PE, Proctor RA, Lew DP. Decreased susceptibility to antibiotic killing of a stable small colony variant of Staphylococcus aureus in fluid phase and on fibronectin-coated surfaces. J Antimicrob Chemother. 1997 May;39(5):603-8.

[39] Kohler C, von Eiff C, Peters G, Proctor RA, Hecker M, Engelmann S. Physiological characterization of a heme-deficient mutant of Staphylococcus aureus by a proteomic approach. J Bacteriol. 2003 Dec;185(23):6928-37.

[40] von Eiff C. Staphylococcus aureus small colony variants: a challenge to microbiologists and clinicians. Int J Antimicrob Agents. 2008 Jun;31(6):507-10.

[41] Baumert N, von Eiff C, Schaaff F, Peters G, Proctor RA, Sahl HG. Physiology and antibiotic susceptibility of Staphylococcus aureus small colony variants. Microb Drug Resist. 2002 Winter;8(4):253-60.

[42] Proctor RA, Peters G. Small colony variants in staphylococcal infections: diagnostic and therapeutic implications. Clin Infect Dis. 1998 Sep;27(3):419-22.

[43] Fournier B, Philpott DJ. Recognition of Staphylococcus aureus by the innate immune system. Clin Microbiol Rev. 2005 Jul;18(3):521-40.

[44] Medzhitov R, Janeway C Jr. The Toll receptor family and microbial recognition. Trends Microbiol. 2000 Oct;8(10):452-6.

[45] Janeway CA, Jr. et al. (2005). Immunobiology. (6th ed.). Garland Science. ISBN 0-443-07310-4.

[46] Akira S. TLR signaling. Curr Top Microbiol Immunol. 2006;311:1-16.

[47] Takeuchi O, Hoshino K, Akira S. Cutting edge: TLR2-deficient and MyD88deficient mice are highly susceptible to Staphylococcus aureus infection. J Immunol. 2000 Nov 15;165(10):5392-6 
[48] Verdrengh M, Tarkowski A. Role of neutrophils in experimental septicemia and septic arthritis induced by Staphylococcus aureus. Infect Immun. 1997 Jul;65(7):2517-21.

[49] Mölne L, Verdrengh M, Tarkowski A. Role of neutrophil leukocytes in cutaneous infection caused by Staphylococcus aureus. Infect Immun. 2000 Nov;68(11):6162-7.

[50] Heyworth PG, Cross AR, Curnutte JT. Chronic granulomatous disease. Curr Opin Immunol. 2003 Oct;15(5):578-84.

[51] Hiramatsu K, Hanaki H, Ino T, Yabuta K, Oguri T, Tenover FC. Methicillinresistant Staphylococcus aureus clinical strain with reduced vancomycin susceptibility J Antimicrob Chemother. 1997 Jul;40(1):135-6.

[52] Rayner C, Munckhof WJ. Antibiotics currently used in the treatment of infections caused by Staphylococcus aureus. Intern Med J. 2005 Dec;35 Suppl 2:S3-16.

[53] Kowalski TJ, Berbari EF, Osmon DR. Epidemiology, treatment, and prevention of community-acquired methicillin-resistant Staphylococcus aureus infections. Mayo Clin Proc. 2005 Sep;80(9):1201-7; quiz 1208.

[54] Trampuz A, Zimmerli W. Antimicrobial agents in orthopaedic surgery: Prophylaxis and treatment. Drugs. 2006;66(8):1089-105.

[55] Kurlenda J, Grinholc M. Alternative therapies in Staphylococcus aureus diseases. Acta Biochim Pol. 2012;59(2):171-84.

[56] Deleo FR, Otto M, Kreiswirth BN, Chambers HF. Community-associated meticillin-resistant Staphylococcus aureus. Lancet. 2010 May 1;375(9725):155768.

[57] Peschel A, Collins LV. Staphylococcal resistance to antimicrobial peptides of mammalian and bacterial origin. Peptides. 2001 Oct;22(10):1651-9.

[58] Zanetti M, Gennaro R, Skerlavaj B, Tomasinsig L, Circo R. Cathelicidin peptides as candidates for a novel class of antimicrobials. Curr Pharm Des. 2002;8(9):77993.

[59] Hiemstra PS, Fernie-King BA, McMichael J, Lachmann PJ, Sallenave JM. Antimicrobial peptides: mediators of innate immunity as templates for the development of novel anti-infective and immune therapeutics. Curr Pharm Des. 2004;10(23):2891-905.

[60] Stryjewski ME, Hall RP, Chu VH, Kanafani ZA, O'Riordan WD, Weinstock MS, Stienecker RS, Streilein R, Dorschner RA, Fowler VG Jr, Corey GR, Gallo RL. Expression of antimicrobial peptides in the normal and involved skin of patients with infective cellulitis. J Infect Dis. 2007 Nov 1;196(9):1425-30

[61] Otto M. Targeted immunotherapy for staphylococcal infections : focus on antiMSCRAMM antibodies. BioDrugs. 2008;22(1):27-36.

[62] Menzies BE, Kourteva Y, Kaiser AB, Kernodle DS. Inhibition of staphylococcal wound infection and potentiation of antibiotic prophylaxis by a recombinant fragment of the fibronectin-binding protein of Staphylococcus aureus. J Infect Dis. 2002 Apr 1;185(7):937-43.

[63] Zimmerli W, Trampuz A, Ochsner PE. Prosthetic-joint infections. N Engl J Med. 2004 Oct 14;351(16):1645-54. 
[64] Sendi P, Rohrbach M, Graber P, Frei R, Ochsner PE, Zimmerli W. Staphylococcus aureus small colony variants in prosthetic joint infection. Clin Infect Dis. 2006 Oct 15;43(8):961-7.

[65] Alexander EH, Hudson MC. Factors influencing the internalization of Staphylococcus aureus and impacts on the course of infections in humans. Appl Microbiol Biotechnol. 2001 Aug;56(3-4):361-6.

[66] Reilly SS, Hudson MC, Kellam JF, Ramp WK. (2000). In vivo internalization of Staphylococcus aureus by embryonic chick osteoblasts.Bone. 26(1):63-70.

[67] Cunha BA. Pseudomonas aeruginosa: resistance and therapy. Semin Respir Infect. 2002 Sep;17(3):231-9.

[68] Norman DC, Yoshikawa TT. Responding to septic arthritis. Geriatrics. 1983 Jan;38(1):83-91.

[69] Sellman BR, Timofeyeva Y, Nanra J, Scott A, Fulginiti JP, Matsuka YV, Baker SM. Expression of Staphylococcus epidermidis SdrG increases following exposure to an in vivo environment. Infect Immun. $2008 \mathrm{Jul} ; 76(7): 2950-7$.

[70] Hall-Stoodley L, Costerton JW, Stoodley P. Bacterial biofilms: from the natural environment to infectious diseases.Nat Rev Microbiol. 2004 Feb;2(2):95-108.

[71] Stewart PS, Franklin MJ. Physiological heterogeneity in biofilms. Nat Rev Microbiol. 2008 Mar;6(3):199-210.

[72] Darouiche RO. Device-associated infections: a macroproblem that starts with microadherence. Clin Infect Dis. 2001 Nov 1;33(9):1567-72.

[73] Zimmerli W, Lew PD, Waldvogel FA. Pathogenesis of foreign body infection. Evidence for a local granulocyte defect. J Clin Invest. 1984 Apr;73(4):1191-200.

[74] Trampuz A, Zimmerli W. Antimicrobial agents in orthopaedic surgery: Prophylaxis and treatment. Drugs. 2006;66(8):1089-105.

[75] Lewis RT. Soft tissue infections. World J Surg. 1998 Feb;22(2):146-51.

[76] Darouiche RO, Hamill RJ. Antibiotic penetration of and bactericidal activity within endothelial cells. Antimicrob Agents Chemother. 1994 May;38(5):105964.

[77] Mosmann, T.R.; Coffman, R.L. TH1 and TH2 cells: different patterns of cytokine secretion lead to different functional properties. Anпи Rev Immunol. 1989, 7, 145173.

[78] Chehimi, J.; Trinchieri, G. Interleukin-12: a bridge between innate resistance and adaptive immunity with a role in infection and acquired immunodeficiency. J Clin Immunol. 1994, 14, 149-161.

[79] Aggarwal, S.; Ghilardi, N.; Xie, M.H.; de Sauvage, F.J.; Gurney, A.L. Interleukin-23 promotes a distinct CD4 T-cell activation state characterized by the production of interleukin-17. J Biol Chem. 2003, 278, 1910-1914.

[80] Beadling, C.; Slifka, M.K. Regulation of innate and adaptive immune responses by the related cytokines IL-12, IL-23, and IL-27. Arch Immunol Ther Exp. 2006, $54,15-24$.

[81] Sinigaglia, F.; D'Ambrosio, D.; Panina-Bordignon, P.; Rogge, L. Regulation of the IL-12/IL-12R axis: a critical step in T-helper cell differentiation and effector function. Immunol Rev. 1999, 170, 65-72.

[82] Merberg, D.M.; Wolf, S.F.; Clark, S.C. Sequence similarity between NKSF and the IL-6/G-CSF family. Immunol Today 1992, 13, 77-78. 
[83] Gearing, D.P.; Cosman, D. Homology of the p40 subunit of natural killer cell stimulatory factor (NKSF) with the extracellular domain of the interleukin-6 receptor. Cell 1991, 66, 9-10.

[84] D’Andrea, A.; Rengaraju, M.; Valiante, N.M.; Chehimi, J.; Kubin, M.; Aste, M.; Chan, S.H.; Kobayashi, M.; Young, D.; Nickbarg, E.; Chizzonite, R.; Wolf, S.F.; Trinchieri, G. Production of natural killer cell stimulatory factor (interleukin 12) by peripheral blood mononuclear cells. J Exp Med. 1992, 176, 1387-1398.

[85] Gately, M.K.; Carvajal, D.M.; Connaughton, S.E.; Gillessen, S.; Warrier, R.R.; Kolinsky, K.D.; Wilkinson, V.L.; Dwyer, C.M.; Higgins, G.F. Jr.; Podlaski, F.J.; Faherty, D.A.; Familletti, P.C.; Stern, A.S.; Presky, D.H. Interleukin-12 antagonist activity of mouse interleukin-12 p40 homodimer in vitro and in vivo. Ann N Y Acad Sci. 1996, 795, 1-12.

[86] Ling, P.; Gately, M.K.; Gubler, U. Human IL-12 p40 homodimer binds to the IL12 receptor but does not mediate biologic activity. J Immunol. 1995, 154, 116127.

[87] Khader, S.A.; Partida-Sanchez, S.; Bell, G.; Jelley-Gibbs, D.M.; Swain, S.; Pearl, J.E.; Ghilardi, N.; Desauvage, F.J.; Lund, F.E; Cooper, A.M. Interleukin 12p40 is required for dendritic cell migration and T-cell priming after Mycobacterium tuberculosis infection. J Exp Med. 2006, 203, 1805-1815.

[88] Presky, D.H.; Yang, H.; Minetti, L.J.; Chua, A.O.; Nabavi, N.; Wu, C.Y.; Gately, M.K.; Gubler, U. A functional interleukin 12 receptor complex is composed of two beta-type cytokine receptor subunits. Proc Natl Acad Sci U S A. 1996, 93, 14002-14007.

[89] Collison, L.W.; Vignali, D.A. Interleukin-35: odd one out or part of the family? Immunol Rev. 2008, 226, 248-262.

[90] Trinchieri, G. Interleukin-12 and the regulation of innate resistance and adaptive immunity. Nat Rev Immunol. 2003, 3, 133-146.

[91] Bacon, C.M.; Petricoin, E.F. ${ }^{\text {rd }}$; Ortaldo, J.R.; Rees, R.C.; Larner, A.C.; Johnston, J.A.; O'Shea, J.J. Interleukin 12 induces tyrosine phosphorylation and activation of STAT4 in human lymphocytes. Proc Natl Acad Sci U S A. 1995, 927, 307-311.

[92] Mullen, A.C.; High, F.A.; Hutchins, A.S.; Lee, H.W.; Villarino, A.V.; Livingston, D.M.; Kung, A.L.; Cereb, N.; Yao, T.P.; Yang, S.Y.; Reiner, S.L. Role of T-bet in commitment of TH1 cells before IL-12-dependent selection. Science. 2001, 292, 1907-1910.

[93] Lighvani, A.A.; Frucht, D.M.; Jankovic, D.; Yamane, H.; Aliberti, J.; Hissong, B.D.; Nguyen, B.V.; Gadina, M.; Sher, A.; Paul, W.E.; O'Shea, J.J. T-bet is rapidly induced by interferon-gamma in lymphoid and myeloid cells. Proc Natl Acad Sci U S A. 2001, 98, 15137-15142.

[94] Usui, T.; Preiss, J.C.; Kanno, Y.; Yao, Z.J.; Bream, J.H.; O'Shea, J.J.; Strober, W. T-bet regulates Th1 responses through essential effects on GATA-3 function rather than on IFNG gene acetylation and transcription. J Exp Med. 2006, 203, 755-766.

[95] Szabo, S.J.; Dighe, A.S.; Gubler, U.; Murphy, K.M. Regulation of the interleukin (IL)-12R beta 2 subunit expression in developing T helper 1 (Th1) and Th2 cells. J Exp Med. 1997, 185, 817-824. 
[96] Boehm, U.; Klamp, T.; Groot, M; Howard, J.C. Cellular responses to interferon- $\gamma$. Annu Rev Immunol. 1997, 15, 749-795.

[97] Watford, W.T.; Moriguchi, M.; Morinobu, A.; O'Shea, J.J. The biology of IL-12: coordinating innate and adaptive immune responses. Cytokine Growth Factor Rev. 2003, 14(5), 361-368.

[98] Brombacher, F.; Kastelein, R.A.; Alber, G. Novel IL-12 family members shed light on the orchestration of Th1 responses. Trends Immunol. 2003, 24, 207-212.

[99] Parham, C.; Chirica, M.; Timans, J.; Vaisberg, E.; Travis, M.; Cheung, J.; Pflanz, S.; Zhang, R.; Singh, K.P.; Vega, F.; To, W.; Wagner, J.; O'Farrell, A.M.; McClanahan, T.; Zurawski, S.; Hannum, C.; Gorman, D.; Rennick, D.M.; Kastelein, R.A.; de Waal Malefyt, R.; Moore, K.W. A receptor for the heterodimeric cytokine IL-23 is composed of IL-12Rbeta1 and a novel cytokine receptor subunit, IL-23R. J Immunol. 2002, 168, 5699-5708.

[100] Oppmann, B.; Lesley, R.; Blom, B.; Timans, J.C.; Xu, Y.; Hunte, B.; Vega, F.; Yu, N.; Wang, J.; Singh, K.; Zonin, F.; Vaisberg, E.; Churakova, T.; Liu, M.; Gorman, D.; Wagner, J.; Zurawski, S.; Liu, Y.; Abrams, J.S.; Moore, K.W.; Rennick, D.; de Waal-Malefyt, R.; Hannum, C.; Bazan, J.F.; Kastelein, R.A. Novel p19 protein engages IL-12p40 to form a cytokine, IL-23, with biological activities similar as well as distinct from IL-12. Immunity. 2000, 13, 715-725.

[101] Kamiya, S.; Owaki, T.; Morishima, N.; Fukai, F.; Mizuguchi, J.; Yoshimoto, T. An indispensable role for STAT1 in IL-27-induced T-bet expression but not proliferation of naive CD4+ T-cells. J Immunol. 2004, 173, 3871-3877.

[102] Pflanz, S.; Timans, J.C.; Cheung, J.; Rosales, R.; Kanzler, H.; Gilbert, J.; Hibbert, L.; Churakova, T.; Travis, M.; Vaisberg, E.; Blumenschein, W.M.; Mattson, J.D.; Wagner, J.L.; To, W.; Zurawski, S.; McClanahan, T.K.; Gorman, D.M.; Bazan, J.F.; de Waal Malefyt, R.; Rennick, D.; Kastelein, R.A. IL-27, a heterodimeric cytokine composed of EBI3 and p28 protein, induces proliferation of naive CD4(+) T-cells. Immunity. 2002, 16, 779-790.

[103] Collison, L.W.; Workman, C.J.; Kuo, T.T.; Boyd, K.; Wang, Y.; Vignali, K.M.; Cross, R.; Sehy, D.; Blumberg, R.S.; Vignali, D.A. The inhibitory cytokine IL-35 contributes to regulatory T-cell function. Nature 2007, 450, 566-569.

[104] Niedbala, W.; Wei, X.Q.; Cai, B.; Hueber, A.J.; Leung, B.P.; McInnes, I.B.; Liew, F.Y. IL-35 is a novel cytokine with therapeutic effects against collageninduced arthritis through the expansion of regulatory T-cells and suppression of Th17 cells. Eur J Immunol. 2007, 37, 3021-3029.

[105] Airoldi, I.; Guglielmino, R.; Carra, G.; Corcione, A.; Gerosa, F.; Taborelli, G.; Trinchieri, G.; Pistoia, V. The interleukin-12 and interleukin-12 receptor system in normal and transformed human B lymphocytes. Haematologica 2002, 87, 434442.

[106] Aragane, Y.; Riemann, H.; Bhardwaj, R.S.; Schwarz, A.; Sawada, Y.; Yamada, H.; Luger, T.A.; Kubin, M.; Trinchieri, G.; Schwarz, T. IL-12 is expressed and released by human keratinocytes and epidermoid carcinoma cell lines. J Immunol. 1994, 153, 5366-5372.

[107] Bost, K.L.; Ramp, W.K.; Nicholson, N.C.; Bento, J.L.; Marriott, I.; Hudson, M.C. Staphylococcus aureus infection of mouse or human osteoblasts induces high 
levels of interleukin-6 and interleukin-12 production. J Infect Dis. 1999, 180, 1912-1920.

[108] Aste-Amezaga, M.; Ma, X.; Sartori, A.; Trinchieri, G. Molecular mechanisms of the induction of IL-12 and its inhibition by IL-10. J Immunol. 1998, 160, 59365944.

[109] Segal, B.M.; Dwyer, B.K.; Shevach, E.M. An interleukin (IL)-10/IL-12 immunoregulatory circuit controls susceptibility to autoimmune disease. $J$ Exp Med. 1998, 187, 537-546.

[110] Bonecchi, R.; Bianchi, G.; Bordignon, P.P.; D'Ambrosio, D.; Lang, R.; Borsatti, A.; Sozzani, S.; Allavena, P.; Gray, P.A.; Mantovani, A.; Sinigaglia, F. Differential expression of chemokine receptors and chemotactic responsiveness of type 1 T helper cells (Th1s) and Th2s. J Exp Med. 1998, 187, 129-134.

[111] Estaquier, J.; Idziorek, T.; Zou, W.; Emilie, D.; Farber, C.M.; Bourez, J.M.; Ameisen, J.C. T helper type 1/T helper type 2 cytokines and $\mathrm{T}$ cell death: preventive effect of interleukin 12 on activation-induced and CD95 (FAS/APO1)-mediated apoptosis of CD4+ T cells from human immunodeficiency virusinfected persons. J Exp Med. 1995, 182, 1759-1767.

[112] Austrup, F.; Vestweber, D.; Borges, E.; Löhning, M.; Bräuer, R.; Herz, U.; Renz, H.; Hallmann, R.; Scheffold, A.; Radbruch, A.; Hamann, A. P- and E-selectin mediate recruitment of T-helper-1 but not T-helper-2 cells into inflammed tissues. Nature 1997, 385, 81-83.

[113] Loetscher, M.; Loetscher, P.; Brass, N.; Meese, E.; Moser, B. Lymphocytespecific chemokine receptor CXCR3: regulation, chemokine binding and gene localization. Eur J Immunol. 1998, 28, 3696-3705.

[114] Gazzinelli, R.T.; Wysocka, M.; Hayashi, S.; Denkers, E.Y.; Hieny, S.; Caspar, P.; Trinchieri, G.; Sher, A. Parasite-induced IL-12 stimulates early IFN-gamma synthesis and resistance during acute infection with Toxoplasma gondii. $J$ Immunol. 1994, 1536, 2533-2543.

[115] Gately, M.K.; Chizzonite, R.; Presky, D.H. Measurement of human and mouse interleukin-12. Curr Protoc Immunol. 2001, 6.16.1-6.16.15.

[116] Wilkinson, V.L.; Warrier, R.R.; Truitt, T.P.; Nunes, P.; Gately, M.K.; Presky, D.H. Characterization of anti-mouse IL-12 monoclonal antibodies and measurement of mouse IL-12 by ELISA. J Immunol Methods. 1996, 189, 15-24.

[117] Shiratori, I.; Matsumoto, M.; Tsuji, S.; Nomura, M.; Toyoshima,. K.; Seya, T. Molecular cloning and functional characterization of guinea pig IL-12. Int Immunol. 2001, 13, 1129-1139.

[118] Shiratori, I.; Suzuki, Y.; Oshiumi, H.; Begum, N.A.; Ebihara, T.; Matsumoto, M.; Hazekim, K.; Kodama, K.; Kashiwazaki, Y.; Seya, T. Recombinant interleukin-12 and interleukin-18 antitumor therapy in a guinea-pig hepatoma cell implant model. Cancer Sci. 2007, 98, 1936-1942.

[119] Novelli, F.; Casanova, J.L. The role of IL-12, IL-23 and IFN-gamma in immunity to viruses. Cytokine Growth Factor Rev. 2004, 15, 367-377.

[120] Hendricks, R.L.; Janowicz, M.; Tumpey, T.M. Critical role of corneal Langerhans cells in the CD4- but not CD8-mediated immunopathology in herpes simplex virus-1-infected mouse corneas. J Immunol. 1992, 148, 2522-2529. 
[121] Matsuo, R.; Kobayashi, M.; Herndon, D.N.; Pollard, R.B.; Suzuki, F. Interleukin12 protects thermally injured mice from herpes simplex virus type 1 infection. $J$ LeukocBiol. 1996, 59, 623-630.

[122] Harandi, A.M.; Svennerholm, B.; Holmgren, J.; Eriksson, K. Interleukin-12 (IL12) and IL-18 are important in innate defense against genital herpes simplex virus type 2 infection in mice but are not required for the development of acquired gamma interferon-mediated protective immunity. J Virol. 2001, 75, 6705-6709.

[123] Bhardwaj, N.; Seder, R.A.; Reddy, A.; Feldman, M.V. IL-12 in conjunction with dendritic cells enhances antiviral $\mathrm{CD}^{+} \mathrm{CTL}$ responses in vitro. J Clin Invest. 1996, 98(3), 715-722.

[124] Gross, P.A.; Hermogenes, A.W.; Sacks, H.S.; Lau, J.; Levandowski, R.A. The efficacy of influenza vaccine in elderly persons. A meta-analysis and review of the literature. Ann Intern Med. 1995, 123, 518-527.

[125] de Boer, T.; van Dissel, J.T.; Kuijpers, T.W.; Rimmelzwaan, G.F.; Kroon, F.P.; Ottenhoff, T.H. Influenza virus vaccination induces interleukin-12/23 receptor beta 1 (IL-12/23R beta 1)-independent production of gamma interferon (IFNgamma) and humoral immunity in patients with genetic deficiencies in IL-12/23R beta 1 or IFN-gamma receptor I. Clin Vaccine Immunol. 2008, 15, 1171-1175.

[126] Maggi, E.; Mazzetti, M.; Ravina, A.; Annunziato, F.; de Carli, M.; Piccinni, M.P.; Manetti, R.; Carbonari, M.; Pesce, A.M.; del Prete, G. Ability of HIV to promote a TH1 to TH0 shift and to replicate preferentially in TH2 and TH0 cells. 1994, 265, 244-248.

[127] Balter, M. Elusive HIV-suppressor factors found. Science 1995, 270, 1560-1561.

[128] Hudson, M.C.; Ramp, W.K.; Nicholson, N.C.; Williams, A.S.; Nousiainen, M.T. Internalization of Staphylococcus aureus by cultured osteoblasts. Microb Pathog. 1995, 6, 409-419.

[129] Almeida, R.A.; Matthews, K.R.; Cifrian, E.; Guidry, A.J.; Oliver, S.P. Staphylococcus aureus invasion of bovine mammary epithelial cells. J Dairy Sci. 1996, 79, 1021-1026.

[130] Marriott, I. Osteoblast responses to bacterial pathogens: a previously unappreciated role for bone-forming cells in host defense and disease progression. Immunol Res. 2004, 30, 291-308.

[131] Torti, D.C.; Feldman, S.R. Interleukin-12, interleukin-23, and psoriasis: current prospects. J Am Acad Dermato. 2007, 57, 1059-1068.

[132] Hultgren, O.H.; Stenson, M.; Tarkowski, A. Role of IL-12 in Staphylococcus aureus-triggered arthritis and sepsis. Arthritis Res. 2001, 3, 41-47.

[133] Sutterwala, F.S.; Noel, G.J.; Clynes, R.; Mosser, D.M. Selective suppression of interleukin-12 induction after macrophage receptor ligation. J Exp Med. 1997, 185, 1977-1985.

[134] Marth, T.; Neurath, M.; Cuccherini, B.A.; Strober, W. Defects of monocyte interleukin 12 production and humoral immunity in Whipple's disease. Gastroenterology 1997, 113, 442-448.

[135] O'Sullivan, S.T.; Lederer, J.A.; Horgan, A.F.; Chin, D.H.; Mannick, J.A.; Rodrick, M. Major injury leads to predominance of the T helper-2 lymphocyte phenotype and diminished interleukin-12 production associated with decreased resistance to infection. Ann Surg. 1995, 222, 482-490. 
[136] Napolitano, L.M.; Napolitano, L.M.; Koruda, M.J.; Meyer, A.A.; Baker, C.C. The impact of femur fracture with associated soft tissue injury on immune function and intestinal permeability. Shock 1996, 5, 202-207.

[137] Huynh, T.; Lemasters, J.J.; Bracey, L.W.; Baker, C.C. Proinflammatory Kupffer cell alterations after femur fracture trauma and sepsis in rats. Shock 2000, 14, 555560.

[138] Spolarics, Z.; Siddiqi, M.; Siegel, J.H.; Garcia, Z.C.; Stein, D.S.; Denny, T.; Deitch, E.A. Depressed interleukin-12-producing activity by monocytes correlates with adverse clinical course and a shift toward Th2-type lymphocyte pattern in severely injured male trauma patients. Crit Care Med., 2003, 31, 1722-1729.

[139] Li, B.; Jiang, B.; Boyce, B.M.; Lindsey, B.A. Multilayer polypeptide nanoscale coatings incorporating IL-12 for the prevention of biomedical device-associated infections. Biomaterials 2009, 30, 2552-2558.

[140] Li, B.; Jiang, B.; Dietz, M.J.; Smith, E.S.; Clovis, N.B.; Rao, K.M.K. Evaluation of local MCP-1 and IL-12 nanocoatings for infection prevention in open fractures. J Orthop Res. 2010; 28(1):48-54

[141] Murray, H.W. Gamma interferon, cytokine-induced macrophage activation, and antimicrobial host defense. In vitro, in animal models, and in humans. Diagn Microbiol Infect Dis. 1990, 13, 411-421.

[142] Orme, I.M.; Miller, E.S.; Roberts, A.D.; Furney, S.K.; Griffin, J.P.; Dobos, K.M.; Chi, D.; Rivoire, B.; Brennan, P.J. T lymphocytes mediating protection and cellular cytolysis during the course of Mycobacterium tuberculosis infection. Evidence for different kinetics and recognition of a wide spectrum of protein antigens. J Immunol. 1992, 148, 189-196.

[143] Flynn, J.L.; Goldstein, M.M.; Triebold, K.J.; Sypek, J.; Wolf, S.; Bloom, B.R. IL12 increases resistance of BALB/c mice to Mycobacterium tuberculosis infection. J Immunol. 1995, 155, 2515-2524.

[144] Cooper, A.M.; Khader, S.A. The role of cytokines in the initiation, expansion, and control of cellular immunity to tuberculosis. Immunol Rev. 2008, 226, 191-204.

[145] Jiang, B.; Li, B. Tunable drug incorporation and release from polypeptide multilayer nanofilms. Int J Nanomedicine 2009, 4, 37-53.

[146] Zhao, Q.; Li, B. pH-controlled drug loading and release from biodegradable microcapsules. Nanomedicine: Nanotechnology, Biology, and Medicine 2008, 4, 302-310. 


\title{
CHAPTER 2
}

\section{Staphylococcus aureus Internalization and Associated Biological Responses of Osteoblasts and Macrophages}

\begin{abstract}
The aims of this study were to compare Staphylococcus aureus (S. aureus) internalization in a phagocytic cell (i.e. macrophage) to a non-phagocytic cell (i.e. osteoblast), and to investigate the cells' responses upon infection. We found that $S$. aureus could internalize within macrophages and osteoblasts, and upon infection, a significantly higher number of live intracellular $S$. aureus was observed in macrophages compared to osteoblasts. The viability of macrophages and osteoblasts both decreased with increasing infection time, and macrophages had significantly lower viability during $2 \mathrm{~h}$ infection and significantly higher viability during $8 \mathrm{~h}$ infection compared to osteoblasts. Moreover, intracellular S. aureus was found to survive within macrophages and osteoblasts for approximately 5 and 7 days, respectively. The percentage of $S$. aureus survival within macrophages and osteoblasts decreased with increasing post-infection time, and the percentage of $S$. aureus survival within macrophages was significantly lower compared to that within osteoblasts. More importantly, compared to non-infected controls, S. aureus infection resulted in (i) significantly increased hydrogen peroxide production in macrophages and osteoblasts, (ii) significantly increased superoxide anion production in macrophages but not in osteoblasts, (iii) relatively lower alkaline phosphatase activity in infected osteoblasts, and (iv) higher phagocytosis activity in infected macrophages.
\end{abstract}


Keywords: Infection; internalization; intracellular bacteria; S. aureus; chronic infection; recurrent infection.

\section{Introduction}

Staphylococcus aureus (S. aureus) is one of the primary causes of bone infections [1-3]. These infections are often chronic, difficult to eradicate, and cause high morbidity rates [4]. S. aureus can gain access deep into bone and soft tissue as a result of severe trauma or foreign body implants [5]. Although S. aureus has been traditionally considered as an extracellular pathogen, it has been reported by several groups that this bacterium can invade and survive within a variety of cells such as neutrophils, macrophages, T-lymphocytes, epithelial cells, endothelial cells, fibroblasts, and osteoblasts [6-15]. One hypothesis, not yet proven, about chronic and recurrent infections is that bacteria internalize into the host cells and such intracellular bacteria may potentially lead to their evasion of the host's immune responses and protection from most conventional antibiotics [16].

The main role of osteoblasts is to synthesize bone components and induce bone matrix mineralization [17]. Osteoblasts are not traditionally considered as part of the immune system. However, osteoblasts were recently found to be able to induce inflammatory cytokines and chemokines upon $S$. aureus internalization $[18,19]$. This finding may suggest an important role for osteoblasts in triggering immune responses after $S$. aureus infection. S. aureus can be internalized into osteoblasts and its internalization is believed to be mediated by binding of fibronectins on osteoblast surfaces, which is connected to the integrin dimer $\alpha_{5} \beta_{1}$ molecule and fibronectin-binding 
proteins on S. aureus surfaces [6]. Protein-ligand interaction leads to $S$. aureus adhesion and invasion by a "zipper-like" mechanism [15]. Eventually, internalized bacteria escape into the cytoplasm and may lead to host cell death by apoptosis [20]. In addition, live osteoblasts are necessary for $S$. aureus internalization as formalin-fixed osteoblasts could not internalize $S$. aureus $[10,21]$.

The major role of phagocytes, such as macrophages, neutrophils, and dendritic cells is to engulf and eliminate a wide variety of invading pathogens. As a result, high influxes of such phagocytes are expected at the infection site upon pathogen invasion. For instance, a high influx of neutrophils was detected at the infection site of $S$. aureus bone infection [22]. Unfortunately, some pathogens can survive within these phagocytes after being phagocytized which may lead to chronic diseases $[23,24]$. It was reported that $S$. aureus can survive within neutrophils and its survival may have contributed to infection persistence as well as dissemination in vivo [7]. Neutrophils are short-lived and are unlikely to carry intracellular pathogens for long [25]. Macrophages, however, are long lived and may possibly allow surviving pathogens to invade the circulatory system from localized infection sites [26] and thereby may be more likely contribute to chronic and recurrent infections.

The aims of this study were to compare $S$. aureus internalization in a phagocytic cell (i.e. macrophage) and a non-phagocytic cell (i.e. osteoblast), and to investigate macrophage and osteoblast responses upon $S$. aureus infection. We hypothesized that $S$. aureus can internalize into macrophages and osteoblasts and survive for at least days, and its internalization may lead to changes in macrophage and osteoblast activities. 


\section{Materials and Methods}

\subsubsection{Reagents}

Tryptic soy agar (TSA, w/5\% sheep blood) plates, tryptic soy broth (TSB), phosphate buffered saline (PBS), fetal bovine serum (FBS), $0.25 \%$ trypsin/2.21 mM ethylenediaminetetraacetic acid (EDTA) solution, 45\% glucose solution, 7.5\% sodium bicarbonate, sodium pyruvate, and HEPES buffer were all obtained from Fisher Scientific (Pittsburgh, PA). Dulbecco's Modified Eagle Media: Nutrient Mixture F-12 (DMEM/F12) and RPMI-1640 media were purchased from LONZA (Walkersville, MD). DiI fluorescent dye, Syto-9, propidium iodide (PI), and $100 \mathrm{U} / \mathrm{mL}$ penicillin $/ 100 \mathrm{mg} / \mathrm{mL}$ streptomycin solution were from Invitrogen (Carlsbad, CA). Gentamicin, Triton X-100, cytochalasin D, dimethyl sulfoxide (DMSO), bovine serum albumin (BSA), lysostaphin, fluorescein isothiocyanate (FITC), paraformaldehyde, and glutaraldehyde were obtained from Sigma (St. Louis, MO). Primary antibody Ab20920 and goat polyclonal to rabbit IgG secondary antibody-Cy5 ab6564 were obtained from Abcam (Cambridge, MA). Dichlorofluorescin diacetate $\left(\mathrm{H}_{2} \mathrm{DCF}-\mathrm{DA}\right)$ and dihydroethidum (DHE) were from Life Technologies (Grand Island, NY).

\subsubsection{Bacteria}

S. aureus (ATCC 25923) was obtained from the American Type Culture Collection (ATCC, Manassas, VA). A fresh inoculum was prepared by suspending 5 colonies of $S$. aureus, grown on a blood agar plate, in $5 \mathrm{~mL}$ TSB and incubated at $37^{\circ} \mathrm{C}$ for $18 \mathrm{~h}$. After incubation, the $S$. aureus inoculum was centrifuged at $3750 \mathrm{rpm}$ for 15 min at $4^{\circ} \mathrm{C}$ and washed once with $10 \mathrm{~mL}$ PBS to obtain an optical density of 0.80 which yields $(6-8) \times 10^{8}$ colony forming units $/ \mathrm{mL}$ or $\mathrm{CFU} / \mathrm{mL}$. The bacteria pellet was then re- 
suspended in either DMEM/F12 for the infection of osteoblasts or in RPMI-1640 medium for the infection of macrophages; both cell culture media were free from streptomycin/penicillin and FBS.

\subsection{Infection of osteoblasts with S. aureus}

Rat osteoblasts (UMR-106) were obtained from ATCC and grown in fullsupplemented DMEM/F12 medium containing $10 \% \quad$ FBS and $1 \%$ of penicillin/streptomycin solution. In 12 -well plates (Fisher Scientific), $3 \times 10^{5}$ cells $/ \mathrm{mL}$ were seeded and cultured in full-supplemented DMEM/F12 medium for at least $24 \mathrm{~h}$ at $37^{\circ} \mathrm{C}$ in a $5 \% \mathrm{CO}_{2}$ incubator until they reached $\sim 80 \%$ confluence. Osteoblasts were infected and the effects of multiplicity of infection (MOI), which represents S. aureus to osteoblast ratio, and infection time on osteoblast infection were investigated: (1) To examine the effect of MOI on osteoblast infection, the osteoblast monolayer was washed 3 times with PBS and then fresh DMEM/F12 media was added (free from streptomycin/penicillin and FBS). Immediately, S. aureus was added at MOIs of 100:1, 500:1, and 1000:1 and incubated for $2 \mathrm{~h}$. (2) To examine the effect of infection time on osteoblast infection, the osteoblast monolayer was washed 3 times with PBS and then fresh DMEM/F12 media (free from streptomycin/penicillin and FBS) was added. $S$. aureus was added at an MOI of 500:1 and incubated for different times, i.e. infection times, of $0.5,2,4,6$, and $8 \mathrm{~h}$. After each time point, the osteoblast monolayer was washed 3 times with PBS and treated with $100 \mu \mathrm{g} / \mathrm{mL}$ gentamicin (an antibiotic known not to penetrate mammalian cell membranes within a few hours $[27,28]$ ) for $2 \mathrm{~h}$ at $37^{\circ} \mathrm{C}$ in a $5 \% \mathrm{CO}_{2}$ incubator. Osteoblasts were then washed 3 times with PBS and immediately lysed with $0.1 \%$ Triton $\mathrm{X}-100$ in $\mathrm{PBS}$ for $10 \mathrm{~min}$ at $37^{\circ} \mathrm{C}$; the cell lysates were diluted in 
PBS and plated on blood agar plates overnight. To determine viability, osteoblasts were detached by incubating them at $37^{\circ} \mathrm{C}$ for $3 \mathrm{~min}$ in a $0.25 \%$ trypsin $/ 2.21 \mathrm{mM}$ EDTA solution; trypsinization was stopped by adding DMEM/F12 medium supplemented with 10\% FBS. Viable osteoblasts were counted using a hemocytometer (Bright-Line Hausser Scientific, Horsham, PA) following the trypan-blue exclusion assay which depends on cellular membrane integrity; dead cells allow the stain to penetrate while live cells do not.

\subsection{Infection of macrophages with S. aureus}

Rat alveolar macrophage cell-line (NR 8383) was obtained from ATCC and grown in full-supplemented RPMI-1640 medium containing 10\% FBS, $1 \%$ streptomycin/penicillin, 45\% glucose solution, $7.5 \%$ sodium bicarbonate, and sodium pyruvate. The infection of macrophages with $S$. aureus was studied at different MOIs and infection times. The protocols for infecting macrophages were similar to those of infecting osteoblasts as described previously. In brief, $3 \times 10^{5}$ cells $/ \mathrm{mL}$ were seeded in 12 well plates and cultured in full-supplemented RPMI-1640 medium for at least $24 \mathrm{~h}$ to achieve adherence at $37^{\circ} \mathrm{C}$ in a $5 \% \mathrm{CO}_{2}$ incubator. Cultured macrophages were washed 3 times with PBS and then infected with $S$. aureus at different MOIs (100:1, 500:1, and 1000:1) or infection times (0.5-8 h). Infected macrophages were washed, treated with gentamicin, washed again, and then lysed to determine the number of live intracellular $S$. aureus. To determine the viability of macrophages, adherent macrophages were scraped using a cell scraper (Fisher Scientific) and combined with floating macrophages from the same sample for trypan-blue exclusion assay and hemocytometry. 
The viability of osteoblasts and macrophages after infection with $S$. aureus was calculated relevant to their control (non-infected) cells according to the following equation:

Viability $(\%)=\frac{\frac{\text { Number of live cells in infected sample }}{\text { Number of live and dead cells in infected sample }}}{\frac{\text { Number of live cells in control sample }}{\text { Number of live and dead cells in control sample }}} \times 100 \%$

Note that the total cell numbers in the infected and control samples were the same at the beginning of the infection (i.e. infection time $=0 \mathrm{~h}$ ) but were different at later infection time periods (i.e. $0.5-8 \mathrm{~h}$ ).

\subsection{Inhibition of S. aureus internalization in osteoblasts}

Cytochalasin D was re-constituted in $1 \% \mathrm{DMSO} ; 3 \times 10^{5}$ cells $/ \mathrm{mL}$ were seeded in 12-well plates and cultured in full-supplemented DMEM/F12 medium to reach $\sim 80 \%$ confluence. The osteoblast monolayer was washed 3 times with PBS and then fresh DMEM/F12 media was added (free from streptomycin/penicillin and FBS) together with cytochalasin D $(0.5,1,5,10$, and $20 \mu \mathrm{g} / \mathrm{mL})$. After culturing for $30 \mathrm{~min}$, S. aureus was added at an MOI of 500:1 and further incubated for $2 \mathrm{~h}$. Following treatment with gentamicin, infected osteoblasts were lysed and plated to determine the number of live intracellular bacteria.

\subsection{Survival of S. aureus within osteoblasts or macrophages}

Osteoblasts or macrophages were infected with S. aureus at an MOI of 500:1 for $2 \mathrm{~h}$, treated with gentamicin, washed, and cultured for up to a week in DMEM/F12 (for 
osteoblasts) or RPMI-1640 (for macrophages) supplemented with 5\% FBS and $5 \mu \mathrm{g} / \mathrm{mL}$ lysostaphin; lysostaphin does not penetrate mammalian cell membranes for long time periods, e.g. weeks [29-31]. The cell culture media was changed every 3 days. At postinfection days $0,1,3,5,6,7$, and/or 8 and 9, independent samples of infected cells were washed with PBS, lysed with $0.1 \%$ Triton X-100, and plated on blood agar plates to determine the number of live intracellular S. aureus. Percentage of live intracellular CFU at different times following infection was calculated based on the live intracellular CFU immediately after infection (i.e. post-infection day 0 ).

\subsection{Confocal microscopy}

A dual staining approach [32,33] was adopted to visualize intracellular S. aureus. Osteoblasts or macrophages were cultured on rounded cover-slips for at least $24 \mathrm{~h}$ in fullsupplemented DMEM/F12 or RPMI-1640, respectively. Fresh S. aureus was cultured for $18 \mathrm{~h}$ at $37^{\circ} \mathrm{C}$ in a $5 \% \mathrm{CO}_{2}$ incubator. After washing the bacteria once with PBS, the pellet was stained with $100 \mu \mathrm{g} / \mathrm{mL}$ FITC in PBS for $30 \mathrm{~min}$ at room temperature prior to infection. Excess FITC was removed by washing with PBS and centrifugation at 3750 rpm for 15 min at $4^{\circ} \mathrm{C}$. After infecting with the stained $S$. aureus for $2 \mathrm{~h}$ at an MOI of 500:1, osteoblasts were trypsinized using a $0.25 \%$ trypsin/2.21 mM EDTA solution for 30 seconds at room temperature to remove adherent extracellular S. aureus; no trypsinization was used in the macrophage samples. Osteoblasts or macrophages were then fixed with $4 \%$ paraformaldehyde in distilled water for $30 \mathrm{~min}$ at room temperature. Fixed cells were washed 3 times with PBS and blocked with 5\% BSA for $1 \mathrm{~h}$ at room temperature. To further label the extracellular $S$. aureus, the fixed cells were incubated overnight at $4^{\circ} \mathrm{C}$ with a primary antibody Ab20920S in 5\% BSA, washed 3 times with 
PBS (to remove excess free primary antibody), and then incubated in the dark with a secondary antibody-conjugated Cy5 fluorescent dye in $2.5 \%$ BSA for 45 min at room temperature. After washing the excess secondary antibody with PBS, the cover-slips were flipped onto microscopic glass slides and used for image observation; macrophage samples were mounted in the presence of 4',6-diamidino-2-phenylindole (DAPI) fluorescent dye to visualize the nuclei of macrophages. Slides were visualized using a 159 Plan-Apochromat 63x/1.40 oil objective on an LSM 510 confocal microscope (Zeiss, Jena, Germany).

To confirm the presence of live intracellular $S$. aureus and the efficacy of gentamicin killing of extracellular S. aureus, osteoblasts were seeded on a rounded coverslip overnight. The monolayer was then stained with DiI fluorescent dye for $20 \mathrm{~min}$ at $37^{\circ} \mathrm{C}$ in the dark. The monolayer was washed once with PBS and infected with Syto-9 labeled S. aureus as aforementioned. After gentamicin treatment, infected osteoblasts were washed 3 times with HEPES buffer and PI stain was added for $15 \mathrm{~min}$ at room temperature in the dark. Immediately after washing off the excess PI, the slides were examined under the LSM 510 confocal microscope and images of Z-stack sections were taken to confirm the live intracellular S. aureus. Z-stack sections were generated and the X-Y planes showed that all live (green) S. aureus was inside the osteoblasts.

\subsection{Transmission electron microscopy (TEM)}

Osteoblasts were infected with S. aureus at an MOI of 500:1 for $2 \mathrm{~h}$, washed once with PBS, and detached using trypsin-EDTA. Osteoblasts were then collected by centrifugation at $1200 \mathrm{rpm}$ at $4^{\circ} \mathrm{C}$ for $7 \mathrm{~min}$, and the pellet was washed twice with $\mathrm{PBS}$ then fixed with $2 \%$ paraformaldehyde and $4 \%$ glutaraldehyde mixed with 0.075 M PBS 
for $30 \mathrm{~min}$ at room temperature. The fixed cell mass was collected in $1.5 \mathrm{~mL}$ Eppendorf tubes. The cell pellet was washed 3 times with PBS, post-fixed in $1 \%$ osmium tetroxide for $2 \mathrm{~h}$ at room temperature, washed 3 times with PBS, treated with aqueous $1 \%$ tannic acid for $1 \mathrm{~h}$ at room temperature, and then dehydrated in a gradient ethanol series. The cells were embedded in pure LR white resin solution and polymerized at $60^{\circ} \mathrm{C}$ for 24 $48 \mathrm{~h}$. Thin $(0.1 \mu \mathrm{m})$ sections were cut and placed on nickel grids, stained with $2 \%$ uranyl acetate and lead citrate, and viewed using TEM (JEOL, Peabody, MA).

\subsection{Reactive oxygen species production}

Osteoblasts and macrophages were infected with S. aureus at an MOI of 500:1. At pre-determined time points $(0.5,1$, and $2 \mathrm{~h})$, samples of infected osteoblasts or macrophages were taken, washed once with PBS, and then incubated with $\mathrm{H}_{2}$ DCF-DA or DHE at $37^{\circ} \mathrm{C}$ for $1 \mathrm{~h}$ in the dark; separate samples were used for the staining of $\mathrm{H}_{2}$ DCF-DA and DHE. Non-infected osteoblasts and macrophages were used as controls and were treated the same as the infected cells except no $S$. aureus was added. Viable cells of infected and control samples at the pre-determined time points were obtained using hemocytometry and were used to analyze the final fluorescent data. The fluorescence intensity was measured using a fluorescent microplate reader (BioTek Instrument, Inc., Winooski, VT) at $492 \mathrm{~nm} / 520 \mathrm{~nm}$ for 2',7'-dichlorofluorescein (DCF), converted intracellularly from $\mathrm{H}_{2}$ DCF-DA, and $492 \mathrm{~nm} / 620 \mathrm{~nm}$ for DHE. $\mathrm{H}_{2}$ DCF-DA and DHE are commonly used to stain intracellular hydrogen peroxide $\left(\mathrm{H}_{2} \mathrm{O}_{2}\right)$ and superoxide anion $\left(\mathrm{O}_{2}^{-}\right)$, respectively [34]. The acetate groups of $\mathrm{H}_{2} \mathrm{DCF}-\mathrm{DA}$ are cleaved by intracellular esterases and oxidation and convert to highly fluorescent DCF. 


\subsection{Osteoblast alkaline phosphatase (ALP) activity}

Osteoblasts were cultured in 12 -well plates at a density of $5 \times 10^{4}$ cells $/ \mathrm{mL}$, infected at an MOI of 500:1 for $2 \mathrm{~h}$ following the aforementioned infection protocol. Non-infected (control) and infected osteoblasts were cultured in DMEM/F12 supplemented with $5 \% \mathrm{FBS}$ and $5 \mu \mathrm{g} / \mathrm{mL}$ lysostaphin solution for a week; media was changed every 3 days. On post-infection days 1,4 , and 7, osteoblast monolayers were washed with PBS once and the ALP activity was determined using an ALP assay kit (Abcam) and expressed as Unit/mL.

\subsection{Macrophage phagocytosis assay}

Macrophage phagocytosis (ingestion) activity was tested by measuring the uptake of FITC-labeled S. aureus by non-infected (control) macrophages and macrophages infected with S. aureus (unlabeled) at an MOI of 500:1 for $2 \mathrm{~h}$. After incubating $5 \times 10^{5}$ cells $/ \mathrm{mL}$ non-infected (control) and infected macrophages separately with FITC-labeled $S$. aureus at 10:1 MOI for $2 \mathrm{~h}$, macrophages (infected and non-infected) were treated with $100 \mu \mathrm{g} / \mathrm{mL}$ gentamicin for $2 \mathrm{~h}$ at $37^{\circ} \mathrm{C}$ in a $5 \% \mathrm{CO}_{2}$ incubator. Macrophages were then scraped and collected for flow cytometry analysis using BD-FACS Calibur (BD, Franklin Lakes, NJ); 10,000 events were collected. Data were acquired in logarithmic mode for the forward scatter (FSC), side scatter (SSC), and green fluorescence channel FL-1H (i.e. FITC). Control macrophages were subjected to the same experimental protocols as the

infected cells but without infection with $S$. aureus. The percentage of macrophages with FITC fluorescent intensity corresponds to the ingestion activity of macrophages. 


\subsection{Statistical analysis}

Statistical analyses were performed using JMP Statistical Visualization Software (SAS Institute, Cary, NC). Experiments were repeated at least twice on separate days to verify reproducibility. All data were expressed as mean \pm SD and analyzed using oneway analysis of variance (ANOVA). Statistical significance was set at $p<0.05$. 


\section{Results}

\subsection{Characterization of S. aureus infection of osteoblasts and macrophages}

After incubating with $S$. aureus for 2 h at an MOI of 100:1 to 1000:1, osteoblasts and macrophages were both found to be infected. However, significantly higher $(\sim 2$ orders) numbers of intracellular $S$. aureus were found within macrophages compared to osteoblasts (Figure 2A); the intracellular CFUs for infected macrophages and osteoblasts were approximately $3.5 \times 10^{6}$ and $3.1 \times 10^{4} \mathrm{CFU} /\left(10^{5}\right.$ cells $)$, respectively. No significant differences were observed in the same cell type at the various MOIs studied (i.e. 100:1, 500:1, and 1000:1). By contrast, significantly lower viability was observed in macrophages compared to osteoblasts at $2 \mathrm{~h}$ infection; the viability of macrophages and osteoblasts were 62-78\% and 90-95\%, respectively (Figure 2B). No significant differences in viability for the same cell type at the MOIs investigated (i.e. 100:1, 500:1, and 1000:1) were noticed following the $2 \mathrm{~h}$ infection.

At an MOI of 500:1, the number of intracellular S. aureus for both macrophages and osteoblasts increased with increasing infection time and reached a plateau at $2 \mathrm{~h}$, at which point the intracellular CFUs for macrophages and osteoblasts were $5.0 \times 10^{6}$ and $3.9 \times 10^{4} \mathrm{CFU} /\left(10^{5}\right.$ cells), respectively (Figure $\left.2 \mathrm{C}\right)$. At the infection times of $2-8 \mathrm{~h}$, the intracellular CFUs for macrophages were significantly (about 2 orders) higher than those of osteoblasts. At an MOI of 500:1, the viability of macrophages and osteoblasts decreased approximately linearly with increasing infection time. The viability of macrophages at infection times of $2,4,6$, and $8 \mathrm{~h}$ was significantly lower than that of both macrophage control and at infection time of $0.5 \mathrm{~h}$. The viability of osteoblasts at 


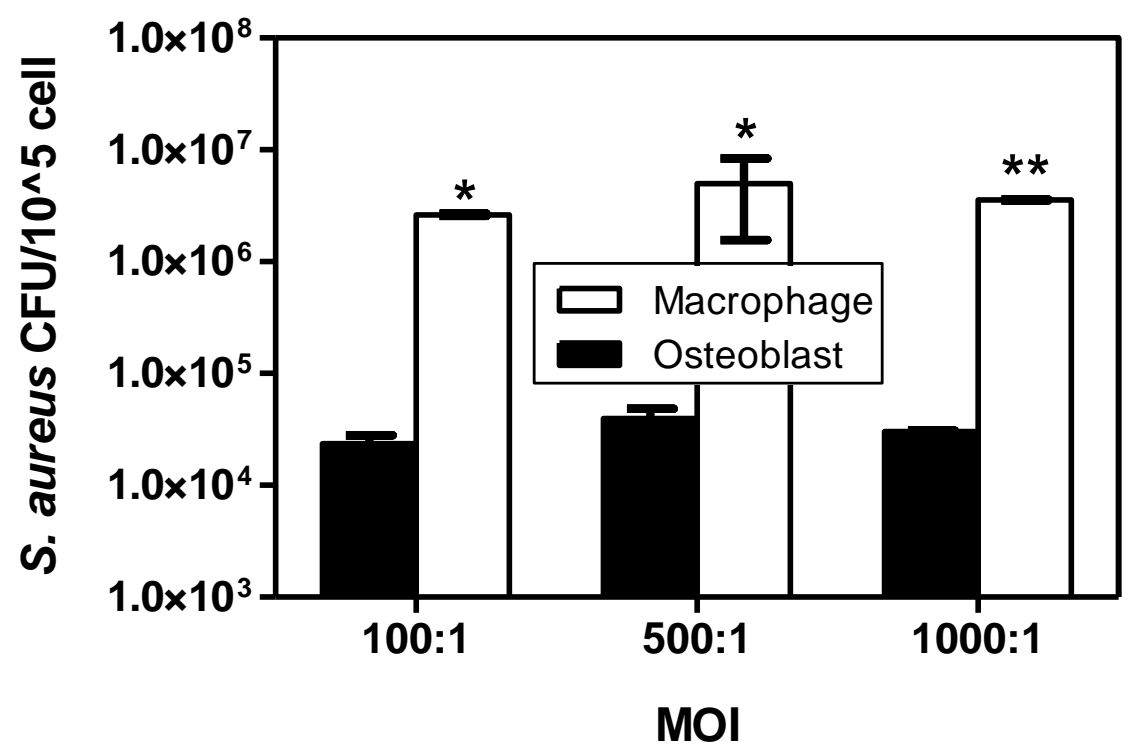

Figure 2 (A)

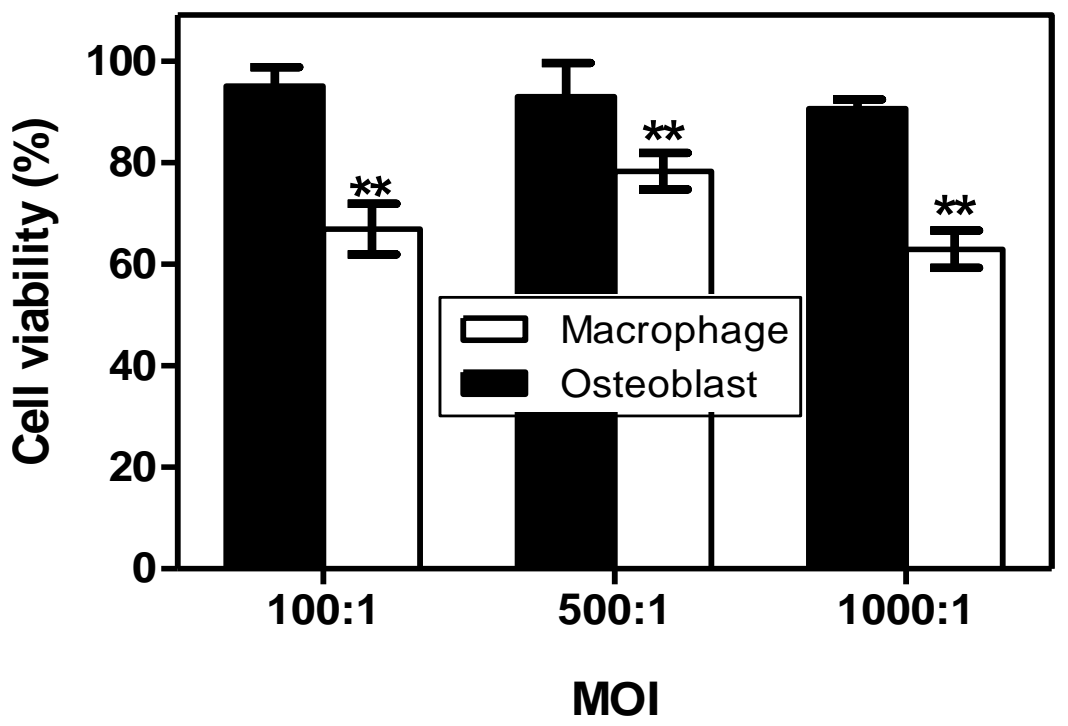

Figure 2 (B)

Figure 2. S. aureus infection of osteoblasts and macrophages. (A) Live intracellular $S$. aureus and (B) viability of osteoblasts and macrophages at different MOIs (100:1, 500:1, and 1000:1) for 2 h. ${ }^{*} p<0.05$ and ${ }^{* *} p<0.001$ compared to osteoblasts at the same MOI. 
infection times of 4,6 , and $8 \mathrm{~h}$ was significantly lower than that of both osteoblast control and at infection time of $0.5 \mathrm{~h}$ (Figure 2D). In addition, the viability of macrophages was significantly lower at $2 \mathrm{~h}$ infection but significantly higher at $8 \mathrm{~h}$ infection compared to osteoblasts at corresponding infection time periods (Figure 2D).

The $S$. aureus infection of osteoblasts was also found to be significantly inhibited by the addition of cytochalasin D. The intracellular CFUs of S. aureus decreased significantly with increasing cytochalasin $\mathrm{D}$ at the dose range studied $(0.5-20 \mu \mathrm{g} / \mathrm{mL})$, reaching $50 \%$ inhibition at $20 \mu \mathrm{g} / \mathrm{mL}$ (Figure 2E). Relatively higher cytochalasin D doses of 10 and $20 \mu \mathrm{g} / \mathrm{mL}$ also led to significantly lower intracellular CFUs of $S$. aureus compared to the doses of $0.5,1$, and $5 \mu \mathrm{g} / \mathrm{mL}$ (Figure 2E).

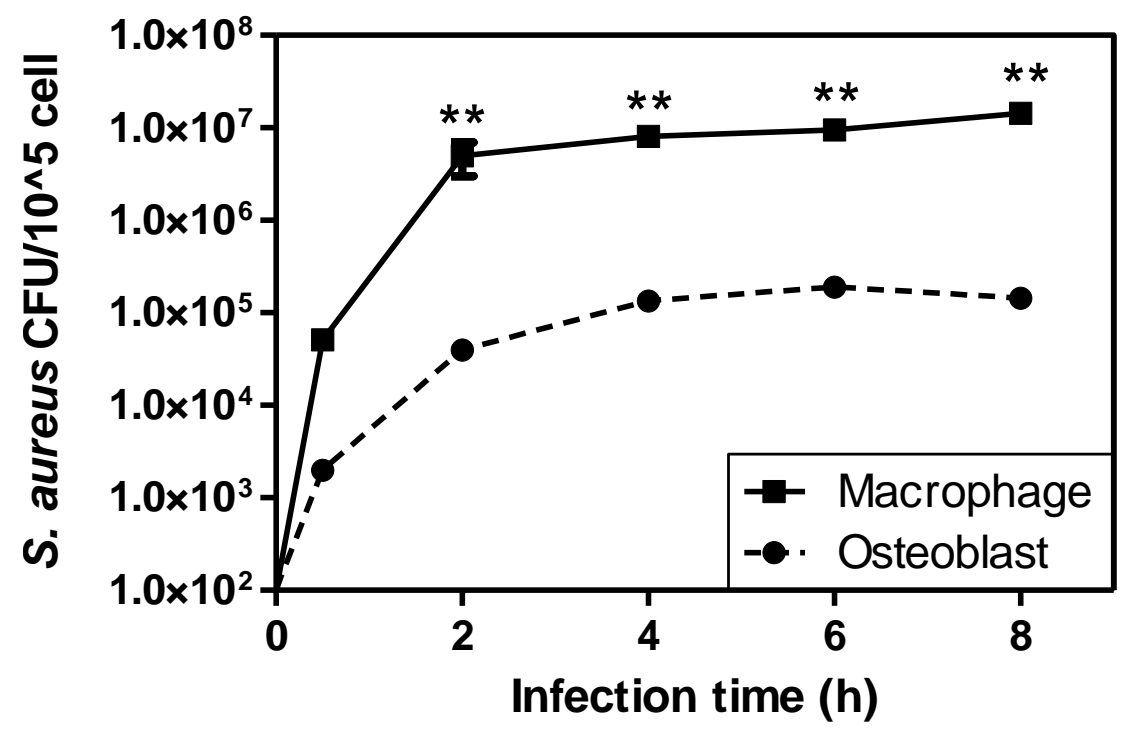

Figure 2 (C). S. aureus infection of osteoblasts and macrophages. Live intracellular $S$. aureus and at an MOI of 500:1 for various infection times. ${ }^{* *} p<0.001$ compared to osteoblasts at the same infection time. 


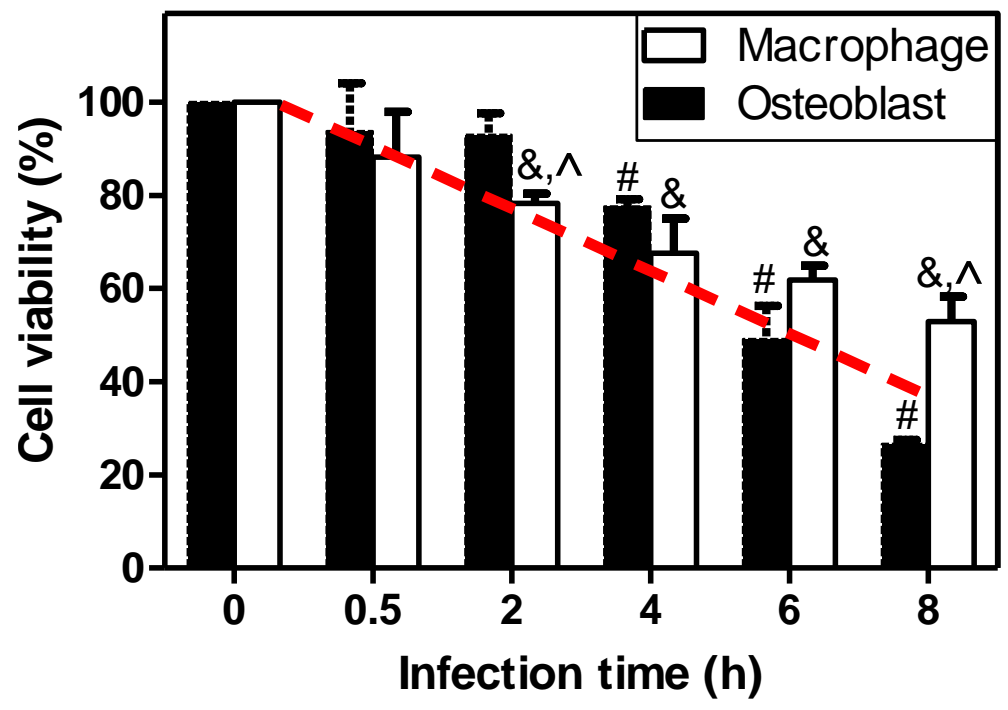

Figure 2 (D). S. aureus infection of osteoblasts and macrophages. Viability of osteoblasts and macrophages at an MOI of 500:1 for various infection times. ${ }^{{ }^{*}} p<0.01$ compared to macrophages at infection times 0 and $0.5 \mathrm{~h}, \hat{p}<0.01$ compared to osteoblasts at the same infection times, and ${ }^{\#}<0.05$ compared to osteoblasts at infection times 0 and $0.5 \mathrm{~h}$

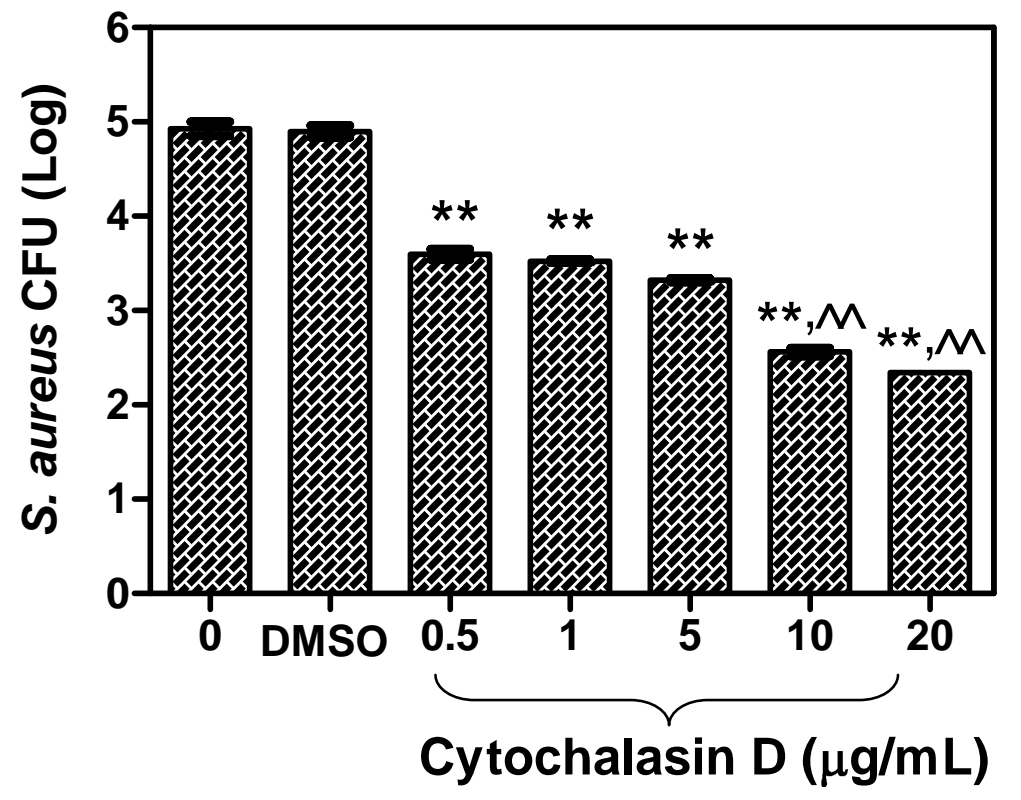

Figure 2 (E). S. aureus infection of osteoblasts and macrophages. Effect of cytochalasin $\mathrm{D}$ on $S$. aureus internalization in osteoblasts. ${ }^{* *} p<0.001$ compared to the controls and ${ }^{\wedge} p<0.001$ compared to $0.5,1$, and $5 \mu \mathrm{g} / \mathrm{mL}$. 
S. aureus was found to be able to survive within macrophages and osteoblasts for approximately a week; live intracellular $S$. aureus was found in macrophages and osteoblasts for 5 and 7 days, respectively (Figure 3). The percentage of live intracellular $S$. aureus for both macrophages and osteoblasts decreased continuously with increasing culturing time after infection, and significantly reduced survival of $S$. aureus was found in macrophages compared to osteoblasts at the same post-infection time period (Figure 3). In addition, no differences in osteoblast proliferation were observed between infected and non-infected osteoblasts within one week post-infection (data not shown).

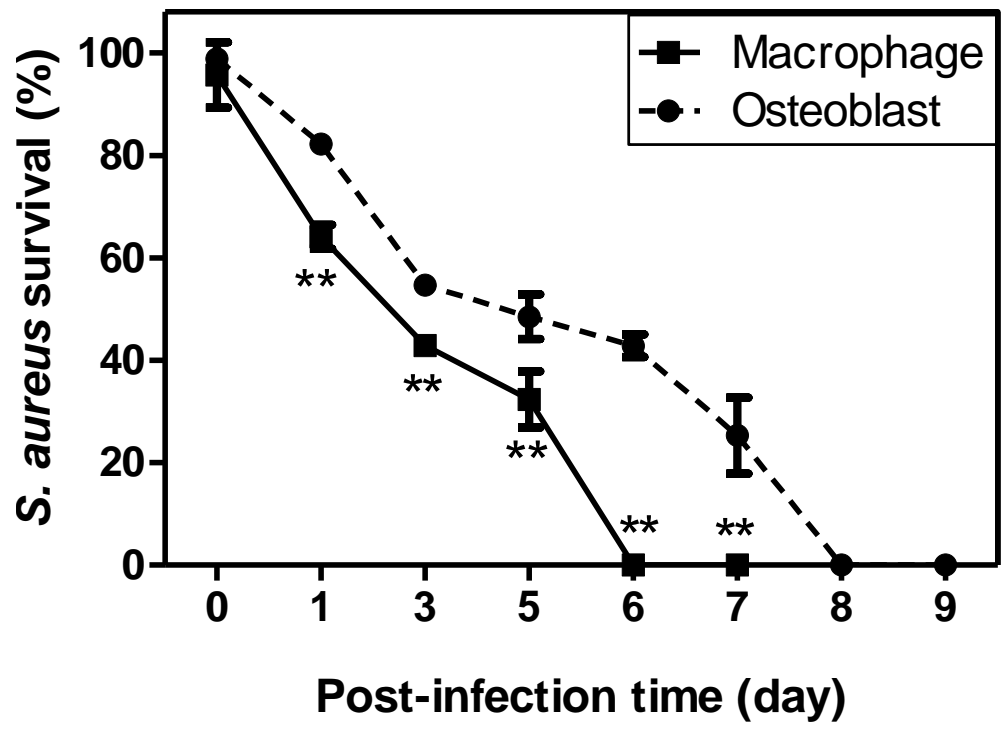

Figure 3. Survival of intracellular S. aureus within osteoblasts and macrophages after infection at an MOI of 500:1 for $2 \mathrm{~h} .{ }^{* *} p<0.001$ compared to osteoblasts at the same postinfection time. 
Confocal microscopy and TEM images confirmed that $S$. aureus was internalized and could survive within macrophages and osteoblasts (Figure 4). Meanwhile, substantially more (likely two orders) S. aureus was internalized (not necessarily alive) by macrophages compared to osteoblasts (Figure 4A and B). Confocal microscopy imaging also found that all live $S$. aureus was inside the osteoblasts and there were no live $S$. aureus on the surface of the osteoblasts after gentamicin treatment (Figure 4C). The internalization of $S$. aureus within osteoblasts was found to be non-uniform as some osteoblasts had multiple $S$. aureus bacteria while others had none (Figure 4D).

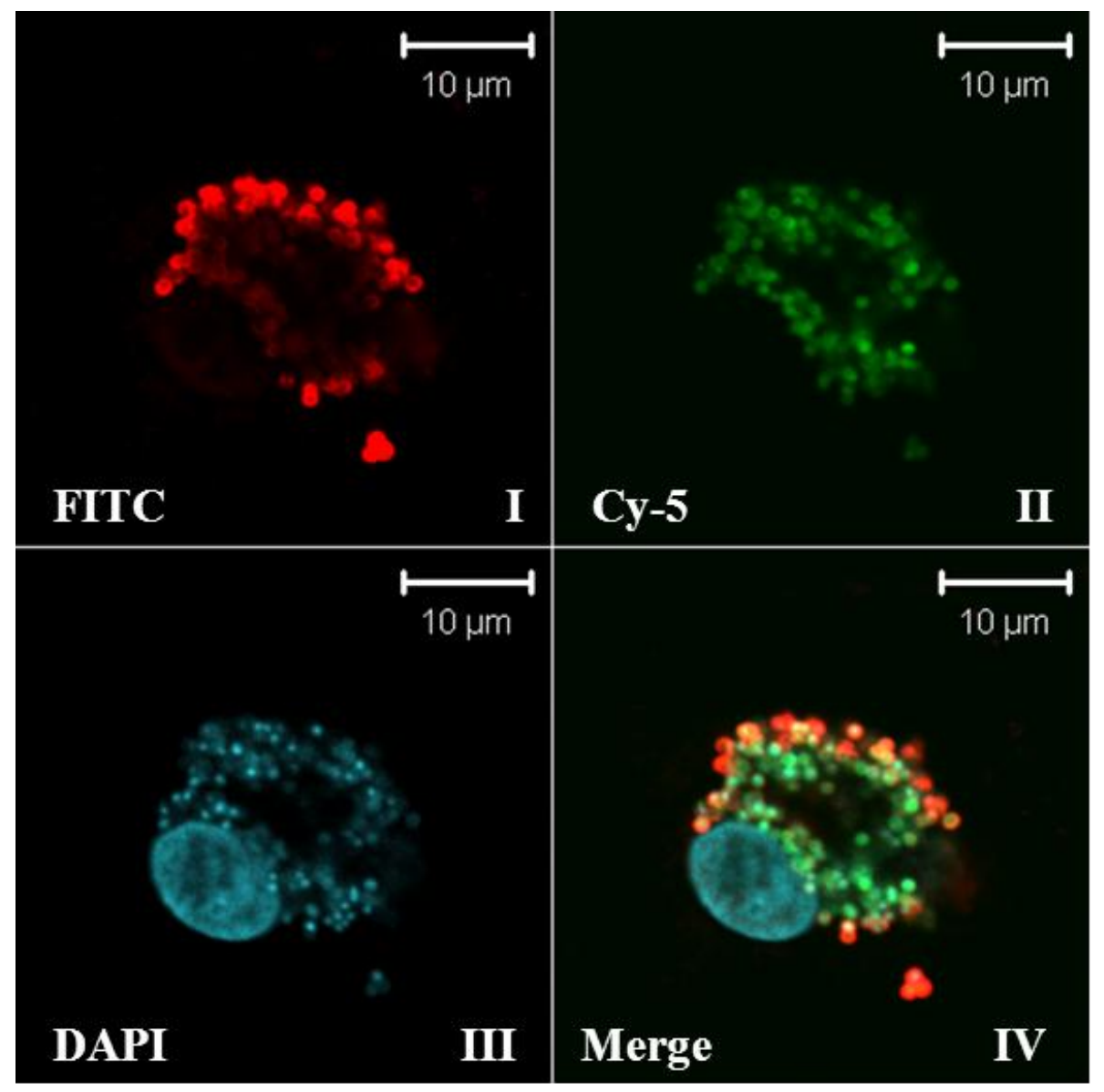

Figure 4 (A) 


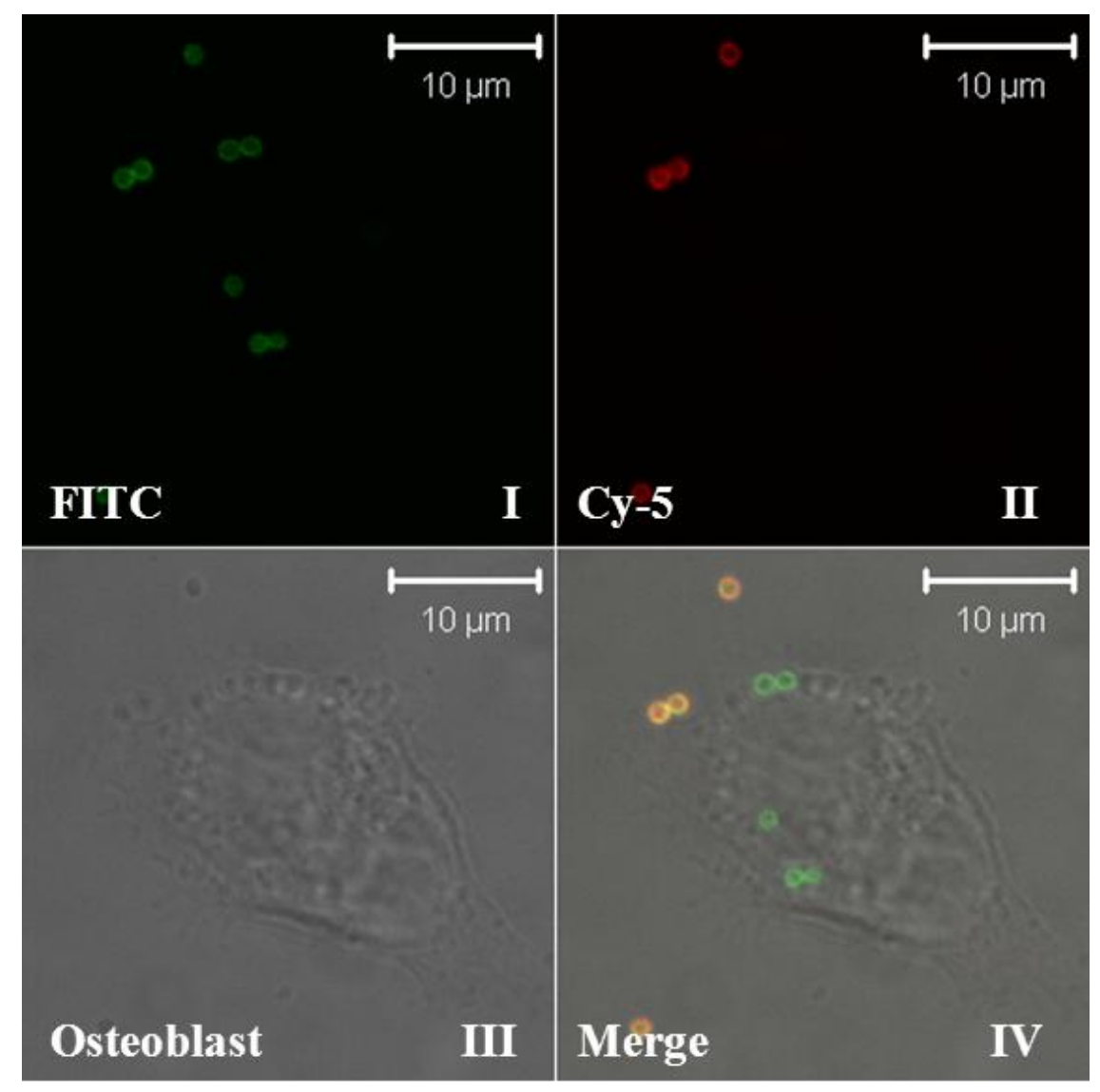

Figure 4 (B)

Figure 4. Visualization of intracellular S. aureus within (A) macrophages and (B) osteoblasts. Osteoblasts and macrophages were infected with $S$. aureus at an MOI of 500:1 for 2 h. (A and B) S. aureus was stained with FITC before infection. Infected osteoblasts and macrophages were fixed, blocked, stained first with primary antibody to $S$. aureus surface protein $\mathrm{A}$, and then secondary antibody conjugated to Cy-5. The nuclei of the macrophages were additionally stained with DAPI. Visualized at (I) $488 \mathrm{~nm}$, (II) 633 $\mathrm{nm}$, and (III) $405 \mathrm{~nm}$. (IV) Merged images of (I), (II), and (III). As a result, intracellular $S$. aureus is shown in green (FITC) and extracellular S. aureus is co-localized with both red (Cy-5) and green (FITC). 


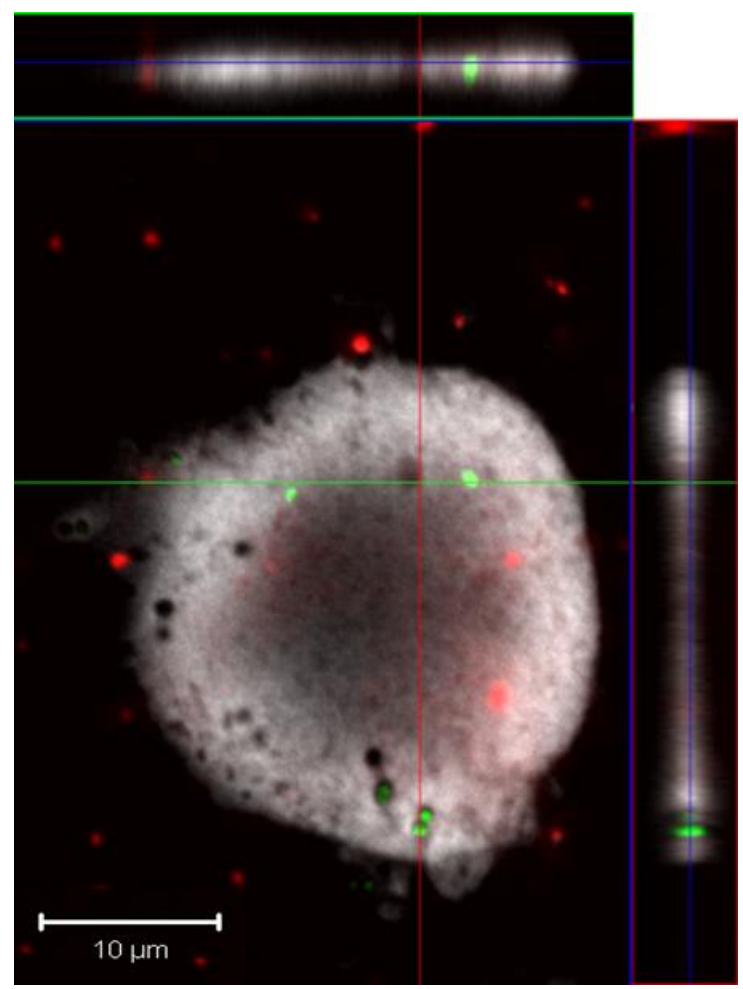

Figure 4. Visualization of intracellular S. aureus within osteoblasts. (C) Z-stack sections were used to confirm that all live $S$. aureus was inside osteoblasts as determined by the $\mathrm{X}-\mathrm{Y}$ planes. Live S. aureus are green (Syto 9) and dead S. aureus are red (PI). Osteoblasts were infected with Syto 9-labeled $S$. aureus, then extracellular bacteria were killed with gentamicin and washed. Osteoblasts were detached from the wells and stained with PI. Approximately 20 cells (randomly selected) were examined.

\subsection{Biological responses of osteoblasts and macrophages upon S. aureus infection}

Significantly higher $\mathrm{H}_{2} \mathrm{O}_{2}$ levels were observed at 0.5 and $1 \mathrm{~h}$ in infected osteoblasts compared to non-infected osteoblasts, i.e. control (Figure 5A). Significantly higher $\mathrm{H}_{2} \mathrm{O}_{2}$ levels were also observed following a $1 \mathrm{~h}$ infection in macrophages compared to non-infected control (Figure 5A). No significant changes in $\mathrm{O}_{2}^{-}$production in osteoblasts were observed at the infection time periods studied (i.e. 0.5, 1, and $2 \mathrm{~h}$ ), 
while significantly higher $\mathrm{O}_{2}^{-}$levels were found in macrophages at 0.5 and $1 \mathrm{~h}$ infection (Figure 5B).

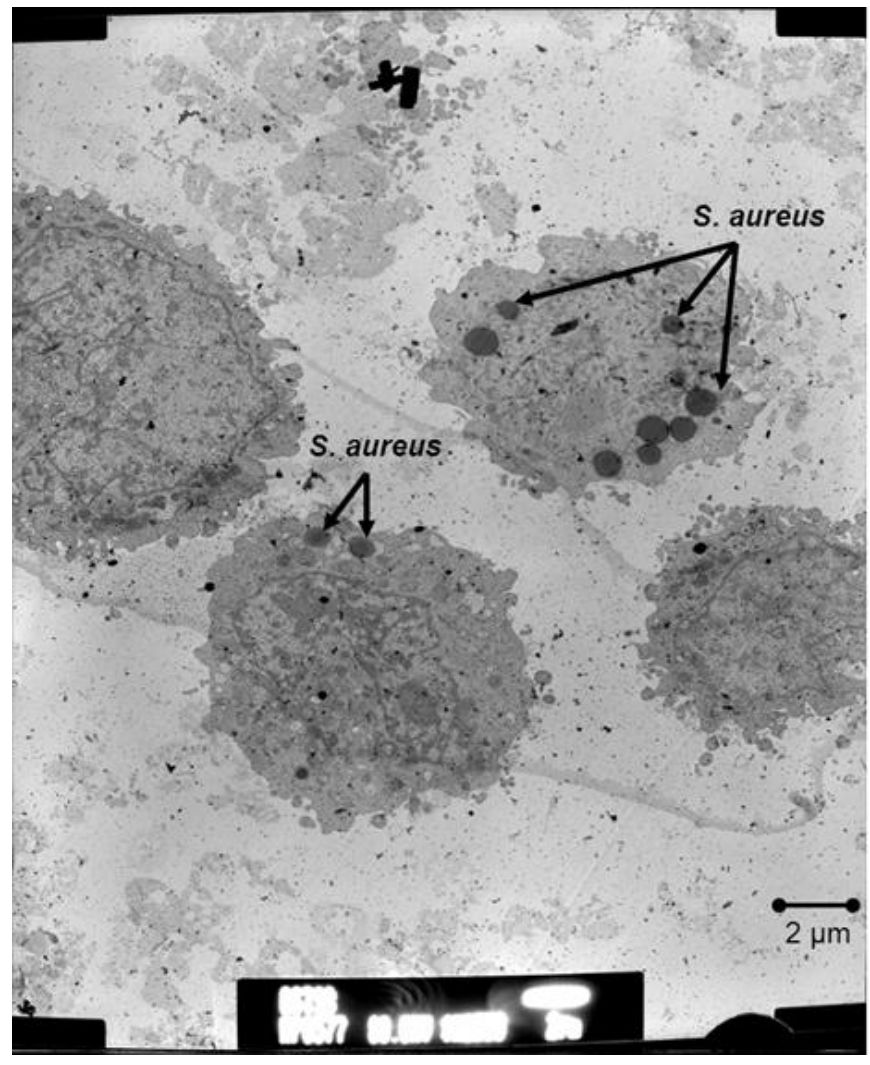

Figure 4 (D). Visualization of intracellular S. aureus within osteoblasts. Confirmation of intracellular $S$. aureus within osteoblasts using TEM. 


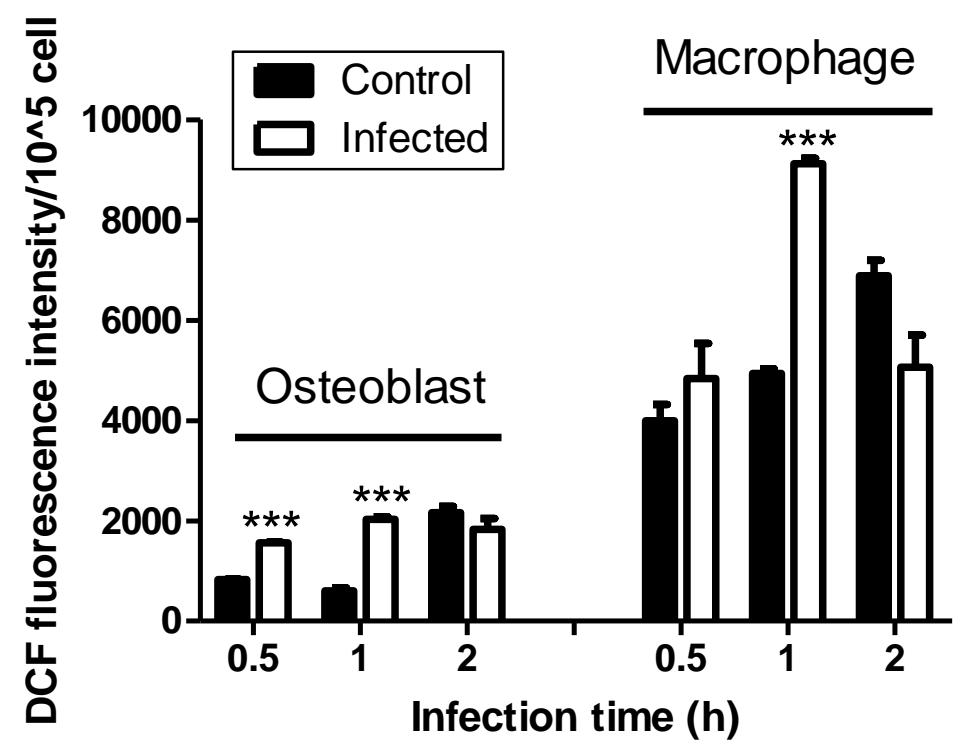

Figure 5 (A)

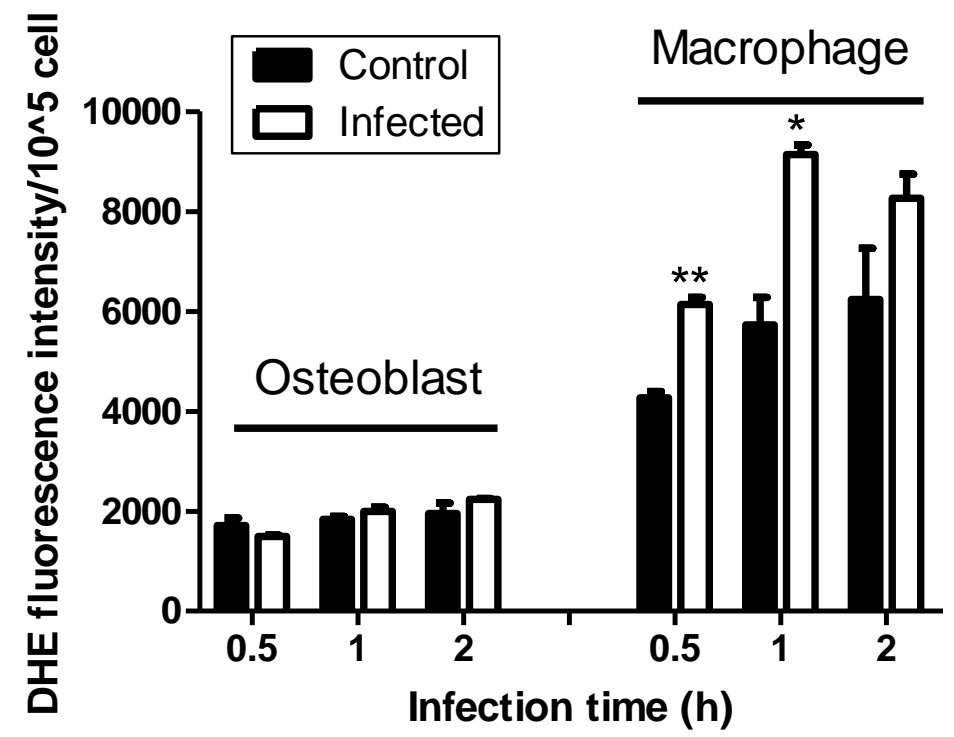

Figure 5 (B)

Figure 5. Cellular and molecular responses of osteoblasts and macrophages infected with $S$. aureus at an MOI of 500:1 for $2 \mathrm{~h}$. (A) DCF fluorescence intensity as an indicator of $\mathrm{H}_{2} \mathrm{O}_{2}$ production by non-infected controls and $S$. aureus-infected osteoblasts and macrophages. (B) DHE fluorescence intensity as an indicator of $\mathrm{O}_{2}^{-}$production by noninfected controls and S. aureus-infected osteoblasts and macrophages. ${ }^{*} p<0.01,{ }^{* *} p<0.001$, and ${ }^{* * *} p<0.0001$ compared to control. 
No significant changes in ALP enzyme activity were found between infected and non-infected osteoblasts at post-infection days 1, 4, and 7, although the ALP activity was lower for the infected cells at days 4 and 7 (Figure 5C). The macrophage phagocytosis activity studies showed that the ability to ingest bacteria was much higher for infected macrophages (83\%) compared to non-infected ones (44\%) (Figure 5D).

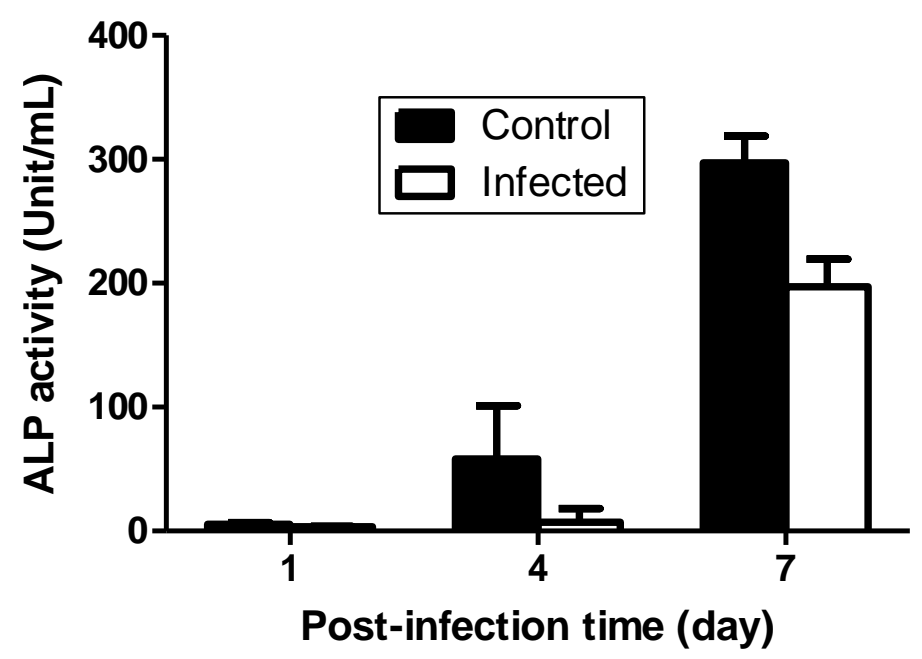

Figure $5(\mathbf{C})$. Cellular and molecular responses of osteoblasts and macrophages infected with $S$. aureus at an MOI of 500:1 for $2 \mathrm{~h}$. Osteoblast ALP activity measured at postinfection days 1,4 , and 7 . 


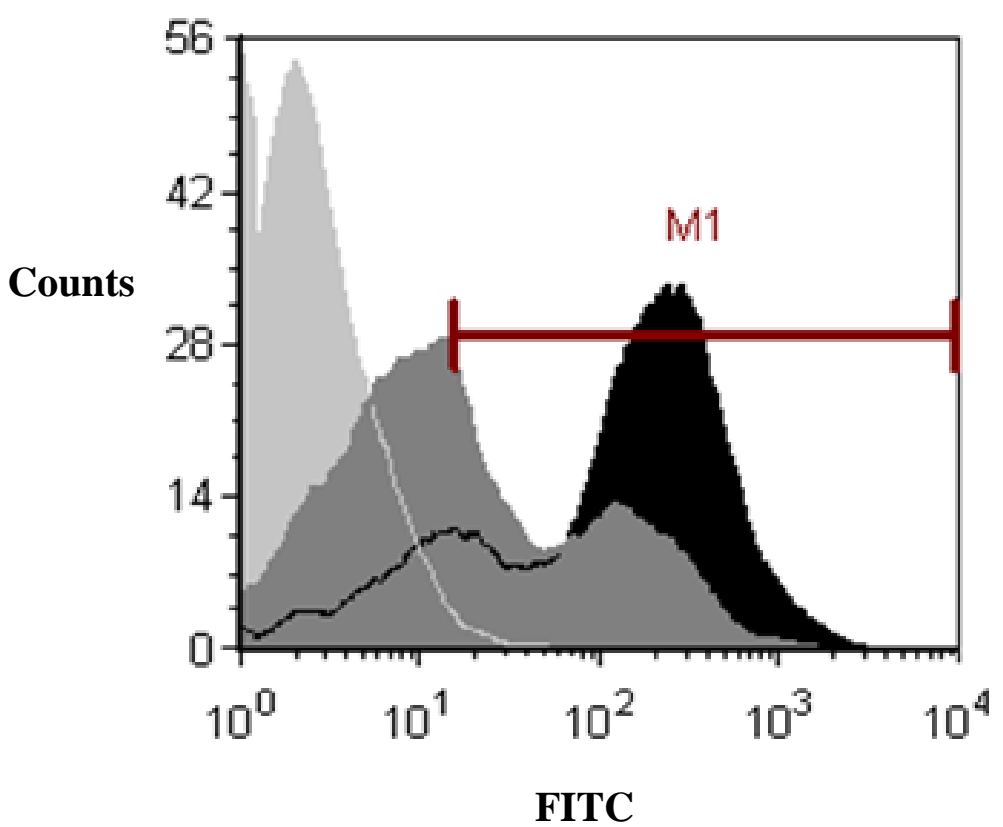

Figure 5 (D)

Figure 5 (D). Cellular and molecular responses of osteoblasts and macrophages infected with $S$. aureus at an MOI of 500:1 for $2 \mathrm{~h}$. Macrophage phagocytosis activity (ingestion). Light gray area: control macrophages without incubation with S. aureus; dark gray area: non-infected macrophages; black area: infected macrophages. ${ }_{* * * *}^{*}<0.01,{ }^{* *} p<0.001$, and ${ }^{* * * *} p<0.0001$ compared to control. 


\section{Discussion}

S. aureus has been traditionally considered as an extracellular pathogen; however, it has been shown to invade and survive within both non-phagocytic and phagocytic cells. By nature, the internalization and survival of $S$. aureus within non-phagocytic and phagocytic cells would be expected to be different, and may play significantly different roles in related diseases. To our knowledge, there are no reports comparing S. aureus infection of a non-phagocytic cell with a phagocytic cell. Therefore, the main goal of the present study was to compare the internalization behavior and related biological responses of $S$. aureus in a non-phagocytic cell (i.e. osteoblast) and a phagocytic cell (i.e. macrophage). Our findings may contribute to the understanding of the pathogenesis of many chronic and recurrent infections.

First, we showed that $S$. aureus can be internalized by both osteoblasts and macrophages. The infection of osteoblasts and macrophages was observed as early as 0.5 $\mathrm{h}$ at an MOI of 500:1; the corresponding live intracellular CFUs of S. aureus for osteoblasts and macrophages at $0.5 \mathrm{~h}$ were $1.4 \times 10^{3}$ and $7.2 \times 10^{4} \mathrm{CFU} /\left(10^{5}\right.$ cells $)$, respectively (Figure 2C). With increasing infection time, the intracellular CFUs of both osteoblasts and macrophages increased significantly from $0.5 \mathrm{~h}$ to $2 \mathrm{~h}$ followed by a plateau from $2 \mathrm{~h}$ to $8 \mathrm{~h}$ (Figure $2 \mathrm{C}$ ). Since macrophages are supposed to engulf and eliminate pathogens on contact, it was not surprising to find that, at the same infection conditions (i.e. MOI of 500:1 for 2 h), significantly more (approximately two orders) $S$. aureus (live and dead) was phagocytized by macrophages compared to those internalized by osteoblasts (Figure 4A and B). Similarly, significantly more live intracellular $S$. aureus was seen in macrophages compared to osteoblasts during infection times 2-8 $\mathrm{h}$ 
(Figure 2A and C). Macrophages had significantly lower viability at a shorter infection time period (i.e. $2 \mathrm{~h}$ ) and significantly higher survival at a longer infection time (i.e. $8 \mathrm{~h}$ ) compared to infected osteoblasts (Figure 2D). In addition, it is possible that the accumulation of toxins produced by $S$. aureus $[35,36]$ and the significantly higher levels of $\mathrm{H}_{2} \mathrm{O}_{2}$ in infected osteoblasts and macrophages and $\mathrm{O}_{2}^{-}$in infected macrophages (Figure 5A and B) affected the viability of macrophages and osteoblasts; both decreased (almost linearly) with increasing infection time (Figure 2D). It also seems that actin cytoskeleton formation plays a major role in $S$. aureus internalization into osteoblasts since cytochalasin $\mathrm{D}$, an inhibitor that disrupts actin filament polymerization, could lead to up to $50 \%$ inhibition of $S$. aureus internalization (Figure 2E). This finding was consistent with other studies [21,37] where actin filament was determined to play a dominant role in S. aureus internalization.

Note that our data (Figure 4C) confirmed that gentamicin treatment was effective in eliminating extracellular $S$. aureus and the post-infection CFU was indeed from live intracellular S. aureus. Gentamicin treatment is commonly used to eliminate extracellular bacteria [19,37], but such a procedure lacks direct confirmation of live intracellular bacteria. In this study, the dual staining approach combined with confocal microscopy presented direct evidence that no live extracellular $S$. aureus was observed after the gentamicin treatment (Figure 4C).

Next, we found that $S$. aureus could survive intracellularly for up to 5 and 7 days, respectively, within macrophages and osteoblasts (Figure 3). As a phagocytic cell, macrophages were obviously more effective than osteoblasts at not only phagocytizing but also destroying the intracellular bacteria. This observation was supported by the 
findings that $S$. aureus infection not only significantly increased the $\mathrm{H}_{2} \mathrm{O}_{2}$ levels in macrophages at $1 \mathrm{~h}$ infection but also significantly increased the $\mathrm{O}_{2}^{-}$levels in macrophages at infection times of 0.5 and $1 \mathrm{~h}$ (Figure 5A and B). In contrast, S. aureus infection induced significantly higher levels of $\mathrm{H}_{2} \mathrm{O}_{2}$ in osteoblasts at 0.5 and $1 \mathrm{~h}$ infection but did not induce significant changes in $\mathrm{O}_{2}^{-}$levels in osteoblasts (Figure 5A and B). As a result, significantly higher intracellular CFUs were found in macrophages immediately after infection (Figure 2C) while significantly less intracellular S. aureus survived in the following days after infection (Figure 3). Complete elimination of the intracellular bacteria by macrophages was found at an earlier time period (day 5 vs. day 7) compared to osteoblasts (Figure 3). Survival of S. aureus within host cells was also reported in other cell types. For instance, S. aureus was found to survive within human lung epithelial cells for up to 2 weeks [38], persisting in macrophage vacuoles for 3-4 days before escaping into the cytoplasm and causing macrophage lysis [6], and remaining viable for up to 5 days within HT-29 and Caco-2 enterocytes [39]. It was proposed that, once inside osteoblasts, macrophages, or other cells, S. aureus may undergo phenotypic switching to small colony variants (SCVs), which are associated with increased anchoring of fibronectin-binding proteins and clumping factors on the bacterial surface $[40,41]$. These proteins may function as substrates for bacterial enzymes needed to evade phagocytic oxidative killing $[6,42]$ thereby contributing to the intracellular survival of $S$. aureus. Moreover, S. aureus produces catalase, which catalyzes the decomposition of $\mathrm{H}_{2} \mathrm{O}_{2}$, thereby protecting itself inside host cells such as macrophages [43]. It was believed that the phenotypic switching of $S$. aureus may make the bacteria more resistant to antibiotics [16,44]. The survival of $S$. aureus within cells like macrophages and 
osteoblasts and the possible phenotypic switching of $S$. aureus may explain why antibiotics have so often failed to cure Staphylococcal infections [2,16,41]. Future studies may focus on investigation of the possible changes that occur to $S$. aureus after internalization into osteoblasts and macrophages.

Lastly, we found that $S$. aureus infection resulted in significantly increased levels of $\mathrm{H}_{2} \mathrm{O}_{2}$ in infected osteoblasts at infection times of 0.5 and $1 \mathrm{~h}$ and in infected macrophages at infection time of $1 \mathrm{~h}$ (Figure 5A). The $\mathrm{O}_{2}^{-}$levels in infected macrophages significantly increased at infection times of 0.5 and $1 \mathrm{~h}$ (Figure 5B). The increase in reactive oxygen species indicates that $S$. aureus internalization induced significant stress in osteoblasts and macrophages which would produce such chemicals to eliminate the invading pathogens. S. aureus infection also resulted in much higher phagocytosis activity of macrophages (Figure 5D) and relatively lower (although not significant) ALP activity of osteoblasts at days 4 and 7 after infection (Figure 5C). This effect could be associated with the significant increase in $\mathrm{H}_{2} \mathrm{O}_{2}$ and $\mathrm{O}_{2}^{-}$levels. It is noteworthy that, besides the significant changes in reactive oxygen species, $S$. aureus internalization in osteoblasts also led to significantly higher production of IL-6 and IL-12 $[19,45]$, macrophage chemoattractant protein 1, IL-8, IP-10, RANTES [19,45], and RANK-L and prostaglandin $\mathrm{E}_{2}$ (two important molecules that can promote osteoclasteogenesis and bone resorption) [46]. 


\section{Conclusions}

In this study, we intended to compare two infection models of osteoblast- $S$. aureus and macrophage-S. aureus. We found that $S$. aureus could internalize in macrophages and osteoblasts, that the internalization increased substantially with increasing infection time from $0.5 \mathrm{~h}$ to $2 \mathrm{~h}$, and that the internalization process may have been primarily mediated by osteoblast actin cytoskeleton formation. Internalized $S$. aureus could survive within macrophages and osteoblasts for up to 5 and 7 days, respectively. Our confocal and transmission electron microscopy observations clearly confirmed the presence of live $S$. aureus within osteoblasts and macrophages and that gentamicin treatment was effective in killing extracellular $S$. aureus; no live extracellular S. aureus was detected after gentamicin treatment. Transmission electron microscopy also demonstrated that the internalization in osteoblasts was not uniform; some osteoblasts had several bacteria while others had none. Confocal microscopy observation showed that significantly more $S$. aureus was internalized in macrophages compared to osteoblasts. Similarly, a significantly higher (two orders) level of live intracellular $S$. aureus was detected in macrophages compared to osteoblasts at $2 \mathrm{~h}$ infection among different MOIs (i.e. 100:1, 500:1, and 1000:1) and at different infection times (2-8 h) at an MOI of 500:1. However, the percentage of $S$. aureus survival after infection was significantly lower in macrophages compared to osteoblasts at post-infection days 1-6. The viability of macrophages and osteoblasts both decreased with increasing infection time between $0-8 \mathrm{~h}$ and macrophages had relatively lower viability at shorter infection time periods (i.e. $0.5-4 \mathrm{~h}$; significant at $2 \mathrm{~h}$ ) and higher viability at longer infection time periods (i.e. 6-8 h; significant at $8 \mathrm{~h}$ ) compared to osteoblasts. 
S. aureus infection also led to noticeable changes in macrophages and osteoblasts. Significantly increased $\mathrm{H}_{2} \mathrm{O}_{2}$ production was observed in osteoblast-S. aureus infection at 0.5 and $1 \mathrm{~h}$ and in macrophage-S. aureus infection at $1 \mathrm{~h}$. At 0.5 and $1 \mathrm{~h}$ infection, significantly increased superoxide anion production was found in macrophages. Infected osteoblasts had relatively lower ALP activity at post-infection days 4 and 7 and infected macrophages had higher phagocytosis activity compared to non-infected cells. Since chronic and recurrent bone infections have been frequently reported, are often associated with $S$. aureus and may be related to the intracellular persistence of $S$. aureus within host cells (e.g. osteoblasts, macrophages), the present study helps to better elucidate S. aureus internalization and its effects on host cells. This study may assist in evaluating the pathogenesis of chronic and recurrent infections and developing new therapeutic strategies against intracellular bacteria and diseases. 


\section{References}

[1] Darouiche RO, Treatment of infections associated with surgical implants, N Engl J Med 350 (2004) 1422-1429.

[2] von Eiff C, Becker K, Metze D, Lubritz G, Hockmann J, Schwarz T, Peters G, Intracellular persistence of Staphylococcus aureus small-colony variants within keratinocytes: a cause for antibiotic treatment failure in a patient with darier's disease, Clin Infect Dis 32 (2001) 1643-1647.

[3] Lentino JR, Prosthetic joint infections: bane of orthopedists, challenge for infectious disease specialists, Clin Infect Dis 36 (2003) 1157-1161.

[4] Berendt T, Byren I, Bone and joint infection, Clin Med 4 (2004) 510-518.

[5] Lew DP, Waldvogel FA, Osteomyelitis, Lancet 364 (2004) 369-379.

[6] Kubica M, Guzik K, Koziel J, Zarebski M, W.Richter, Gajkowska B, Golda A, Maciag-Gudowska A, Brix K, Shaw L, Foster T, Potempa J, A potential new pathway for Staphylococcus aureus dissemination: the silent survival of S. aureus phagocytosed by human monocyte-derived macrophages, PLoS One 3 (2008) e1409.

[7] Gresham HD, Lowrance JH, Caver TE, Wilson BS, Cheung AL, Lindberg FP, Survival of Staphylococcus aureus inside neutrophils contributes to infection, J Immunol 164 (2000) 3713-3722.

[8] Voyich JM, Braughton KR, Sturdevant DE, Whitney AR, Saïd-Salim B, Porcella SF, Long RD, Dorward DW, Gardner DJ, Kreiswirth BN, Musser JM, DeLeo FR, Insights into mechanisms used by Staphylococcus aureus to avoid destruction by human neutrophils, J Immunol 175 (2005) 3907-3919.

[9] Baughn R, Bonventre PF, Phagocytosis and intracellular killing of Staphylococcus aureus by normal mouse peritoneal macrophages, Infect Immun 12 (1975) 346-352.

[10] Hudson MC, Ramp WK, Nicholson NC, Williams AS, Nousiainen MT, Internalization of Staphylococcus aureus by cultured osteoblasts, Microb Pathog 19 (1995) 409-419.

[11] Krut O, Sommer H, Krönke M, Antibiotic-induced persistence of cytotoxic Staphylococcus aureus in non-phagocytic cells, J Antimicrob Chemother 53 (2004) 167-173.

[12] Almeida RA, Matthews KR, Cifrian E, Guidry AJ, Oliver SP, Staphylococcus aureus invasion of bovine mammary epithelial cells, J Dairy Sci 79 (1996) 10211026.

[13] Vesga O, Groeschel MC, Otten MF, Brar DW, Vann JM, Proctor RA, Staphylococcus aureus small colony variants are induced by the endothelial cell intracellular milieu, J Infect Dis 173 (1996) 739-742.

[14] Balwit JM, van Langevelde P, Vann JM, Proctor RA, Gentamicin-resistant menadione and hemin auxotrophic Staphylococcus aureus persist within cultured endothelial cells, J Infect Dis 170 (1994) 1033-1037.

[15] Garzoni C, Kelley WL, Staphylococcus aureus: new evidence for intracellular persistence, Trends Microbiol 17 (2009) 59-65. 
[16] Ellington JK, Harris M, Hudson MC, Vishin S, Webb LX, Sherertz R, Intracellular Staphylococcus aureus and antibiotic resistance: implications for treatment of staphylococcal osteomyelitis, J Orthop Res 24 (2006) 87-93.

[17] Puzas JE, The osteoblast, in Favus MJ, Primer on the metabolic bone diseases and disorders of mineral metabolism, Raven Press, New York, 1993, pp 15-21.

[18] Bost KL, Ramp WK, Nicholson NC, Bento JL, Marriott I, Hudson MC, Staphylococcus aureus infection of mouse or human osteoblasts induces high levels of interleukin-6 and interleukin-12 production, J Infect Dis 180 (1999) 1912-1920.

[19] Wright KM, Friedland JS, Differential regulation of chemokine secretion in tuberculous and staphylococcal osteomyelitis, J Bone Miner Res 17 (2002) 16801690.

[20] Tucker KA, Reilly SS, Leslie CS, Hudson MC, Intracellular Staphylococcus aureus induces apoptosis in mouse osteoblasts, FEMS Microbiol Lett 186 (2000) 151-156.

[21] Ellington JK, Reilly SS, Ramp WK, Smeltzer MS, Kellam JF, Hudson MC, Mechanisms of Staphylococcus aureus invasion of cultured osteoblasts, Microb Pathog 26 (1999) 317-323.

[22] Allardyce RA, Wang Y, Rogers GR, Gillespia WJ, Doyle JS, The destruction of bone by neutrophils, Chin Med J (Engl) 108 (1995) 708-709.

[23] Amer AO, Swanson MS, Aphagosome of one's own: a microbial guide to life in the macrophage, Curr Opin Microbiol 5 (2002) 56-61.

[24] Staali L, Bauer S, Morgelin M, Bjorck L, Tapper H, Streptococcus pyogenes bacteria modulate membrane traffic in human neutrophils and selectively inhibit azurophilic granule fusion with phagosomes, Cell Microbiol 8 (2006) 690-703.

[25] Haslett C, Savill JS, Whyte MK, Stern M, Dransfield I, Meagher LC, Granulocyte apoptosis and the control of inflammation, Philos Trans R Soc Lond B Biol Sci 345 (1994) 327-333.

[26] Petti CA, Fowler VG Jr., Staphylococcus aureus bacteremia and endocarditis, Cardiol Clin 21 (2003) 219-233.

[27] Eze MO, Yuan L, Crawford RM, Paranavitana CM, Hadfield TL, Bhattacharjee AK, Warren RL, Hoover DL, Effects of opsonization and gamma interferon on growth of Brucella melitensis $16 \mathrm{M}$ in mouse peritoneal macrophages in vitro, Infect Immun 68 (2000) 257-263.

[28] Murillo O, Pachón ME, Euba G, Verdaguer R, Carreras M, Cabellos C, Cabo J, Gudiol F, Ariza J, Intracellular antimicrobial activity appearing as a relevant factor in antibiotic efficacy against an experimental foreign-body infection caused by Staphylococcus aureus, J Antimicrob Chemother 64 (2009) 1062-1066.

[29] Easmon CS, Lanyon H, Cole PJ, Use of lysostaphin to remove cell-adherent staphylococci during in vitro assays of phagocyte function. Br J Exp Pathol 59 (1978) 381-385.

[30] Maurin M, Raoult D, Use of aminoglycosides in treatment of infections due to intracellular bacteria, Antimicrob Agents Chemother 45 (2001) 2977-2986.

[31] Kumar JK, Lysostaphin: an antistaphylococcal agent, Appl Microbiol Biotechnol 80 (2008) 555-561. 
[32] Heesemann J, Laufs R, Double immunofluorescence microscopic technique for accurate differentiation of extracellularly and intracellularly located bacteria in cell culture, J Clin Microbiol 22 (1985) 168-175.

[33] Agerer F, Waeckerle S, Hauck CR, Microscopic quantification of bacterial invasion by a novel antibody-independent staining method, J Microbiol Methods 59 (2004) 23-32.

[34] Bass DA, Parce JW, Dechatelet LR, Szejda P, Seeds MC, Thomas M, Flow cytometric studies of oxidative product formation by neutrophils: a graded response to membrane stimulation, J Immunol 130 (1983) 1910-1917.

[35] Haslinger-Löffler B, Kahl BC, Grundmeier M, Strangfeld K, Wagner B, Fischer U, Cheung AL, Peters G, Schulze-Osthoff K, Sinha B, Multiple virulence factors are required for Staphylococcus aureus-induced apoptosis in endothelial cells, Cell Microbiol 7 (2005) 1087-1097.

[36] Haslinger B, Strangfeld K, Peters G, Schulze-Osthof K, Sinha B, Staphylococcus aureus alpha-toxin induces apoptosis in peripheral blood mononuclear cells: role of endogenous tumour necrosis factor-alpha and the mitochondrial death pathway, Cell Microbiol 5 (2003) 729-741.

[37] Jevon M, Guo C, Ma B, Mordan N, Nair SP, Harris M, Henderson B, Bentley G, Meghji S, Mechanisms of internalization of Staphylococcus aureus by cultured human osteoblasts, Infect Immun 67 (1999) 2677-2681.

[38] Garzoni C, Francois P, Huyghe A, Couzinet S, Tapparel C, Charbonnier Y, Renzoni A, Lucchini S, Lew DP, Vaudaux P, Kelley WL, Schrenzel J, A global view of Staphylococcus aureus whole genome expression upon internalization in human epithelial cells, BMC Genomics 14 (2007) 171.

[39] Hess DJ, Henry-Stanley MJ, Erickson EA, Wells CL, Intracellular survival of Staphylococcus aureus within cultured enterocytes, J Surg Res 114 (2003) 42-49.

[40] Thwaites GE, Gant V, Are bloodstream leukocytes Trojan Horses for the metastasis of Staphylococcus aureus? Nat Rev Microbiol 9 (2001) 215-222.

[41] Tuchscherr L, Medina E, Hussain M, Volker W, Heitmann V, Niemann S, Holzinger D, Roth J, Proctor RA, Becker K, Peters G, Loffler B, Staphylococcus aureus phenotype switching: an effective bacterial strategy to escape host immune response and establish a chronic infection, EMBO Mol Med 3 (2011) 129-141.

[42] Melvin JA, Murphy CF, Dubois LG, Thompson JW, Moseley MA, McCafferty DG, Staphylococcus aureus sortase A contributes to the Trojan horse mechanism of immune defense evasion with its intrinsic resistance to Cys184 oxidation, Biochemistry 50 (2011) 7591-7599.

[43] Das D, Bishayi B, Staphylococcal catalase protects intracellularly survived bacteria by destroying $\mathrm{H}_{2} \mathrm{O}_{2}$ produced by the murine peritoneal macrophages, Microb Pathog 47 (2009) 57-67.

[44] McNamara PJ, Proctor RA, Staphylococcus aureus small colony variants, electron transport and persistent infections, Int J Antimicrob Agents 14 (2000) 117-122.

[45] Marriott I, Gray DL, Rati DM, Fowler VG Jr, Stryjewski ME, Levin LS, Hudson $\mathrm{MC}$, Bost KL, Osteoblasts produce monocyte chemoattractant protein-1 in a murine model of Staphylococcus aureus osteomyelitis and infected human bone tissue, Bone 37 (2005) 504-512. 
[46] Somayaji SN, Ritchie S, Sahraei M, Marriott I, Hudson MC, Staphylococcus aureus induces expression of receptor activator of NF-kappaB ligand and prostaglandin E2 in infected murine osteoblasts, Infect Immun 76 (2008) 51205126. 


\title{
CHAPTER 3
}

\section{Intracellular Staphylococcus aureus Causes Bone Infection: In vivo Evidence}

\begin{abstract}
Chronic and recurrent bone infections occur frequently but have not been fully explained. Staphylococcus aureus (S. aureus) is often found in these chronic and recurrent infections and may be responsible for such infections. One possible reason is that $S$. aureus can internalize and survive within host cells and by doing so, $S$. aureus can evade both host defense mechanisms and most conventional antibiotic treatments. However, no in vivo evidence in the literature has shown that S. aureus internalized into host cells is directly responsible for infections. In this study, we hypothesized that intracellular S. aureus could induce infections in vivo. Osteoblasts were infected with $S$. aureus and, after eliminating extra-cellular S. aureus, the osteoblasts were inoculated into an open femur fracture rat model. Bacterial cultures and radiographic observations confirmed local bone infections in animals inoculated with intra-cellular $S$. aureus within osteoblasts alone at post-operative day 21 . We present the first direct in vivo evidence that intra-cellular S. aureus could be sufficient to induce bone infection in animals; we found that intra-cellular $S$. aureus inoculation of as low as $10^{2}$ colony forming units could induce severe bone infections. Our data may suggest that intra-cellular S. aureus can "hide" in host cells during symptom-free periods and, under certain conditions, they may escape and lead to infection recurrence. Intra-cellular S. aureus therefore could play an important role in the pathogenesis of $S$. aureus infections, especially those chronic and
\end{abstract}


recurrent infections in which disease episodes may be separated by weeks, months, or even years.

Keywords: Chronic infection, infection recurrence, intra-cellular pathogen, Staphylococcus aureus, in vivo, co-culture 


\section{Introduction}

Bone infection or osteomyelitis is a significant clinical problem which can lead to prolonged hospitalization, sepsis, poor functional outcome, and even death [1-4]. Patients with traumatic open fractures have a high risk of infection $(5-33 \%)$ due to microbial contamination and soft tissue damage [5], and such infections are often hard to eradicate, long-lasting (i.e. chronic), and recurrent [6]. For instance, over a million Americans are hospitalized every year for bone fractures [7]; such injuries are increasingly common because of increased survivability of high energy trauma in civilian settings as well as in combat activities. Treatment of bone infections, particularly chronic and recurrent infections, frequently requires long-term hospitalization for repeated debridement and prolonged parenteral antibiotic therapy. Bacteria including Staphylococcus aureus (S. aureus), however, are often surprisingly successful in overcoming both host defense mechanisms and antibiotic treatments resulting in chronic and recurrent bone infections; indeed, a high rate of recurrence or relapse of bone infections was reported where $\sim 17 \%$ of infections related to traumatic extremity injuries recur or relapse $[8,9]$. It is thought that bacteria may elude host defenses and antibiotics and can "hide" themselves intracellularly within host cells [10]. Unfortunately, evidence to support the hypothesis that intracellular bacteria are responsible for or contribute to bone infections in animals or humans is sparse or does not exist.

A wide range of bacterial species have been isolated related to bone infections. The pathogen $S$. aureus is the most common causative agent of bone infections, contributing to approximately $80 \%$ of all human disease cases [11]. S. aureus is a normal flora that colonizes the skin, skin glands, and mucous membranes, specifically in the nose 
of healthy individuals. $S$. aureus expresses a large number of cell surface proteins (i.e. adhesins) of the microbial surface components recognizing adhesive matrix molecules or MSCRAMMs $[12,13]$ through which it can colonize the bone matrix and adhere to bone cell surfaces. S. aureus, while generally considered an extracellular pathogen, is one such bacterium that has the ability to invade and live within different cell types, including phagocytic and non-phagoytic cells (reviewed in reference 14). By "hiding" inside the host cells, S. aureus may escape from host defenses and most antibiotic treatments and may be responsible for chronic and recurrent bone infections.

To our knowledge, there is no definitive in vivo evidence showing that $S$. aureus "hiding" intracellularly is directly responsible for or contributes to infections. The objective of this study was to determine whether intracellular S. aureus can induce bone infections in a rat model. By pre-infecting osteoblasts in vitro with $S$. aureus, killing extracellular bacteria with gentamicin, and inoculating infected osteoblasts into an open femur fracture rat model, we examined the bone infections in rats induced by intracellular S. aureus. 


\section{Materials and Methods}

\section{Reagents}

Dulbecco's modified Eagle's medium-F 12 (DMEM-F 12) and phosphate buffered saline (PBS) were purchased from Lonza (Walkersville, MD). Tryptic soy broth (TSB) and tryptic soy agar (TSA w/5\% sheep blood) plates were from Fisher Scientific

(Pittsburgh, PA). Fetal bovine serum (FBS), 0.25\% trypsin-ethylenediaminetetraacetic acid (EDTA), and $100 \mathrm{U} / \mathrm{mL}$ penicillin $/ 100 \mathrm{mg} / \mathrm{mL}$ streptomycin were obtained from Invitrogen (Carlsbad, CA). Triton X-100 was from Sigma (St. Louis, MO). S. aureus (American Type Culture Collection or ATCC 25923) and rat osteoblast cells (UMR-106) were purchased from ATCC (Manassas, VA).

Preparation of osteoblasts with intracellular S. aureus via co-culturing osteoblast-S. aureus

Rat osteoblast cells were seeded at a density of $5 \times 10^{5}$ osteoblasts $/ \mathrm{mL}$ and cultured in 6-well plates overnight to form a monolayer in DMEM-F12 supplemented with 10\% FBS and 1\% penicillin/streptomycin solution. Fresh S. aureus inoculum was prepared by suspending 5 colonies of $S$. aureus into $5 \mathrm{~mL} \mathrm{TSB}$, and incubated at $37^{\circ} \mathrm{C}$ for $18 \mathrm{~h}$. The bacterial suspension was centrifuged $(3750 \mathrm{rpm})$ at $4^{\circ} \mathrm{C}$ for $15 \mathrm{~min}$, washed once with PBS, and its optical density was then adjusted to have $S$. aureus of $5 \times 10^{8}$ colony forming units/mL (CFU/mL). Rat osteoblasts and S. aureus were then infected as follows (Fig. 1): (i) Osteoblast monolayer was first washed twice with PBS. S. aureus was pelleted, resuspended in DMEM-F12 (without FBS and antibiotics), and then added to the osteoblast monolayer at a multiplicity of infection (MOI) of 500:1 S. aureus to osteoblasts. Osteoblasts and S. aureus were next infected at $37^{\circ} \mathrm{C}$ in $5 \% \mathrm{CO}_{2}$ humidified incubator for 
2 h. (ii) The osteoblast monolayer was then washed twice with PBS to remove any nonadherent bacteria, and cell culture media supplemented with gentamicin $(100 \mu \mathrm{g} / \mathrm{mL})$ was added and kept for $2 \mathrm{~h}$ to kill remaining extracellular bacteria; gentamicin is an antibiotic that is unable to penetrate mammalian cell membranes within short time periods $[2,15$, 16]. Infected osteoblasts were immediately used or kept on ice before being used in the rat animal studies. (iii) Samples of infected osteoblasts were lysed using Triton X-100. (iv) Cell lysates were cultured on blood agar plates to determine the CFU which represents the viable colonies of intracellular S. aureus within osteoblasts.

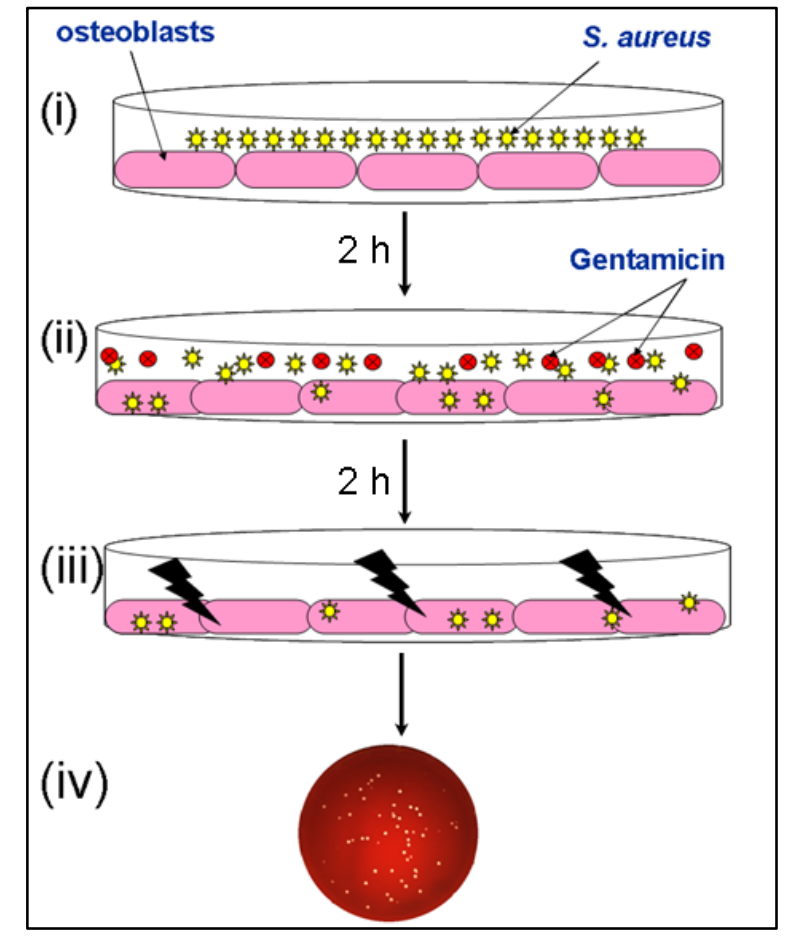

Figure 1. A schematic diagram describes the process of infecting osteoblasts with intracellular S. aureus and confirming that the osteoblasts are infected. (i) Rat osteoblasts were infected with $S$. aureus for $2 \mathrm{~h}$. (ii) Extracellular $S$. aureus were killed with gentamicin and washed. (iii) Osteoblasts were lysed using a lysing buffer. (iv) Cell lysates were cultured on blood agar plates to count live intracellular $S$. aureus colonies. 
Animal groups and open fracture infection procedure

Sprague-Dawley rats (400-500 g) were obtained from Hilltop Lab Animals (Scottdale, PA). All studies were approved by the West Virginia University Institutional Animal Care and Use Committee. Our open femur fracture rat model $[17,18]$ was modified and the surgical procedure was described in brief as follows (Fig. 2): After sedation of the animals with intraperitoneal anesthetic, the hind leg was shaved prior to fracture. A midshaft femur fracture was produced using a custom-made device (Fig. 2A), an incision was made to expose the fracture (Fig. 2B), and then the fracture was fixed using an intramedullary stainless steel Kirschner wire or K-wire (Fig. 2C). Next, $100 \mu \mathrm{L}$ of treatment solution was gently pipetted into the fracture site without contacting the surgical instruments (Fig. 2D). Based on the treatment solutions, rats were randomly assigned into the following six groups (six rats per group):

\begin{tabular}{|c|c|}
\hline Group & Treatment solution $(100 \mu \mathrm{L})$ \\
\hline Group I & PBS \\
\hline Group II & $10^{6}$ osteoblasts \\
\hline Group III & $10^{6}$ osteoblasts combined with $20 \mathrm{CFU}$ of extracellular $S$. aureus \\
\hline Group IV & $10^{6}$ osteoblasts with $* 10^{2}$ CFU intracellular $S$. aureus \\
\hline Group V & $10^{6}$ osteoblasts (infected) with $10^{6} \mathrm{CFU}$ intracellular $S$. aureus \\
\hline Group VI & $\begin{array}{l}10^{6} \text { osteoblasts (infected) with } 10^{6} \mathrm{CFU} \text { intracellular S. aureus combined } \\
\text { with } 20 \mathrm{CFU} \text { of extracellular S. aureus }\end{array}$ \\
\hline
\end{tabular}

* This was obtained by diluting the $10^{6} \mathrm{CFU}$ of intracellular $S$. aureus with non-infected osteoblasts.

The incision was subsequently closed (Fig. 2E) and post-operative radiographs were taken to verify the fracture fixation. All animals were monitored for the study duration of three weeks and euthanized on post-operative day 21. 

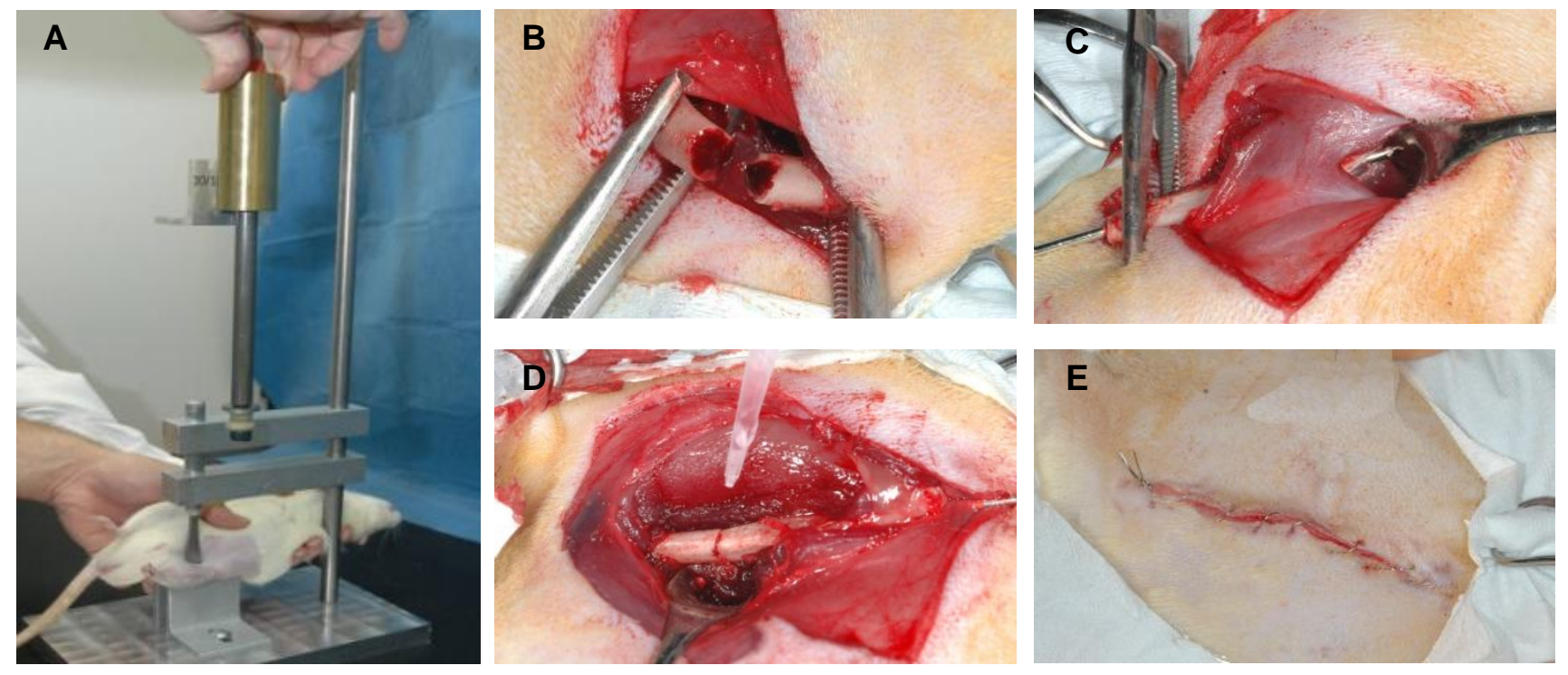

Figure 2. The rat femur was fractured, fixed with a K-wire, and inoculated with $0.1 \mathrm{~mL}$ solution of PBS, osteoblasts, mixture of osteoblasts and extracellular S. aureus (20 CFU), infected osteoblasts with intracellular $S$. aureus, or mixture of infected osteoblasts and extracellular $S$. aureus (20 CFU). Rats were euthanized on post-operative day 21. (A) Creation of a femur fracture using a custom-designed setup. (B) Exposure of the fracture. (C) Intramedullary fixation of the fracture using a K-wire. (D) Injection of $0.1 \mathrm{~mL}$ solution using a pipette. (E) Closure of incision.

\section{Microbiological and radiographic evaluations}

On the day of euthanasia, bone and muscle tissues were collected in $15 \mathrm{~mL}$ centrifuge tubes with $5 \mathrm{~mL}$ PBS and homogenized. Samples of bone and muscle homogenates were diluted and plated on blood agar plates, and $S$. aureus colonies were counted after incubating the plates, at $37^{\circ} \mathrm{C}$ for $24 \mathrm{~h}$. In addition, K-wires that were used to fix the fractured femurs were collected at euthanasia, cut into $2 \mathrm{~cm}$-long pieces, rolled on blood agar plates and cultured at $37^{\circ} \mathrm{C}$ for $24 \mathrm{~h}$. Radiographs of fractured femurs were taken on post-operative days 0,7 , and 21 . 


\section{Body weight and complete blood count}

The body weights of animals were measured on the day of surgery and immediately before euthanasia and the net weight gain/loss was calculated. Blood samples were collected immediately prior to euthanasia from the heart and analyzed for complete blood counts by Antech Diagnostics, Inc. (Southaven, MS).

\section{Statistical analysis}

Values of CFU, body weight gain/loss, and blood cell counts were expressed as the mean \pm standard deviation. Differences in body weight gain and blood cell counts were analyzed using one-way ANOVA. $P$ value $\leq 0.05$ was considered statistically significant. JMP (V9) software was used (SAS Institute, Inc., Cary, NC). 


\section{Results}

Intracellular S. aureus causes high bacterial burden in bone and muscle tissues

Rats (Groups IV, V, and VI) inoculated with infected osteoblasts $\left(10^{2}\right.$ or $10^{6} \mathrm{CFU}$ of intracellular $S$. aureus) led to high CFU counts (i.e. $\sim 10^{6} \mathrm{CFU} / \mathrm{mL}$ ) on post-operative day 21 in the bone and muscle samples (Fig. 3A). There were no significant differences in CFUs among the animal groups (i.e. Groups IV, V, and VI) inoculated with infected osteoblasts on post-operative day 21 , although relatively higher CFU counts were found in the bone samples compared to the muscle samples of the same animal group. By contrast, no bacteria were observed on post-operative day 21 in the rats (i.e. Groups I, II, and III) inoculaed with PBS, osteoblasts, and osteoblasts combined with 20 CFU of extracellular S. aureus (Fig. 3A). Correspondingly, heavy bacterial growth was seen in the blood agar plates rolled with the K-wires from animals inoculated with infected osteoblasts $\left(10^{2}\right.$ or $\left.10^{6} \mathrm{CFU}\right)$ while no bacterial colonies were found in rolling $\mathrm{K}$-wires extracted from animals inoculated with PBS, osteoblasts, and osteoblasts combined with 20 CFU of extracellular S. aureus (Fig. 3B). Gross observation before euthanasia showed pus pockets at the fracture sites in rats inoculated with infected osteoblasts (i.e. Groups IV, V, and VI). No S. aureus growth (data not shown) was observed on post-operative day 21 in the blood samples collected from all the animal groups studied. 


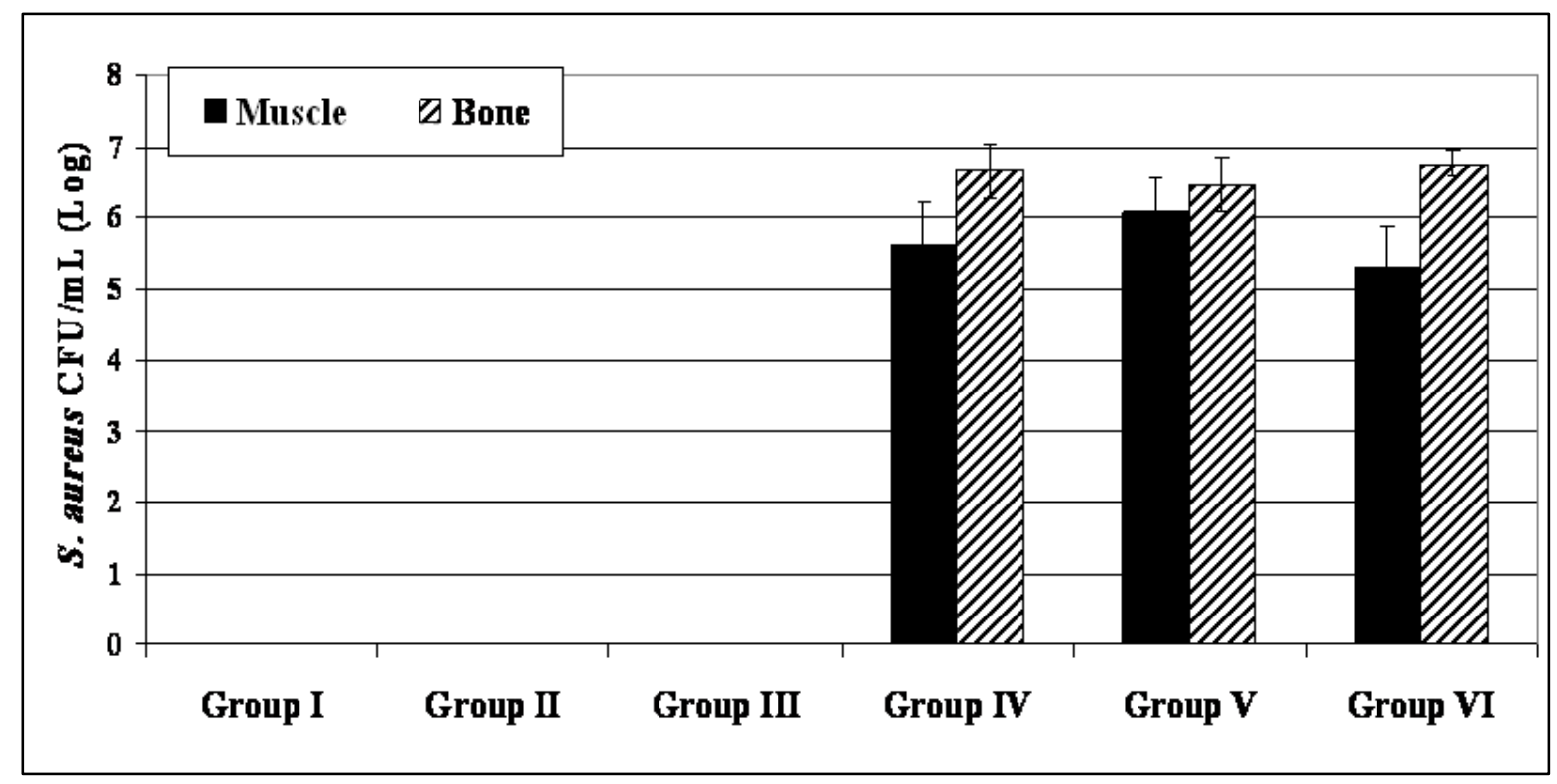

Figure 3 (A)

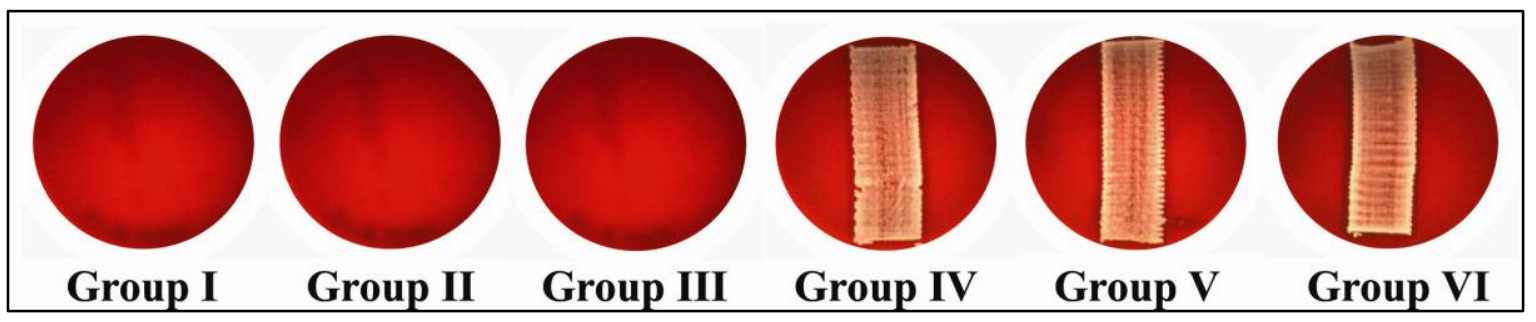

Figure 3 (B)

Figure 3. (A) Bone (femur) and muscle tissue homogenates reported high S. aureus CFUs in the animal groups inoculated with infected osteoblasts (i.e. Groups IV, V, and VI); data were from six rats. No CFU was found in the animal groups inoculated with PBS, osteoblasts, and a mixture of osteoblasts and extracellular S. aureus (20 CFU) (i.e. Groups I, II, and III). (B) K-wire rolling experiments showed high S. aureus growth in the animal groups inoculated with infected osteoblasts; no bacterial growth was observed in the animal groups inoculated with PBS, osteoblasts, and a mixture of osteoblasts and extracellular S. aureus (20 CFU). 


\section{Radiographic assessment of bone infection}

No signs of infection were observed on post-operative day 21 in the radiographs of rats (i.e. Groups I, II, and III) inoculated with PBS, osteoblasts, and osteoblasts combined with $20 \mathrm{CFU}$ of extracellular S. aureus (Fig. 4A); the X-ray images of these animals were characterized by the formation of normal bridging calluses at the fracture sites. By contrast, animal groups (i.e. Groups IV, V, and VI) inoculated with infected osteoblasts $\left(10^{2}\right.$ or $\left.10^{6} \mathrm{CFU}\right)$ exhibited severe osteolysis on post-operative day 21. Meanwhile, no severe osteolysis was observed on post-operative day 7 in the animals inoculated with infected osteoblasts (Fig. 4B).
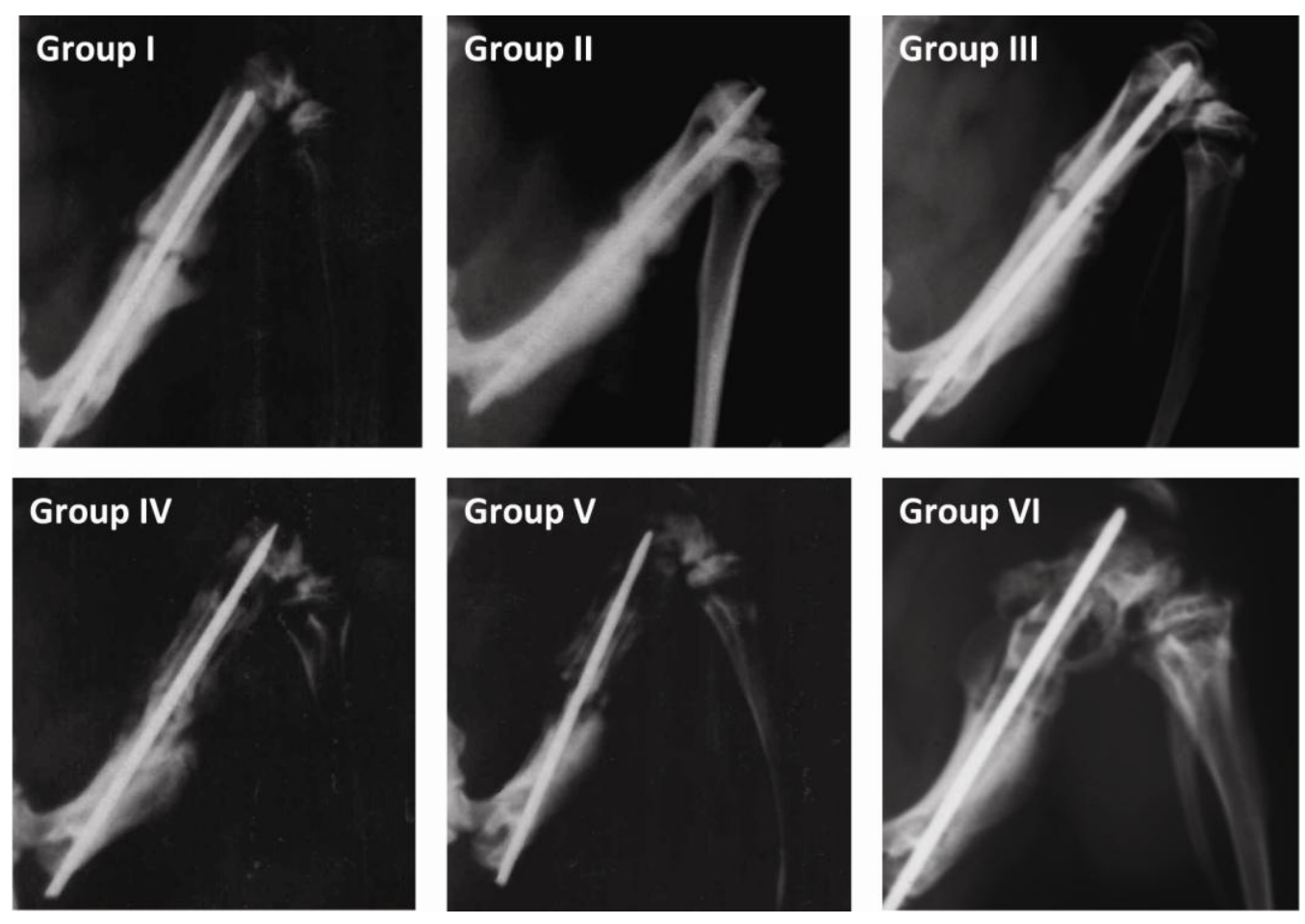

Figure 4 (A) 

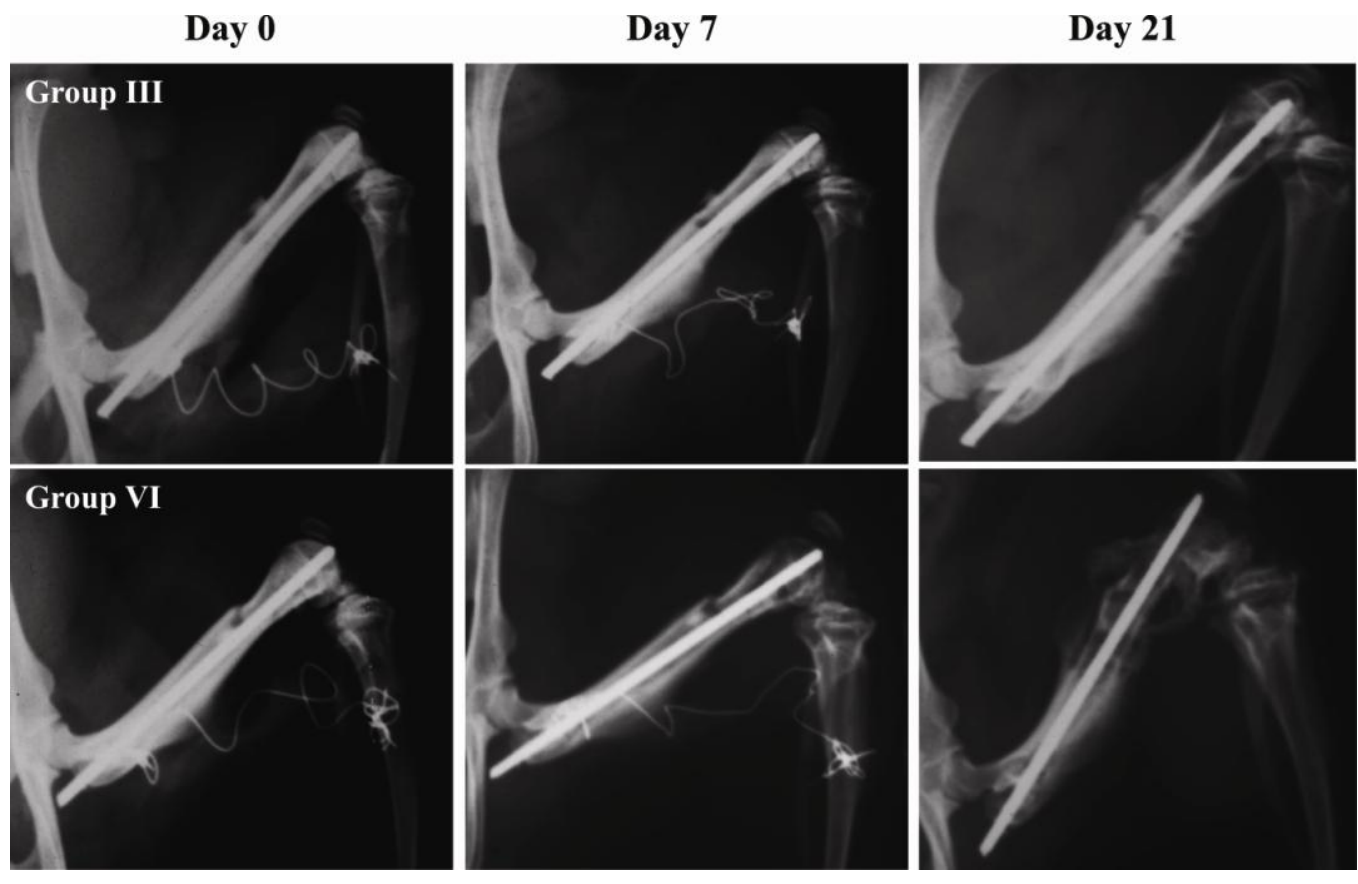

Figure 4 (B)

Figure. 4. (A) Radiographs of fractured femurs on post-operative day 21 presented significant osteolysis in the animal groups inoculated with infected osteoblasts (i.e. Groups IV, V, and VI) while normal bone healing was seen in the animal groups inoculated with PBS, osteoblasts, and a mixture of osteoblasts and extracellular S. aureus (20 CFU) (i.e. Groups I, II, and III). (B) Radiographs of fractured femurs on postoperative day 0,7 , and 21 did not show severe osteolysis in the rats inoculated with infected osteoblasts (e.g. Group VI) on post-operative day 7.

Body weight and complete blood counts

A significant loss in body weight was observed in rat groups (i.e. Groups IV, V, and VI) inoculated with infected osteoblasts $\left(10^{2}\right.$ or $10^{6} \mathrm{CFU}$ of intracellular S. aureus) compared to the animal groups (i.e. Groups I, II, and III) inoculated with PBS, osteoblasts, and osteoblasts combined with $20 \mathrm{CFU}$ of extracellular S. aureus (Fig. 5). Interestingly, relatively more, although not significant, weight gain was seen on post- 
operative day 21 in the animal groups (i.e. Groups II and III) inoculated with osteoblasts compared to the group (i.e. Group I) inoculated with PBS (Fig. 5).

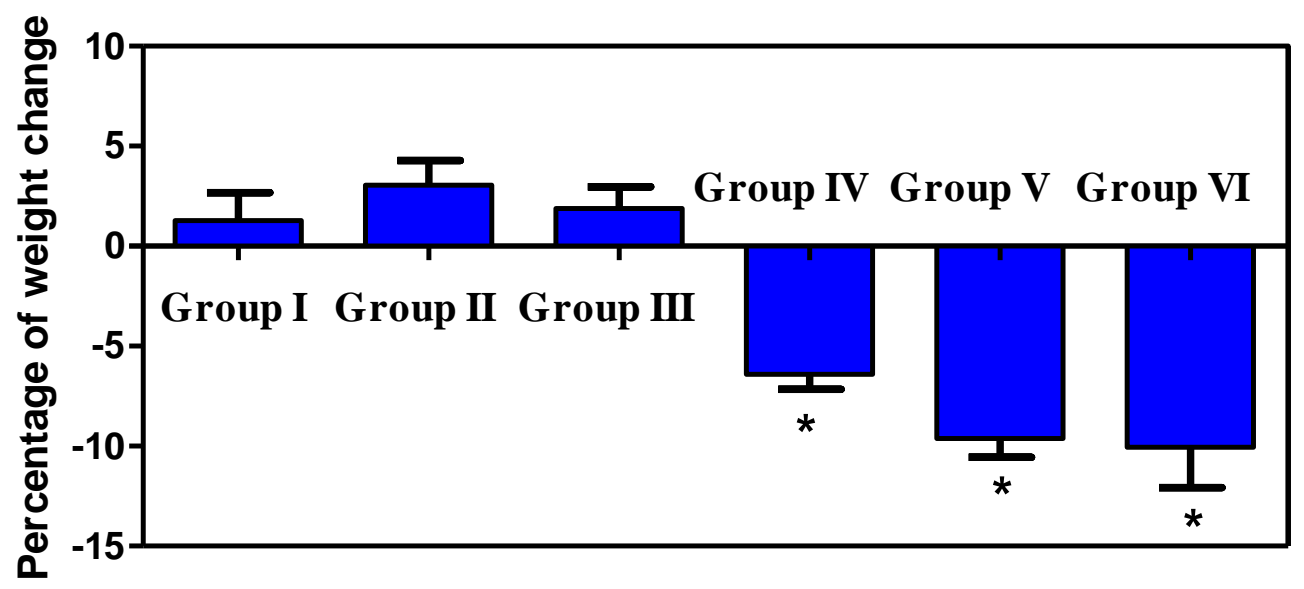

Figure 5. Net weight loss of the rats on post-operative day 21 was significantly higher in the animal groups inoculated with infected osteoblasts (i.e. Groups V, and VI) compared to those in the animal groups inoculated with PBS, osteoblasts, and a mixture of osteoblasts and extracellular S. aureus (20 CFU) (i.e. Groups I, II, and III). Data were an average of six rats in each group.

The neutrophils in the blood of rat groups (i.e. Groups IV, V, and VI) inoculated with infected osteoblasts $\left(10^{2}\right.$ or $\left.10^{6} \mathrm{CFU}\right)$ were significantly elevated on post-operative day 21 compared to the animal groups (i.e. Groups I, II, and III) inoculated with PBS, osteoblasts, and osteoblasts combined with $20 \mathrm{CFU}$ of extracellular S. aureus (Fig. 6). No significant differences (data not shown) were seen on post-operative day 21 in the numbers of lymphocytes, monocytes, and eosinophils among all the animal groups studied. 


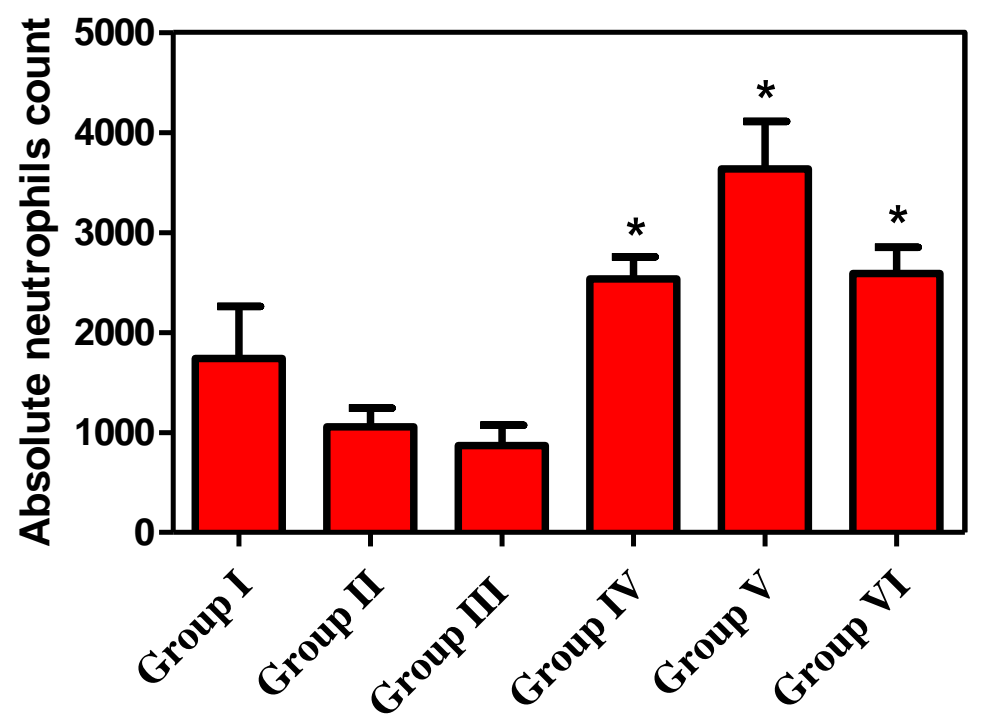

Figure 6. Complete blood counts on post-operative day 21 showed that neutrophil numbers were significantly higher in the animal groups inoculated with infected osteoblasts (i.e. Groups IV, V, and VI) compared to those animal groups inoculated with osteoblasts and a mixture of osteoblasts and extracellular S. aureus (20 CFU) (i.e. Groups II and III). 


\section{Discussion}

S. aureus is a major human pathogen causing significant morbidity and mortality in both community- and hospital-acquired infections. Surprisingly, S. aureus is frequently successful in overcoming both host defense mechanisms and most antibiotic treatments, was found among chronic and recurrent infections, and could be responsible for such infections. This bacterium is believed to have developed several means to combat conventional antibiotic therapies, among which are its ability to survive for long periods of time inside host cells [14]. The purpose of the present study was to examine whether intracellular S. aureus contributes to infection in vivo. Effort was taken to completely eradicate extracellular $S$. aureus in the inoculums by treating them with gentamicin; the complete killing of extracellular S. aureus was verified in our studies as well as by others $[15,16,19,20]$. Also, gentamicin remaining in the inoculum samples was expected to eliminate any extracellular S. aureus that leaked out within the first few hours after infection.

We investigated whether intracellular S. aureus within osteoblasts could induce infection in our open femur fracture rat model. An open femur fracture model was used because open fractures have high rates of infection and infection recurrence, and a high rate of recurrence or relapse of infections was reported in traumatic extremity injuries $(8$, 9). We found that animals inoculated with $S$. aureus infected osteoblasts with intracellular S. aureus CFU of $10^{2}$ (i.e. Group IV) and $10^{6}$ (i.e. Groups V and VI) all led to severe infections. The results were confirmed by culturing bone and muscle specimens from the fracture sites and explanted K-wires (Fig. 3) and visualizing via radiography of the fractured bones (Fig. 4). Inoculation of intracellular S. aureus of $10^{2} \mathrm{CFU}$ led to the 
same degree of infection as $10^{6} \mathrm{CFU}$ inoculum, evidenced by approximately the same CFU of bone or muscle specimens on post-operative day 21 (Fig. 3). Animals inoculated with no bacteria (i.e. Groups I and II) or with $20 \mathrm{CFU}$ of extracellular S. aureus (i.e. Group III) did not exhibit infection on post-operative day 21. No systemic infection was observed in any of the animal groups investigated because no CFU was found in blood samples. These suggest that intracellular S. aureus of as low as $10^{2} \mathrm{CFU}$ within osteoblasts induced bone infections in our rat open femur fracture model; the infection was localized.

It was interesting that severe bone infections could be induced by intracellular $S$. aureus within osteoblasts at a low rate of $10^{2} \mathrm{CFU}$, which was the same quantity of inoculum as our previous rat studies where $10^{2} \mathrm{CFU}$ of extracellular S. aureus was sufficient to induce bone infections in our open fracture rat model $[17,18,21]$. This suggested that not only extracellular but also intracellular S. aureus of as low as $10^{2} \mathrm{CFU}$ could induce severe bone infections in open fractures. Note that inoculation of uninfected osteoblasts did not have an effect on infection; no CFU was observed in corresponding bone, muscle, and K-wire samples (Fig. 3). However, although not significant, increased weight gain was observed with injection of uninfected osteoblasts compared to injection of PBS (Fig. 5); the reason was unknown.

Meanwhile, neutrophils were significantly increased on post-operative day 21 in the animal groups inoculated with infected osteoblasts. This finding might suggest that neutrophils have played a deleterious role in infections induced by $S$. aureus infected osteoblasts. In the literature, neutrophils may have a protective or a deleterious role in $S$. aureus infection. On one hand, neutrophils have long been believed to provide significant 
host defense against $S$. aureus infection. This is mainly because patients who are neutropenic or who have defects in neutrophil functions are more susceptible to $S$. aureus infection, and total ablation of neutrophils in an experimental mouse model of S. aureusinduced septic arthritis led to decreased survival of the animals and increased bacteremia [22]. On the other hand, increased neutrophils were also found to correlate with decreased survival of mice and increased bacterial burden at the infection site [23, 24].

It is important to note that both in vitro and in vivo studies have shown that $S$. aureus can internalize and survive within both phagocytic and non-phagocytic cells. In vitro, S. aureus can invade and survive within polymorphonuclear neutrophils and monocytes [25-27] and osteoblasts [28, 29]. Infected human osteoblasts were shown to release viable $S$. aureus, which were able to re-infect new osteoblasts [28]. S. aureus can also internalize and perhaps even replicate within bovine mammary epithelial cells, both in cell lines and in primary culture [30, 31]. In vivo, intracellular S. aureus was found, in limited cases, in animals and patients. In animal studies, S. aureus was found to be able to internalize and survive in osteoblasts in chick embryos [32] and in bovine alveolar cells isolated from milk of infected cows [33]. In patient studies, intracellular S. aureus was found inside epithelium, glandular, and myofibroblastic cells in intranasal biopsy specimens obtained, during infection symptom-free periods, in three patients with recurrent rhinosinusitis [34]. Molecular typing proved the clonal relationship of the patient-specific Staphylococci. Intracellular S. aureus was also found in surgical bone specimens from a patient who had chronic and recurrent bone infection [35]. The intracellular S. aureus appeared to be sequestered and protected from the host immune system within the osteoblast or osteocyte cytoplasm for years [35]. In another case, 
intracellular $S$. aureus was cultured from five patients with persistent and recurrent infections [36]. Alarmingly, some of those intracellular S. aureus were small-colony variants which were non-hemolytic and non-pigmented, grew very slowly on routine culture media, and were resistant to aminoglycosides under routine conditions.

Therefore, there is some in vitro and in vivo evidence supporting the potential role of intracellular S. aureus in Staphylococci pathogenesis. However, there is no definitive in vivo proof before this study showing that intracellular $S$. aureus is directly responsible for or contributes to infections (e.g. chronic and recurrent infection). The results presented here are important because they have demonstrated, for the first time, that intracellular S. aureus could induce infection in vivo. Bacteria (e.g. S. aureus) could internalize and survive within host cells (e.g. osteoblast) and, after "hiding" for some time period (could be up to years [35]), these quiescent bacteria could escape from the infected host cells into the surrounding tissue and could be sufficient to initiate a recurrence of symptomatic infection.

Taken together, the findings reported here present the first in vivo direct evidence that intracellular $S$. aureus can induce bone infections and may be responsible for chronic and recurrent infections. These findings also suggested that as low as $10^{2} \mathrm{CFU}$ of intracellular $S$. aureus may induce severe bone infections in open fractures. These findings may greatly advance our understanding of the pathogenesis of bone infections, especially chronic and recurrent infections. The induction of bone infections by intracellular S. aureus was studied in this work; however, the findings are expected to be applicable to other infections/diseases and intracellular pathogens. 


\section{References}

[1] Pull terGunne AF, Cohen DB. (2009). Incidence, prevalence, and analysis of risk factors for surgical site infection following adult spinal surgery.Spine. 34(13):1422-8.

[2] de Lissovoy G, Fraeman K, Hutchins V, Murphy D, Song D, Vaughn BB. (2009). Surgical site infection: incidence and impact on hospital utilization and treatment costs. Am J Infect Control. 37(5):387-97.

[3] Johnson EN, Burns TC, Hayda RA, Hospenthal DR, Murray CK. (2007). Infectious complications of open type III tibial fractures among combat casualties. Clin Infect Dis. 45(4):409-15.

[4] Sugarman B, Young EJ. (1989). Infections associated with prosthetic devices: magnitude of the problem. Infect Dis Clin North Am. 3(2):1871-98.

[5] Zalavras CG, Patzakis MJ. (2003). Open fractures: evaluation and management. $J$ Amer Acad Orthop Surg. 11(3):212-9.

[6] Berendt T, Byren I. 2004. Bone and joint infection. Clin Med. 4:510-518.

[7] Canale ST. Campbell's Operative Orthopaedics. $10^{\text {th }}$ ed. St Louis, Mo: Mosby-Year Book; 2003.

[8] Murray CK, Hsu JR, Solomkin JS, Keeling JJ, Andersen RC, Ficke JR, Calhoun JH. (2008). Prevention and management of infections associated with combat-related extremity injuries. J Trauma. 64(3 Suppl):S239-51.

[9] Murray CK, Obremskey WT, Hsu JR, Andersen RC, Calhoun JH, Clasper JC, Whitman TJ, Curry TK, Fleming ME, Wenke JC, Ficke JR; Prevention of CombatRelated Infections Guidelines Panel. (2011). Prevention of infections associated with combat-related extremity injuries. J Trauma. 71(2 Suppl 2):S235-57.

[10] Ciampolini J, Harding KG (2000). Pathophysiology of chronic bacterial osteomyelitis. Why do antibiotics fail so often? Postgrad Med J. 76(898):479-83.

[11] Sax H, Lew D. (1999). Osteomyelitis. Curr Infect Dis Rep. 1:261-266.

[12] Patti JM, Höök M. (1994). Microbial adhesins recognizing extracellular matrix macromolecules. Curr Opin Cell Biol. 6:752-758.

[13] Clarke SR, Foster SJ. (2006). Surface adhesins of Staphylococcus aureus. Adv Microb Physiol. 51:187-224.

[14] Garzoni C, Kelley WL. (2009). Staphylococcus aureus: new evidence for intracellular persistence. Trends Microbiol. 17:59-65

[15] Hamad MA, Skeldon AM, Valvano MA. (2010). Construction of aminoglycosidesensitive Burkholderia cenocepacia strains for use in studies of intracellular bacteria with the gentamicin protection assay. Appl Environ Microbiol. 76(10):3170-6.

[16] Plotkowski MC, de Bentzmann S, Pereira SH, Zahm JM, Bajolet-Laudinat O, Roger P, Puchelle E. (1999). Pseudomonas aeruginosa internalization by human epithelial 
respiratory cells depends on cell differentiation, polarity, and junctional complex integrity. Am J Respir Cell Mol Biol. 20(5):880-90.

[17] Li B, Jiang B, Boyce BM et al. (2009). Multilayer polypeptide nanoscale coatings incorporating IL-12 for the prevention of biomedical device-associated infections. Biomaterials. 30: 2552-8.

[18] Boyce BM, Lindsey BA, Clovis NB et al. (2012). Additive effects of exogenous IL12 supplementation and antibiotic treatment in infection prophylaxis. J Orthop Res. 30: 196-202.

[19] Hamrick TS, Diaz AH, Havell EA, Horton JR, Orndorff PE. (2003). Influence of extracellular bactericidal agents on bacteria within macrophages. Infect Immun. 71(2):1016-9.

[20] Hamza T, Li B. Staphylococcus aureus internalization and associated osteoblast responses. Orthopaedic Research Society (ORS) Annual Meeting, paper \#0919. Feb. 4-7, 2012, San Francisco, CA.

[21] Li B, Jiang B, Dietz MJ et al. (2010) Evaluation of local MCP-1 and IL-12 nanocoatings for infection prevention in open fractures. J Orthop Res. 28: 48-54.

[22] Verdrengh M, Tarkowski A. (1997). Role of neutrophils in experimental septicemia and septic arthritis induced by Staphylococcus aureus. Infect Immun. 65(7):2517-21.

[23] Lowrance JH, O'Sullivan FX, Caver TE, Waegell W, Gresham HD. (1994). Spontaneous elaboration of transforming growth factor beta suppresses host defense against bacterial infection in autoimmune MRL/lpr mice. J Exp Med. 1;180(5):1693703.

[24] Caver TE, O'Sullivan FX, Gold LI, Gresham HD. (1996). Intracellular demonstration of active TGFbeta1 in B cells and plasma cells of autoimmune mice. IgG-bound TGFbeta1 suppresses neutrophil function and host defense against Staphylococcus aureus infection. J Clin Invest. 98(11):2496-506.

[25] Rogers DE, Tompsett R. (1952). The survival of staphylococci within human leukocytes.J Exp Med. 95(2):209-30.

[26] Kapral FA, Shayegani MG. (1959). Intracellular survival of staphylococci. J Exp Med. 110(1):123-38.

[27] Melly MA, Thomison JB, Rogers DE. (1960). Fate of staphylococci within human leukocytes.J Exp Med. 112:1121-30.

[28] Ellington JK, Harris M, Webb L, Smith B, Smith T, Tan K, Hudson M. (2003) Intracellular Staphylococcus aureus.A mechanism for the indolence of osteomyelitis.J Bone Joint Surg Br. 85(6):918-21.

[29] Pillai RR, Somayaji SN, Rabinovich M, Hudson MC, Gonsalves KE. (2008). Nafcillin-loaded PLGA nanoparticles for treatment of osteomyelitis. Biomed Mater. 3(3):034114.

[30] Almeida RA, Matthews KR, Cifrian E, Guidry AJ, Oliver SP. (1996). Staphylococcus aureus invasion of bovine mammary epithelial cells. J Dairy Sci. 
79(6):1021-6.

[31] Bayles KW, Wesson CA, Liou LE, Fox LK, Bohach GA, Trumble WR. (1998). Intracellular Staphylococcus aureus escapes the endosome and induces apoptosis in epithelial cells. Infect Immun. 66(1):336-42.

[32] Reilly SS, Hudson MC, Kellam JF, Ramp WK. (2000). In vivo internalization of Staphylococcus aureus by embryonic chick osteoblasts.Bone. 26(1):63-70.

[33] Hébert A, Sayasith K, Sénéchal S, Dubreuil P, Lagacé J. (2000). Demonstration of intracellular Staphylococcus aureus in bovine mastitis alveolar cells and macrophages isolated from naturally infected cow milk. FEMS Microbiol Lett. 193(1):57-62.

[34] Clement S, Vaudaux P, Francois P, Schrenzel J, Huggler E, Kampf S, Chaponnier C, Lew D, Lacroix JS. (2005). Evidence of an intracellular reservoir in the nasal mucosa of patients with recurrent Staphylococcus aureus rhinosinusitis. J Infect Dis. 192(6):1023-8. Epub 2005 Aug 9.

[35] Bosse MJ, Gruber HE, Ramp WK. (2005). Internalization of bacteria by osteoblasts in a patient with recurrent, long-term osteomyelitis. A case report. J Bone Joint Surg Am. 87(6):1343-7.

[36] Proctor RA, van Langevelde P, Kristjansson M, Maslow JN, Arbeit RD. (1995). Persistent and relapsing infections associated with small-colony variants of Staphylococcus aureus. Clin Infect Dis. 20(1):95-102. 


\title{
CHAPTER 4
}

\section{Effect of Interleukin 12 on the Killing of Intracellular Staphylococcus aureus}

\begin{abstract}
The proinflammatory cytokine IL-12 may play a critical role in host defense against intracellular pathogens, including bacteria, viruses, and parasites. We have previously demonstrated the ability of intracellular $S$. aureus to live inside macrophages, which may explain the chronic and recurrent nature of Staphylococcal infections. The aim of this study was to determine the effect of IL-12 on killing intracellular S. aureus by macrophages. Splenic macrophages were isolated from rat spleens, infected, and treated with IL-12 or IL-12 neutralized with anti-IL-12 antibody or without IL-12. IL-12 treatment was found to exhibit a dose-dependent relationship with intracellular S. aureus, and resulted in significant reduction of intracellular S. aureus at IL-12 dosages of 250 and $2500 \mathrm{pg} / \mathrm{mL}$. The enhancement of macrophage killing activity was most effective and significant at post-infection $24-36 \mathrm{~h}$. Meanwhile, significantly higher levels of IFN- $\gamma$ and IL-12 were released from infected macrophages treated with IL-12 compared to untreated cells. No significant changes in reactive oxygen species production were detected between treated and un-treated macrophages at post-infection time 0 and $24 \mathrm{~h}$. These findings demonstrate that IL-12 can stimulate macrophages to be more potent in killing intracellular S. aureus and could be an effective immunotherapeutic agent for preventing and treating intracellular Staphylococcal infections.
\end{abstract}

Keywords: Intracellular pathogens, Interleukin 12, S. aureus, macrophages, cytokine therapy. 


\section{Introduction}

Intracellular pathogens are known to be a strong inducer of type-1 immune responses, which are characterized by the robust production of interleukin 12 (IL-12) from innate phagocytes and interferon gamma (IFN- $\gamma)$ from natural killer (NK) cells and T-cells. Studies have shown that macrophages failed to be activated to kill intracellular bacteria in mice treated with IL-12 or IFN- $\gamma$ neutralizing antibodies [1-6].

IL-12 is produced mainly by antigen-presenting cells and acts to connect the innate and acquired immunities by inducing differentiation of antigen-specific T-cells of Th1 phenotype and the release of IFN- $\gamma$ from activated T-cells and NK cells [7-10]. IFN$\gamma$ is produced by T-cells and considered to play an important role in activating macrophages, the ultimate effector cells in host defense against intracellular infection $[11,12]$. Studies have reported that macrophages can be competent cells regarding the ability to respond to IL-12, which has led to the notion that this cytokine can induce macrophage activation through an autocrine pathway $[15,16]$. It has been shown that macrophages express $\beta 1$ and $\beta 2$ chains from the IL-12 receptor (IL-12R) [16]. IL-12 has also been involved in programming the macrophage response to lipopolysaccharide (LPS) by up-regulating the production of TNF- $\alpha$ [17].

In this study, we investigated the effects of IL-12 on the bacterial killing capacity of macrophages with intracellular $S$. aureus, and presented evidence to support the antibacterial activity of IL-12 against intracellular S. aureus. The findings will extend our understanding of the effects of IL-12 on macrophages and may offer insights into an immunotherapeutic approach to control chronic and recurrent $S$. aureus infection. 


\section{Materials and Methods}

Reagents

Tryptic soy agar (TSA, w/5\% sheep blood) plates, tryptic soy broth (TSB), phosphate buffered saline (PBS), fetal bovine serum (FBS), 45\% glucose solution, 7.5\% sodium bicarbonate, sodium pyruvate, and Tris-buffer were all obtained from Fisher Scientific (Pittsburgh, PA). RPMI-1640 media were purchased from LONZA (Walkersville, MD). $100 \mathrm{U} / \mathrm{mL}$ penicillin/100 mg/mL streptomycin solution, rat IL-12 p70 ELISA kit, rat IFN- $\gamma$ ELISA kit, and recombinant rat IL-12 (IL-12) were from Invitrogen (Carlsbad, CA). Gentamicin, Triton X-100, lysostaphin, and ammonium chloride were obtained from Sigma (St. Louis, MO). Dichlorofluorescin diacetate $\left(\mathrm{H}_{2}\right.$ DCF-DA) was from Life Technologies (Grand Island, NY). Rat anti-IL-12 antibody was purchased from R \& D Systems (Minneapolis, MN).

\section{IL-12 bioactivity}

The bioactivity of recombinant rat IL-12 used in this study was assessed based on the ability of IL-12 to induce secretion of IFN- $\gamma$ by macrophages. In brief, splenic macrophages of $(0.5-1) \times 10^{7}$ cells $/ \mathrm{mL}$ were cultured in a 96 -well plate (Fisher Scientific, Pittsburgh, PA) in RPMI-1640 supplemented with different doses $(0,1,10,100$, and $1000 \mathrm{pg} / \mathrm{mL}$ ) of recombinant rat $\mathrm{IL}-12$ at $37^{\circ} \mathrm{C}$ in a $5 \% \mathrm{CO}_{2}$ incubator. After $48 \mathrm{~h}$ of culturing, the supernatant was collected for IFN- $\gamma$ analysis using enzyme-linked immunosorbent assay (ELISA) by measuring the optical density at $450 \mathrm{~nm}$ following the manufacturer's guidelines. IFN- $\gamma$ levels were determined by comparison with a standard curve. The results were expressed as mean $\pm \mathrm{SE}$ and are presented in Figure 1, which shows that the recombinant rat IL-12 studied was bioactive. 


\section{Bacterial culture}

S. aureus (ATCC 25923) obtained from the American Type Culture Collection (ATCC, Manassas, VA). A fresh inoculum was prepared by suspending 5 colonies of $S$. aureus, grown on a blood agar plate, in $5 \mathrm{~mL}$ TSB and incubating at $37^{\circ} \mathrm{C}$ for $18 \mathrm{~h}$. After incubation, the $S$. aureus inoculum was centrifuged at $3750 \mathrm{rpm}$ for $15 \mathrm{~min}$ at $4^{\circ} \mathrm{C}$ and washed once with $10 \mathrm{~mL}$ PBS to obtain $(6-8) \times 10^{8}$ colony forming units $/ \mathrm{mL}$ or CFU/mL. The bacteria pellet was then re-suspended in RPMI-1640 medium free from streptomycin/penicillin and FBS.

\section{Splenic macrophage isolation and culture}

Splenic macrophages were obtained as described in (Figure 2). Spleens were obtained from healthy adult Sprague Dawley rats, and cut into small pieces in a petri-dish, and minced between the frosted ends of microscopic slides. The splenocyte suspension was filtered through a $70 \mu \mathrm{m}$ nylon cell strainer (Fisher Scientific), and centrifuged at $2500 \mathrm{rpm}$ at $4^{\circ} \mathrm{C}$ for $5 \mathrm{~min}$. The supernatant was subsequently aspirated and the red blood cells were lysed with a $5 \mathrm{~mL}$ lysis buffer containing $0.17 \mathrm{M}$ tris-buffer and $0.16 \mathrm{M}$ ammonium chloride for $10 \mathrm{~min}$. The lysis process was stopped by adding RPMI-1640 media supplemented with penicillin/streptomycin, FBS, glucose, sodium bicarbonate, and sodium pyruvate (this will be referred to as complete media). The splenocyte suspension was then centrifuged again at $2500 \mathrm{rpm}$ at $4^{\circ} \mathrm{C}$ for $5 \mathrm{~min}$ followed by aspiration of the supernatant. The splenocyte pellet was washed once with complete RPMI-1640 media by

centrifugation then re-suspended in complete RPMI-1640 media to obtain $(0.5-1) \times 10^{7}$ cells/mL. Cell viability was determined by trypan-blue exclusion assay. Splenocytes were 
seeded in 48-well plate (Fisher Scientific) for $4 \mathrm{~h}$ and non-adherent cells (mainly B and T-cells) were washed twice with PBS and adherent cells (primarily macrophages, and referred to as splenic macrophages here) were further cultured in complete RPMI-1640 media and incubated in a $5 \% \mathrm{CO}_{2}$ incubator at $37^{\circ} \mathrm{C}$ for $48 \mathrm{~h}$.
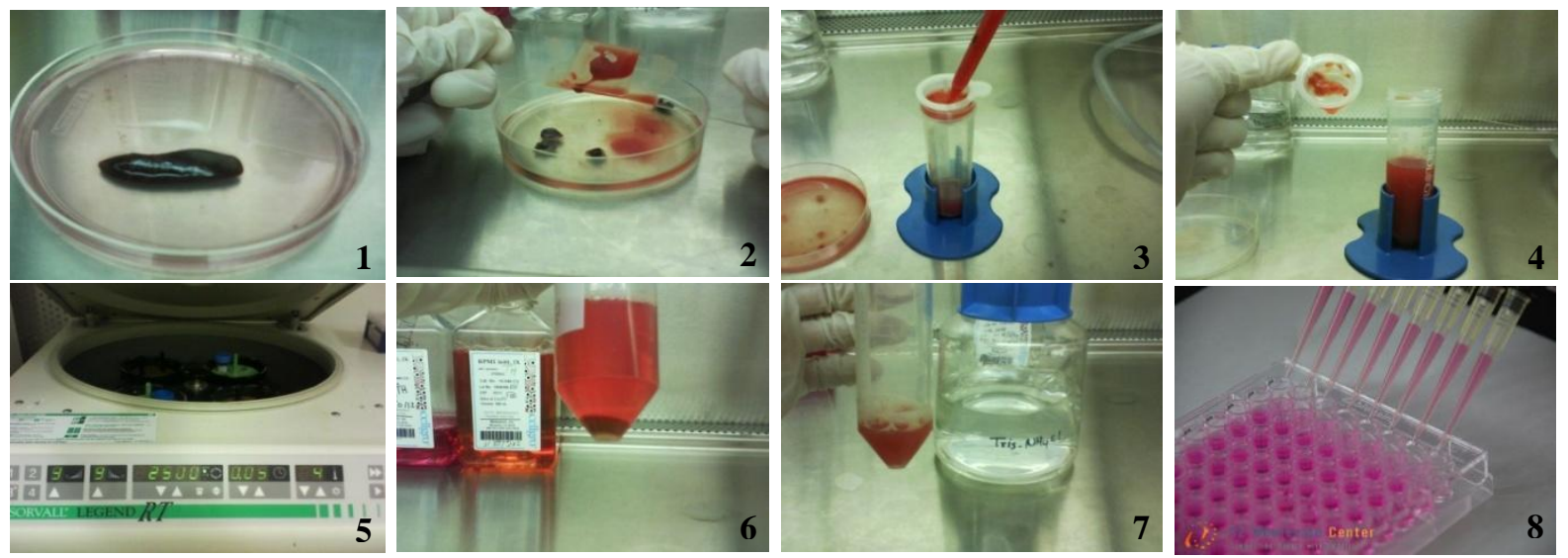

Figure 2. Steps for isolating splenic macrophages. (I) Rat spleens were collected in RPMI-1640 complete media. (II) Spleens were cut into small pieces in petri-dish and minced between the frosted ends of microscope glass slides to make a single cell suspension. (III) and (IV) The cell suspension was filtered through a $70 \mu \mathrm{m}$ cell strainer. (V) Cells were collected by centrifugation at $2500 \mathrm{rpm}$ and $4{ }^{\circ} \mathrm{C}$ for $5 \mathrm{~min}$. (VI) Cell pellet was washed once with RPMI-1640 complete media and the pellet was obtained by centrifugation. (VII) Red blood cells in the cell pellet were lysed with Tris-ammonium chloride for 10 min and the lysis step was stopped by adding RPMI-1640 complete media. (VIII) Cells were re-suspended in RPMI-1640 complete media for further culture.

\section{Splenic macrophage infection and IL-12 treatment}

Splenic macrophages of $(0.5-1) \times 10^{7}$ cells $/ \mathrm{mL}$ were washed 3 times with PBS, cultured with S. aureus at a multiplicity of infection (MOI) of 10:1 for $2 \mathrm{~h}$, washed, and incubated with gentamicin $(100 \mu \mathrm{g} / \mathrm{mL})$ for $2 \mathrm{~h}$. The infected splenic macrophages were first treated with different doses of recombinant rat IL-12 $(0,0.25,2.5,25,250$, and 2500 
$\mathrm{pg} / \mathrm{mL}$ ) in RPMI-1640 media supplemented with $5 \mu \mathrm{g} / \mathrm{mL}$ lysostaphin and 5\% FBS for $24 \mathrm{~h}$. The splenic macrophages were washed and lysed to determine the number of live intracellular S. aureus by plating the lysates on blood agar plates. Next, the infected splenic macrophages were treated with $250 \mathrm{pg} / \mathrm{mL}$ of IL-12 for different time periods $(0$, $12,24,36$, and 48 h). The cell culture supernatants were collected for IFN- $\gamma$ and IL-12 quantification using ELISA kits following the manufacturer's guidelines; duplicates were collected for each sample. The splenic macrophages were washed and lysed to determine the number of live intracellular $S$. aureus. Data were presented as mean $\pm \mathrm{SE}$ from at least 3 different trials.

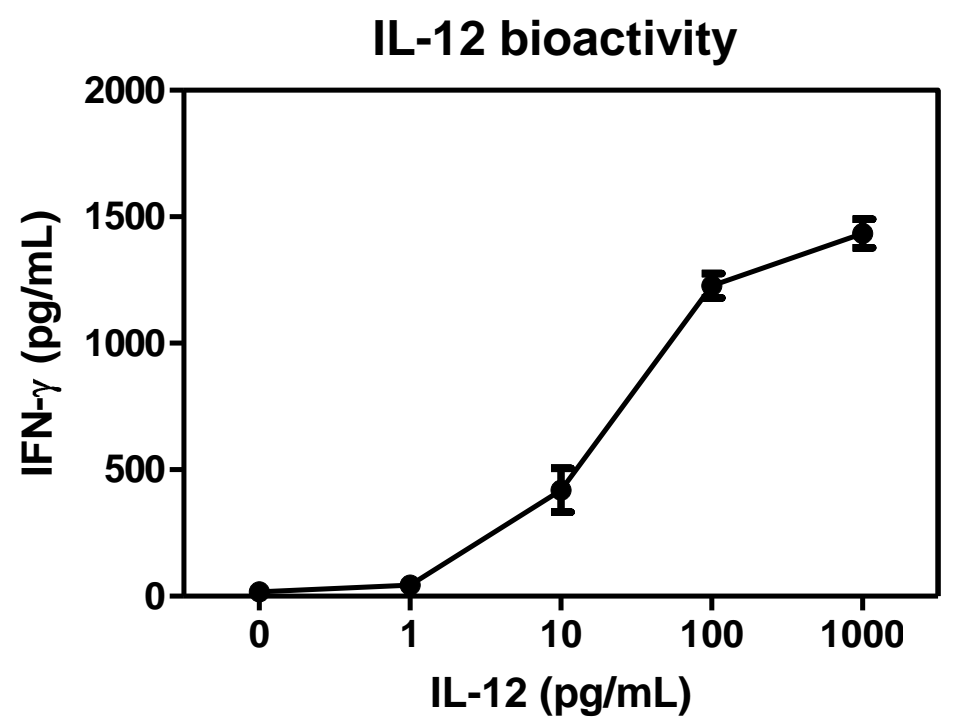

Figure 1. Quantitative measurement of bioactivity of IL-12 studied.

\section{IL-12 action specificity}

In order to further confirm the role of IL-12 treatment on infected splenic macrophages, IL-12 was pre-treated with anti-IL-12 antibody and then added to infected 
splenic macrophages. As described in Chart 1 , splenic macrophages of $(0.5-1) \times 10^{7}$ cells/mL were cultured, infected at an MOI of 10:1 for $2 \mathrm{~h}$, incubated with gentamicin, and washed. IL-12 of $250 \mathrm{pg} / \mathrm{mL}$ was neutralized with $0.1 \mu \mathrm{g} / \mathrm{mL}$ rat anti-IL-12 antibody for $1 \mathrm{~h}$ at $37^{\circ} \mathrm{C}$, and subsequently added to infected splenic macrophages and incubated for $24 \mathrm{~h}$. For comparison, infected splenic macrophages were also treated with or without IL-12 of $250 \mathrm{pg} / \mathrm{mL}$ for $24 \mathrm{~h}$. The cell culture supernatants were collected to determine IFN- $\gamma$ levels using an ELISA kit; duplicates were collected for each sample. The infected splenic macrophages were washed with PBS and lysed to determine the number of intracellular S. aureus.

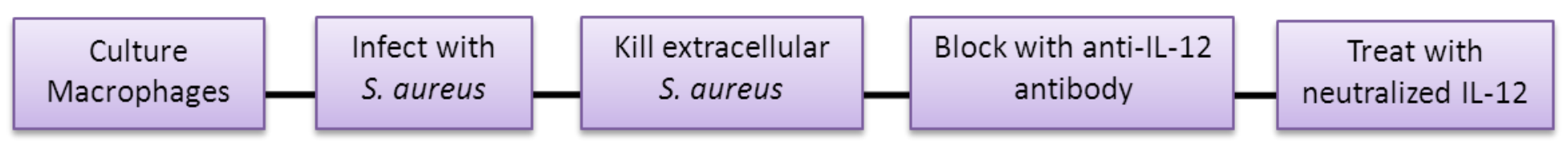

Chart 1. A flowchart for testing IL-12 specificity by adding anti-IL-12 antibody $(0.1$ $\mu \mathrm{g} / \mathrm{mL})$ to neutralize IL-12 (250 pg/mL) biological activity for $1 \mathrm{~h}$ at $37^{\circ} \mathrm{C}$.

\section{Reactive oxygen species detection}

Infected or non-infected splenic macrophages of $(0.5-1) \times 10^{7}$ cells $/ \mathrm{mL}$ were treated either with or without recombinant rat IL-12. At post-infection time 0 and $24 \mathrm{~h}$, cells were washed once with PBS and incubated with $\mathrm{H}_{2}$ DCF-DA at $37^{\circ} \mathrm{C}$ for $1 \mathrm{~h}$ in the dark. The fluorescence intensity was measured using a fluorescent microplate reader (BioTek Instrument, Inc., Winooski, VT) at $492 \mathrm{~nm} / 520 \mathrm{~nm}$ for 2',7'-dichlorofluorescein (DCF), converted intracellularly from $\mathrm{H}_{2}$ DCF-DA. The $\mathrm{H}_{2}$ DCF-DA fluorescent probe is 
commonly used to detect reactive oxygen species. Data were average of six samples per treatment.

Statistical analysis

All data were presented as means \pm SE. Statistical significance was set at $p<0.05$. Statistical analysis was performed using GraphPad InStat Version 3.0 (GraphPad Software Inco, La Jolla, CA). 


\section{Results}

Effect of IL-12 treatment on the survival of S. aureus within infected splenic macrophages

The S. aureus CFU within infected splenic macrophages decreased with increasing IL-12 concentration in the range of $0-250 \mathrm{pg} / \mathrm{mL}$, and was significantly lower at IL-12 of 250 and $2500 \mathrm{pg} / \mathrm{mL}$ compared to the control (i.e. without IL-12 treatment) (Figure 3A). The intracellular S. aureus $\mathrm{CFU}$ within infected splenic macrophages that were treated with 250 and $2500 \mathrm{pg} / \mathrm{mL}$ of IL-12 was 18- and 14- fold lower than that of the control, respectively. Meanwhile, the S. aureus CFU splenic macrophages also decreased with increasing treatment time. The $S$. aureus $\mathrm{CFU}$ within splenic macrophages that were treated with $250 \mathrm{pg} / \mathrm{mL}$ of IL-12 was significantly lower at 24 and $36 \mathrm{~h}$ compared to the corresponding controls without IL-12 treatment (Figure 3B).

\section{Optimal dose of IL-12}

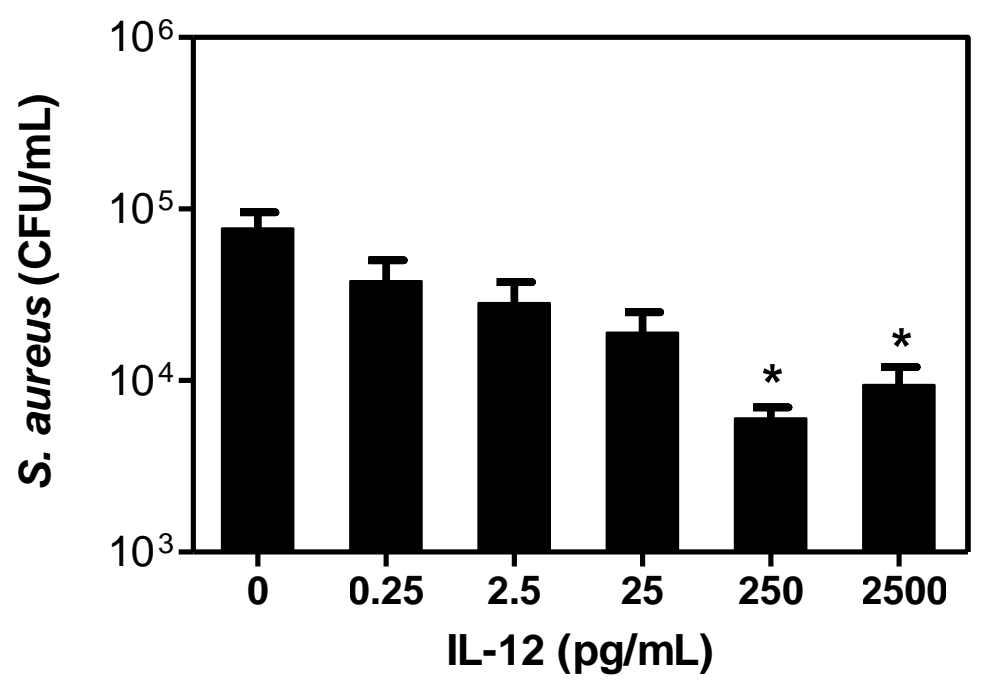

Figure 3 (A). Intracellular $S$. aureus of infected splenic macrophages that were treated with recombinant rat IL-12 at different doses $(0,0.25,2.5,25,250$, and $2500 \mathrm{pg} / \mathrm{mL})$ for $24 \mathrm{~h}$. 
After blocking the activity of IL-12 using anti-IL-12, no significant differences were observed in intracellular $S$. aureus $\mathrm{CFU}$ between infected splenic macrophages without IL-12 treatment and splenic macrophages treated with antibody pre-treated IL-12 (Figure 3C).

\section{Time course for IL-12 activity}

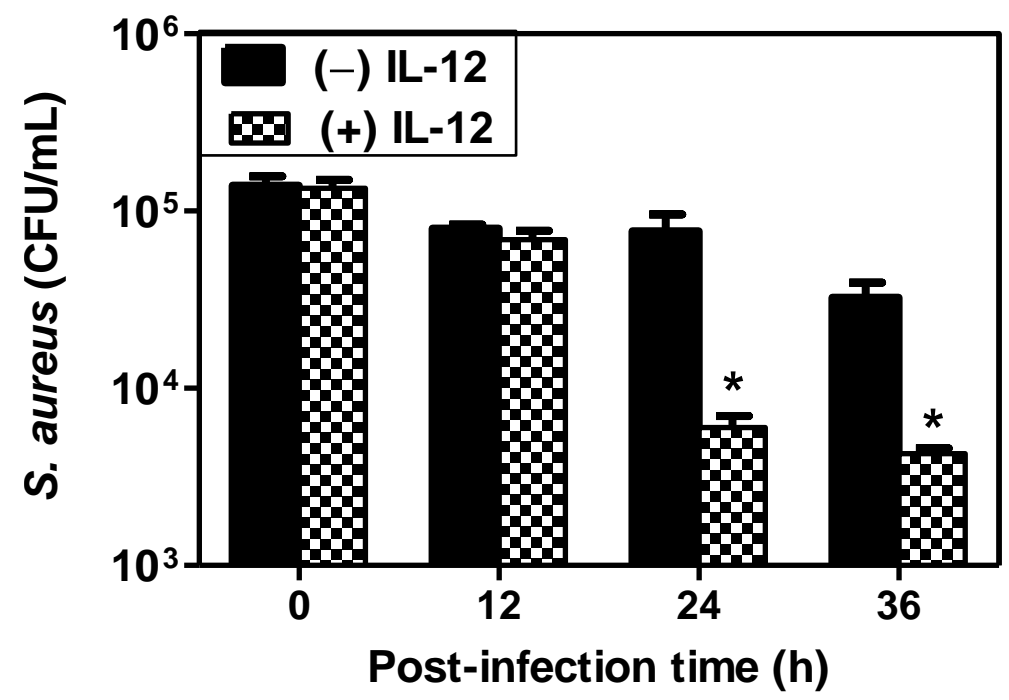

Figure 3 (B). Intracellular S. aureus of infected splenic macrophages that were treated with or without recombinant rat IL-12 of $250 \mathrm{pg} / \mathrm{mL}$ for different time periods $(0,12,24$, and $36 \mathrm{~h}$ ).

\section{Effect of IL-12 treatment on cytokine production in infected splenic macrophages}

Compared to cells without IL-12 treatment, infected splenic macrophages treated with IL-12 had significantly higher IL-12 production at the post-infection times (i.e. 12, 24, 36, and 48 h) studied (Figure 4A). Similarly, a significant increase in IFN- $\gamma$ production was observed at the time periods investigated in IL-12 treated infected splenic macrophages compared to the controls without IL-12 treatment (Figure 4B). At post- 
infection $24 \mathrm{~h}$, the IL-12 levels in the IL-12 treated cells and the controls were approximately 427 and $324 \mathrm{pg} / \mathrm{mL}$, respectively, and the IFN- $\gamma$ levels in the IL-12 treated cells and the controls were approximately 810 and $130 \mathrm{pg} / \mathrm{mL}$, respectively.

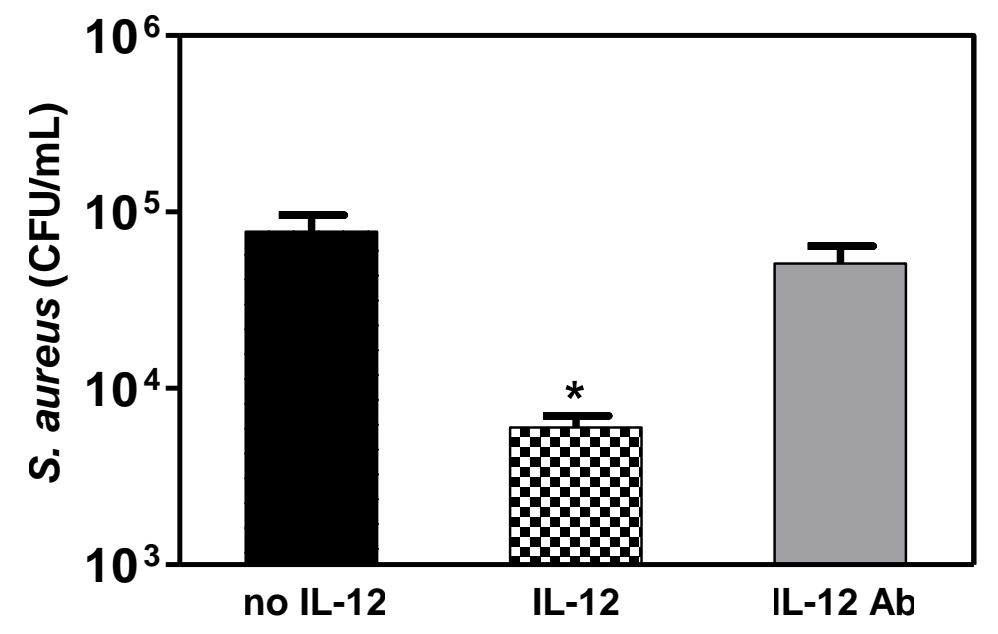

Figure $3(\mathbf{C})$. Comparison of intracellular $S$. aureus among infected splenic macrophages treated with IL-12 $(250 \mathrm{pg} / \mathrm{mL})$, IL-12 $(250 \mathrm{pg} / \mathrm{mL})$ that was pre-treated with the anti-IL12 antibody, and without IL-12 for $24 \mathrm{~h}$.

After blocking the activity of IL-12 using the anti-IL-12 antibody, no significant differences were observed in IFN- $\gamma$ levels between infected splenic macrophages without IL-12 treatment and splenic macrophages treated with anti-IL-12 antibody pre-treated IL12 (Figure 4C). 


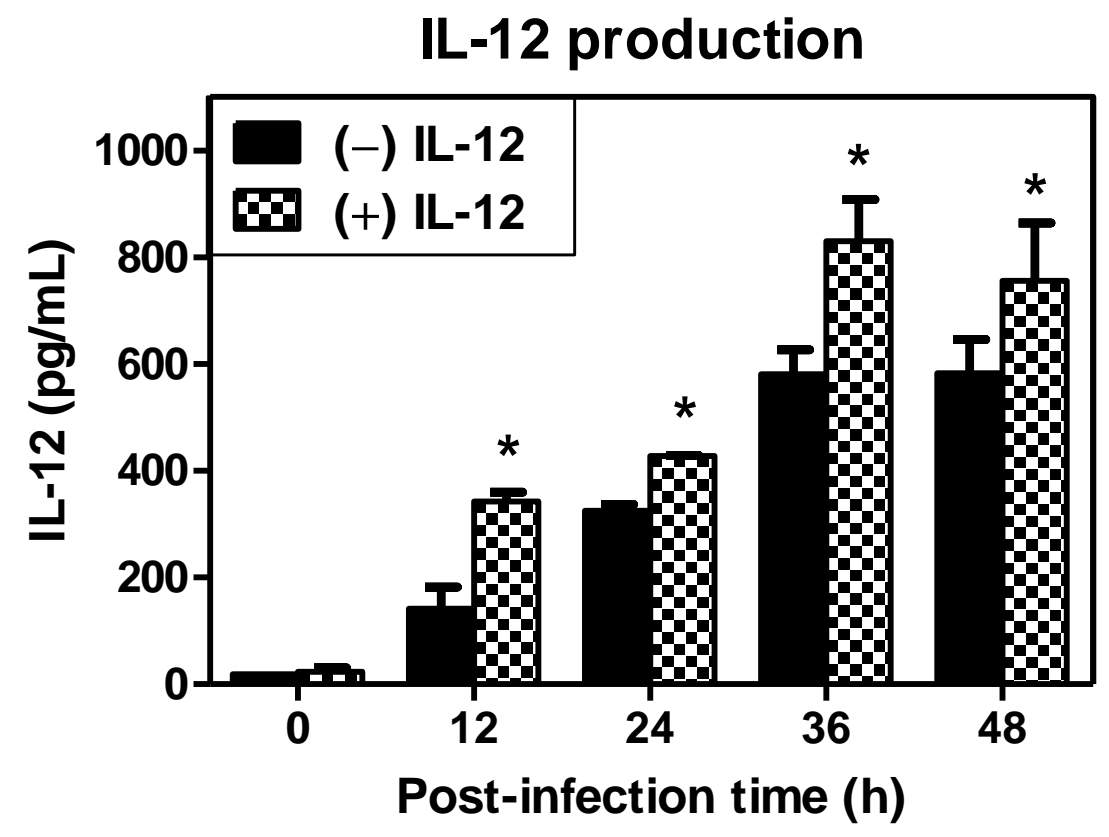

Figure 4 (A). IL-12 levels of infected splenic macrophages treated with or without IL-12 of $250 \mathrm{pg} / \mathrm{mL}$ for different time periods

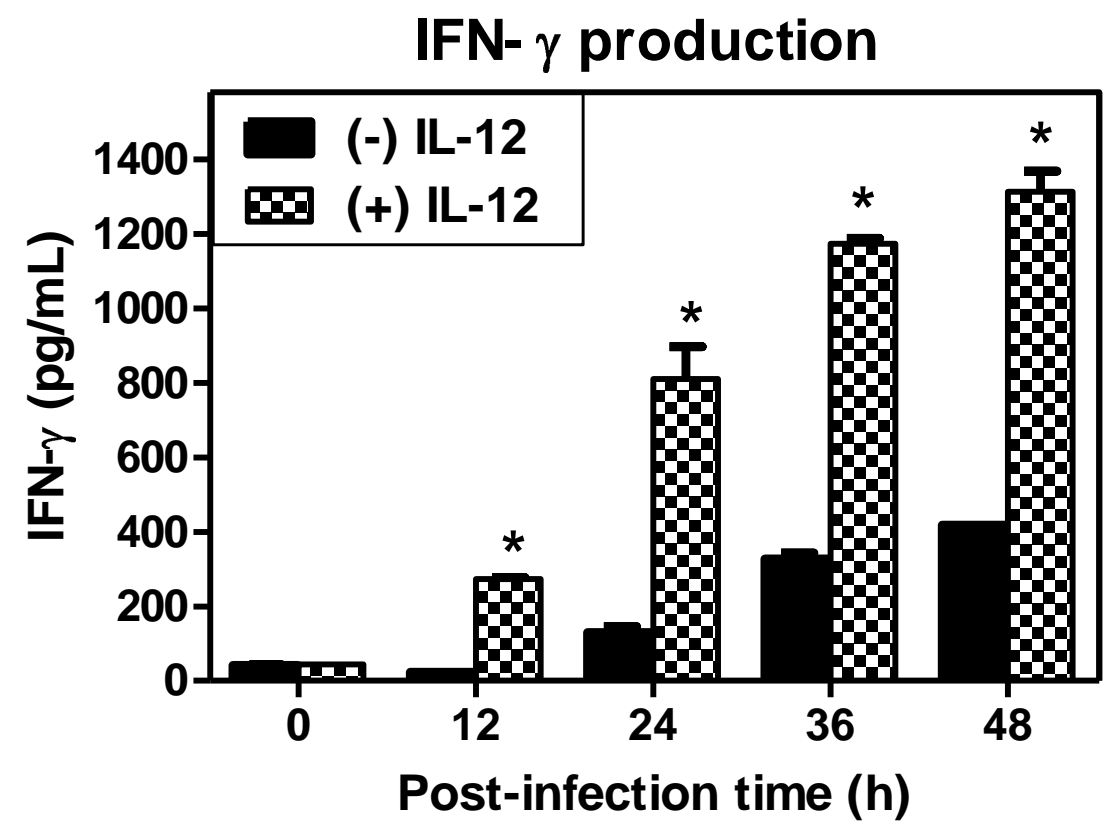

Figure 4 (B). IFN- $\gamma$ levels of infected splenic macrophages treated with or without IL-12 of $250 \mathrm{pg} / \mathrm{mL}$ for different time periods. 


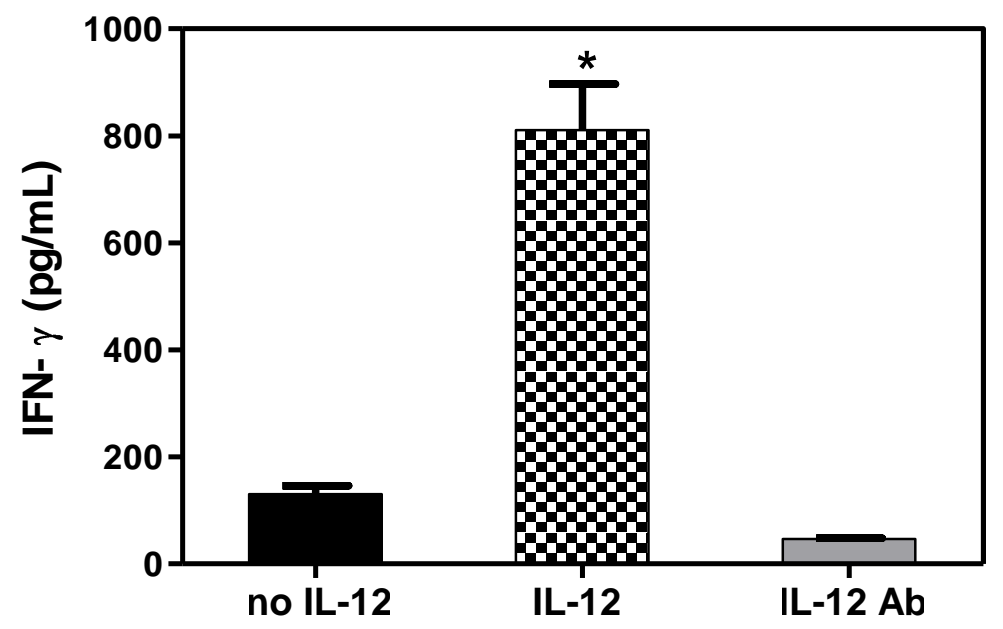

Figure 4 (C). Comparison of IFN- $\gamma$ levels among infected splenic macrophages treated with IL-12 $(250 \mathrm{pg} / \mathrm{mL}), \mathrm{IL}-12(250 \mathrm{pg} / \mathrm{mL})$ that was pre-treated with the anti-IL-12 antibody, and without IL-12 for $24 \mathrm{~h}$.

Effect of IL-12 treatment on reactive oxygen species production in splenic macrophages

No significant differences in DCF levels were detected between IL-12 treated and un-treated splenic macrophages at post-infection time 0 and $24 \mathrm{~h}$ (Figure 5).

\section{Effect of IL-12 treatment on ROS production}

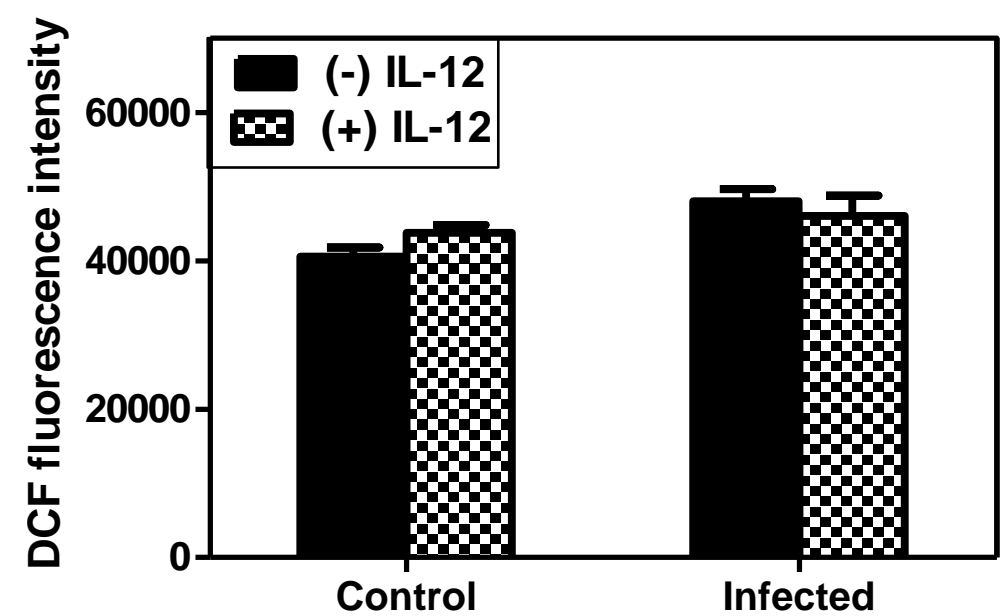

Figure 5. DCF levels of infected and non-infected splenic macrophages that were treated with or without IL-12 of $250 \mathrm{pg} / \mathrm{mL}$ for $24 \mathrm{~h}$. 


\section{Discussion}

Killing of intracellular S. aureus may be critical for effective therapies to treat and prevent chronic and recurrent Staphylococcal infections. In vivo, the control of intracellular pathogens depends on the activation of Th1 immune responses, suggesting a key role for macrophages. The importance of IL-12 production and subsequent IFN- $\gamma$ secretion to control intracellular bacteria has been demonstrated in multiple studies $[4,6$, $19,20]$. However, few studies to date have examined the activity of IL-12 on macrophage killing activity in vitro. Herein, we used an in vitro infection model of intracellular $S$. aureus to examine the effect of IL-12 on the killing activity of splenic macrophages against intracellular S. aureus.

We found that the intracellular killing activity of macrophages was enhanced with IL-12 treatment, since the intracellular S. aureus CFU decreased with increasing IL-12 doses. Compared to the control without IL-12 treatment, significant differences were observed at 250 and $2500 \mathrm{pg} / \mathrm{mL}$ (Figure 3A); and the best effective time span was found to be between post-infection 24-36 h (Figure 3B). The enhancement of macrophage killing activity by IL-12 treatment was further confirmed by neutralizing IL-12 with an antibody specific to rat IL-12 where no significant differences were observed between macrophages treated with and without IL-12 neutralized with anti-IL-12 antibody (Figure 3C). This finding was consistent with the observation that animals challenged with bacteria and subsequently receiving treatment with anti-IL-12 antibody presented more severe disease symptoms [4, 18]. Similarly, neutralizing IL-12 using the anti-IL-12 antibody increased morbidity in virus-infected mice compared with un-treated animals [24]. By contrast, exogenous IL-12 was able to induce the activities of dendritic cells and 
cytotoxic T-cells against influenza virus infection when patients' own antiviral immune responses were poor $[27,26]$. Exogenous IL-12 also rescued mice that were challenged with a lethal dose of encephalomyocarditis virus through IFN- $\gamma$-mediated responses [25]. As a result, Orange and Coutelier suggested that low doses of IL-12 combined with dendritic cells may be used as a potential immunotherapeutic approach against viral infections $[28,29]$.

We further found that the enhancement of macrophage killing activity was associated with the production of IL-12 and IFN- $\gamma$. Significantly higher levels of IL-12 and IFN- $\gamma$ were detected in infected macrophages treated with IL-12 compared to controls without IL-12 treatment (Figures 4A and 4B) while no significant differences were observed in IFN- $\gamma$ levels between macrophages treated with and without IL-12 that was neutralized with anti-IL-12 antibody (Figure 4C). It was clear that exogenous IL-12 treatment resulted in significantly higher production of IFN- $\gamma$ and IL-12 within infected macrophages, which may reflect the notion that IL-12 could induce macrophage activation through an autocrine pathway $[15,16]$. Both IL-12 and IFN- $\gamma$ were previously found to be required for activating immune cells like macrophages during parasitic infections, such as Leishmania major [30], by inducing Th1 differentiation and activating macrophages to produce nitrogen oxide [31-33]. IL-12 also plays a critical role during the early stages of viral infection by inducing NK cell cytotoxicity and IFN- $\gamma$ production, which leads to improved antimicrobial activity of phagocytic cells [27, 34-36].

Oxidative burst is one of the defense mechanisms used against pathogens, and macrophages activated by IFN- $\gamma$ were found to have increased release of nitric oxide (NO) and reactive oxygen species (ROS) and enhanced bactericidal activities [13, 14]. 
However, some bacteria such as Brucella, Salmonella, and Shigella can avoid inducing oxidative burst when they encounter host cells $(21,22)$, and some bacteria like $S$. aureus may express enzymes that can scavenge ROS species including $\mathrm{O}_{2}^{-}$(23). In this study, no significant differences in ROS levels were observed between macrophages treated with and without IL-12 at post-infection time 0 and $24 \mathrm{~h}$ (Figure 5). This observation may suggest an alternative killing activity than oxidative burst.

\section{Conclusions}

In this study, we examined the effect of IL-12 treatment on macrophage killing activity in vitro by assessing the viable intracellular bacteria and cytokine as well as reactive oxygen species production in infected splenic macrophages. We found that IL-12 treatment could significantly enhance the in vitro killing activity of macrophages and the

enhancement was dose and time dependent. Moreover, IL-12 treatment led to a significant increase in IFN- $\gamma$ and IL-12 production with no significant changes in ROS production in infected macrophages compared to cells without IL-12 treatment. The enhancement of macrophage killing activity by IL-12 was abolished when IL-12 was pretreated with the anti-IL-12 antibody. 


\section{References}

[1] Tripp CS, Wolf SF, Unanue ER. Interleukin 12 and tumor necrosis factor alpha are costimulators of interferon gamma production by natural killer cells in severe combined immunodeficiency mice with listeriosis, and interleukin 10 is a physiologic antagonist. Proc Natl Acad Sci U S A. 1993 Apr 15;90(8):3725-9.

[2] Zhan Y, Cheers C. Endogenous interleukin-12 is involved in resistance to Brucella abortus infection. Infect Immun. 1995 Apr;63(4):1387-90.

[3] Flynn JL, Goldstein MM, Triebold KJ, Sypek J, Wolf S, Bloom BR. IL-12 increases resistance of BALB/c mice to Mycobacterium tuberculosis infection. $\mathrm{J}$ Immunol. 1995 Sep 1;155(5):2515-24.

[4] Kincy-Cain T, Clements JD, Bost KL. Endogenous and exogenous interleukin-12 augment the protective immune response in mice orally challenged with Salmonella dublin. Infect Immun. 1996 Apr;64(4):1437-40.

[5] Mastroeni P, Harrison JA, Robinson JH, Clare S, Khan S, Maskell DJ, Dougan G, Hormaeche CE. Interleukin-12 is required for control of the growth of attenuated aromatic-compound-dependent salmonellae in $\mathrm{BALB} / \mathrm{c}$ mice: role of gamma interferon and macrophage activation. Infect Immun. 1998 Oct;66(10):4767-76.

[6] Beekhuizen H, van de Gevel JS. Gamma interferon confers resistance to infection with Staphylococcus aureus in human vascular endothelial cells by cooperative proinflammatory and enhanced intrinsic antibacterial activities. Infect Immun. 2007 Dec;75(12):5615-26. Epub 2007 Sep 24.

[7] Flesch IE, Hess JH, Huang S, Aguet M, Rothe J, Bluethmann H, Kaufmann SH. Early interleukin 12 production by macrophages in response to mycobacterial infection depends on interferon gamma and tumor necrosis factor alpha. J Exp Med. 1995 May 1;181(5):1615-21.

[8] Trinchieri G. Interleukin-12: a proinflammatory cytokine with immunoregulatory functions that bridge innate resistance and antigen-specific adaptive immunity. Annu Rev Immunol. 1995;13:251-76.

[9] Okamura H, Kashiwamura S, Tsutsui H, Yoshimoto T, Nakanishi K. Regulation of interferon-gamma production by IL-12 and IL-18. Curr Opin Immunol. 1998 Jun;10(3):259-64.

[10] Doherty TM, Sher A. IL-12 promotes drug-induced clearance of Mycobacterium avium infection in mice. J Immunol. 1998 Jun 1;160(11):5428-35.

[11] Orme IM, Roberts AD, Griffin JP, Abrams JS. Cytokine secretion by CD4 T lymphocytes acquired in response to Mycobacterium tuberculosis infection. $\mathrm{J}$ Immunol. $1993 \mathrm{Jul}$ 1;151(1):518-25.

[12] Jouanguy E, Döffinger R, Dupuis S, Pallier A, Altare F, Casanova JL. IL-12 and IFN-gamma in host defense against mycobacteria and salmonella in mice and men. Curr Opin Immunol. 1999 Jun;11(3):346-51. 
[13] Scharton-Kersten TM, Yap G, Magram J, Sher A. Inducible nitric oxide is essential for host control of persistent but not acute infection with the intracellular pathogen Toxoplasma gondii. J Exp Med. 1997 Apr 7;185(7):1261-73.

[14] Ouadrhiri Y, Sibille Y, Tulkens PM. Modulation of intracellular growth of Listeria monocytogenes in human enterocyte Caco-2 cells by interferon-gamma and interleukin-6: role of nitric oxide and cooperation with antibiotics. J Infect Dis. 1999 Oct; 180(4):1195-204.

[15] Magram J, Connaughton SE, Warrier RR, Carvajal DM, Wu CY, Ferrante J, Stewart C, Sarmiento U, Faherty DA, Gately MK. IL-12-deficient mice are defective in IFN gamma production and type 1 cytokine responses. Immunity. 1996 May;4(5):471-81.

[16] Bramson J, Hitt M, Gallichan WS, Rosenthal KL, Gauldie J, Graham FL. Construction of a double recombinant adenovirus vector expressing a heterodimeric cytokine: in vitro and in vivo production of biologically active interleukin-12. Hum Gene Ther. 1996 Feb 10;7(3):333-42.

[17] Shnyra A, Brewington R, Alipio A, Amura C, Morrison DC. Reprogramming of lipopolysaccharide-primed macrophages is controlled by a counterbalanced production of IL-10 and IL-12. J Immunol. 1998 Apr 15;160(8):3729-36.

[18] Hultgren OH, Stenson M, Tarkowski A. Role of IL-12 in Staphylococcus aureustriggered arthritis and sepsis. Arthritis Res. 2001;3(1):41-7. Epub 2000 Nov 3.

[19] Gordon MA, Jack DL, Dockrell DH, Lee ME, Read RC. Gamma interferon enhances internalization and early nonoxidative killing of Salmonella enterica serovar Typhimurium by human macrophages and modifies cytokine responses. Infect Immun. 2005 Jun;73(6):3445-52.

[20] Xing Z, Zganiacz A, Santosuosso M. Role of IL-12 in macrophage activation during intracellular infection: IL-12 and mycobacteria synergistically release TNF-alpha and nitric oxide from macrophages via IFN-gamma induction. J Leukoc Biol. 2000 Dec;68(6):897-902.

[21] Rittig MG, Alvarez-Martinez MT, Porte F, Liautard JP, Rouot B. Intracellular survival of Brucella spp. in human monocytes involves conventional uptake but special phagosomes. Infect Immun. 2001 Jun;69(6):3995-4006.

[22] Thi EP, Lambertz U, Reiner NE. Sleeping with the enemy: how intracellular pathogens cope with a macrophage lifestyle. PLoS Pathog. 2012;8(3):e1002551. doi: 10.1371/journal.ppat.1002551. Epub 2012 Mar 22.

[23] Karavolos MH, Horsburgh MJ, Ingham E, Foster SJ. Role and regulation of the superoxide dismutases of Staphylococcus aureus. Microbiology. 2003 Oct;149(Pt 10):2749-58.

[24] Orange JS, Biron CA. Characterization of early IL-12, IFN-alphabeta, and TNF effects on antiviral state and NK cell responses during murine cytomegalovirus infection. J Immunol. 1996 Jun 15;156(12):4746-56. 
[25] Ozmen L, Aguet M, Trinchieri G, Garotta G. The in vivo antiviral activity of interleukin-12 is mediated by gamma interferon. J Virol. 1995 Dec;69(12):814750.

[26] Bhardwaj N, Seder RA, Reddy A, Feldman MV. IL-12 in conjunction with dendritic cells enhances antiviral CD8+ CTL responses in vitro. J Clin Invest. 1996 Aug 1;98(3):715-22.

[27] Carr JA, Rogerson J, Mulqueen MJ, Roberts NA, Booth RF.Interleukin-12 exhibits potent antiviral activity in experimental herpesvirus infections. J Virol. 1997 Oct;71(10):7799-803.

[28] Orange JS, Wolf SF, Biron CA. Effects of IL-12 on the response and susceptibility to experimental viral infections. J Immunol. 1994 Feb 1;152(3):1253-64.

[29] Coutelier JP, Van Broeck J, Wolf SF. Interleukin-12 gene expression after viral infection in the mouse. J Virol. 1995 Mar;69(3):1955-8.

[30] Ota H, Takashima Y, Matsumoto Y, Hayashi Y, Matsumoto Y. Pretreatment of macrophages with the combination of IFN-gamma and IL-12 induces resistance to Leishmania major at the early phase of infection. J Vet Med Sci. 2008 Jun;70(6):589-93.

[31] Afonso LC, Scharton TM, Vieira LQ, Wysocka M, Trinchieri G, Scott P. The adjuvant effect of interleukin-12 in a vaccine against Leishmania major. Science. 1994 Jan 14;263(5144):235-7.

[32] Green SJ, Nacy CA, Meltzer MS. Cytokine-induced synthesis of nitrogen oxides in macrophages: a protective host response to Leishmania and other intracellular pathogens. J Leukoc Biol. 1991 Jul;50(1):93-103.

[33] Di Marzio P, Puddu P, Conti L, Belardelli F, Gessani S. Interferon gamma upregulates its own gene expression in mouse peritoneal macrophages. J Exp Med. 1994 May 1;179(5):1731-6.

[34] Scharton TM, Scott P. Natural killer cells are a source of interferon gamma that drives differentiation of $\mathrm{CD} 4+\mathrm{T}$-cell subsets and induces early resistance to Leishmania major in mice. J Exp Med. 1993 Aug 1;178(2):567-77.

[35] Chehimi J, Valiante NM, D'Andrea A, Rengaraju M, Rosado Z, Kobayashi M, Perussia B, Wolf SF, Starr SE, Trinchieri G. Enhancing effect of natural killer cell stimulatory factor (NKSF/interleukin-12) on cell-mediated cytotoxicity against tumor-derived and virus-infected cells. Eur J Immunol. 1993 Aug;23(8):1826-30.

[36] Chan SH, Perussia B, Gupta JW, Kobayashi M, Pospísil M, Young HA, Wolf SF, Young D, Clark SC, Trinchieri G. Induction of interferon gamma production by natural killer cell stimulatory factor: characterization of the responder cells and synergy with other inducers. J Exp Med. 1991 Apr 1;173(4):869-79. 


\section{CHAPTER 5}

\section{General Discussion}

Although S. aureus has been primarily considered an extracellular pathogen, it is now clear that it can be internalized by both phagocytes and non-phagocytic cells. Intracellular S. aureus is considered to play an important role in their persistence (host defenses evasion) and recurrence (antibiotic failure) of infection.

The goal of my dissertation was to understand the invasion of $S$. aureus in macrophages and osteoblasts and to explore potential prophylactic and therapeutic interventions. The in vitro infection models demonstrate direct evidence for the ability of S. aureus to be internalized by both phagocytic and non-phagocytic cells. Osteoblasts are the most important cells for bone formation; therefore, any damage occurring to these cells may result in disrupted bone homeostasis. Macrophages, on the other hand, are important immune cells against invading pathogens and need to be fully efficient in clearing bacteria in a short period of time. Our data have shown that S. aureus could survive for several days within osteoblasts and macrophages, in the presence of antibiotics. This time may be sufficient to induce phenotypic and genotypic changes in the intracellular S. aureus which may make it harder to clear.

The success of the in vitro infection models has led us to examine the potential that intracellular S. aureus alone could induce infection in an animal model. By inoculating $S$. aureus infected osteoblasts, we found that intracellular $S$. aureus inoculation of as low as $10^{2}$ CFUs could induce severe bone infections in an open femur fracture rat model. 
The role of IL-12 in intracellular pathogens' clearance can be multifaceted. It is well established that IL-12 stimulates IFN- $\gamma$ in T-cells and NK cells. Also, IL-12 induces CD4 Th cell differentiation toward a Th1 subset, and could have indirect, but more widespread, effects within bone tissue. Our data have shown that IL-12 treatment has led to a significant upgrade of IFN- $\gamma$ production by infected macrophages and resulted in significant reduction of intracellular $S$. aureus. As a result, IL-12 may be an innovative therapeutic agent for eliminating intracellular S. aureus surviving within host cells.

\section{Future Studies}

According to the publication report from Web of Knowledge, there are very few publications studying the pathogenesis of $S$. aureus infection in an in vitro co-culture system which involves both osteoblasts and macrophages. Our data from Chapter 4 gives a promising future for IL-12 treatment in the presence of antibiotics to eliminate intracellular S. aureus infection; therefore, studying the effect of IL-12 in a system where both cell types (osteoblasts and macrophages) are present will provide a better model of the actual situation.

Although our in vivo model is the first proof to directly link of the contribution of intracellular S. aureus to cause bone infection; however, antibiotics were dismissed from this model. In any clinical case of implant-associated infection, patients are treated with antibiotics for at least 6 weeks following the surgery. A better model should be designed to introduce antibiotics during the animal infection time to eliminate extracellular $S$. aureus that leaks out from osteoblasts in the first several days. 


\section{CURRICULUM VITA}

\section{Therwa Hamza}

U.S. Citizen

Home Address:

106 Meadowridge Townhomes

Cell phone: (304) 216-5741

Morgantown, WV 26505

E-mail: tharwahamza@hotmail.com
University Address:

Department of Orthopaedics

West Virginia University

1 Medical Drive Center

Morgantown. WV 26506-9196

\section{Education}

West Virginia University, School of Medicine, Morgantown, WV December 2012

PhD Candidate, Pharmaceutical \& Pharmacological Sciences

- Dissertation Project: Infection models of intracellular Staphylococcus aureus and the impact of Interleukin 12 on intracellular Staphylococcus aureus

Committee Members:

- Bingyun Li, PhD (Chair)

- Yon Rojanasakul, PhD

- Patrick Callery, PhD

- Peter Gannett, PhD

- Kathleen Brundage, PhD

University of Jordan, Amman, Jordan

- BS, Medical Analysis
Pharmaceutical \& Pharmacological Sciences Pharmaceutical \& Pharmacological Sciences Pharmaceutical \& Pharmacological Sciences Pharmaceutical \& Pharmacological Sciences Microbiology, Immunology \& Cell Biology

\section{Honors}

Van Liere Research Day (First Place)

This award was granted for Poster Presentation: "Growth of $S$. aureus and osteosarcoma cells in a co-culture environment on common orthopaedic biomaterials". McConda D, Hamza T., Tidwell J., Lindsey B., Morgantown, West Virginia

WVU Doctoral Student Travel Award

This award was granted for Poster Presentation: "Staphylococcus aureus Internalization and Associated Osteoblast Responses". Hamza T., and Li B., at the Orthopaedic Research Society (ORS) Annual Meeting, San Francisco, California 
Van Liere Research Day (Second Place)

This award was granted for Poster Presentation: "Biological responses to intracellular Staphylococcus aureus by macrophages in development of a co-culture model". Amoroso J., Hamza T., and Li B., Morgantown, West Virginia

WVU Doctoral Student Travel Award

This award was granted for Poster Presentation: "Intracellular Staphylococcus aureus infection: In vivo evidence for chronic osteomyelitis disease", Hamza T., Pham, D., Dietz M., Tidwell J., Jones A., Clovis N., Smith S., and Li B., at the Orthopaedic Research Society (ORS) Annual Meeting, Long Beach, California

Van Liere Research Day (Second Place)

2010

This award was granted for Poster Presentation: "Intracellular Staphylococcus aureus and its link with chronic osteomyelitis", Pham, D., Hamza T., Dietz M., Tidwell J., Jones A., Clovis N., Smith S., and Li B., Morgantown, West Virginia

WVNano Research Symposium (First Place) 2009

This award was granted for Poster Presentation: "Cefazolin-embedded polypeptide nanofilms promising for infection prevention: a preliminary study on cell responses". Hamza T., Li H., Ogle H., and Li B., Morgantown, West Virginia

\section{Laboratory Expertise}

Cell Culture: Isolating and culturing mammalian cells (primary and cell lines), and culturing Gram + and Gram - bacterial strains

Immunology: Enzyme-linked immunosorbent assay (ELISA), flow cytometry, immunostaining, and confocal microscopy

Molecular Biology: Western blot, MTT viability assay, DNA proliferation assay, polymerase chain reaction (PCR), and protein purification

\section{Publications}

1. Hamza T, Li B. Staphylococcus aureus internalization and associated osteoblast and macrophage responses. Microbes and Infection (submitted, October 2012)

2. Li H, Hamza T, Li B. In vitro and in vivo antimicrobial properties of platelet-rich plasma. Acta Biomaterialia (in revision)

3. Hamza T, Dietz M, Pham, D, Clovis N, Smith, S, Li B. Intracellular Staphylococcus aureus infection: In vivo evidence for chronic osteomyelitis disease. Journal of Infectious Diseases (submitted, August 2012)

4. McConda D, Hamza T, Lindsey B. Tissue cell adherence and biofilm formation on common orthopaedic biomaterials in a co-culture environment. Journal of Orthopaedic Research (to be submitted in December 2012) 
5. Hamza T, Barnett J, Li B. Interleukin 12 a key immunoregulatory cytokine in infection applications. International Journal of Molecular Science 11;789-806, 2010

\section{Positions}

- Department of Microbiology, Immunology \& Cell Biology, Lab rotation Dr. John Thomas. Role of biofilm in chronic wound infections

- Department of Neurobiology \& Anatomy-Eye Institute, Lab rotation Dr. Maxim Sokolov. Characterization of proteins involved in retinal neurodegenerative diseases

- Department of Orthopaedics, Lab rotation

Dr. Bingyun Li. Antibiotic-eluting nanotechnology coatings for potential prevention of device-associated infections

- Department of Microbiology, Immunology \& Cell Biology, Lab rotation Dr. Slawomir Lukomski. Investigate the role of Scl proteins in Group A Streptococcus pathogenesis

- Mon General Hospital, Volunteer: Pre-Admission Testing and Human Resources, Morgantown, WV

- Al-Essra Hospital Laboratories, Volunteer: Practical experience was gained in sample testing: Hematology, Immunology, Endocrinology, Biochemistry, Microbiology, and Parasitology, Amman, Jordan

- The University of Jordan Hospital Laboratories: A training program in: Out Patient Department (OPD), Blood Bank, Haematology, Histology, Biochemistry, Immunology, Endocrinology, Bacteriology, and Parasitology. Amman, Jordan

\section{Teaching Experience}

- Lecturer: (382) Biomaterials, Chemical Engineering, WVU

- Mentoring: I have mentored many students including undergraduate, graduate, and medical students. My training involved teaching to perform experiments and work independently. Also, I have helped students to write review articles, give seminars, and prepare posters to be presented at national conferences.

- Assisting Orthopaedics and Prosthodontics Residents: I have helped resident fellow to conduct their basic science research related to pathological chronic diseases such as implant-associated biofilm infections and periodontal diseases.

\section{Workshops \& Internships}

USA (West Virginia)

June 2012

- Participant: Drug Discovery \& Therapeutics Retreat. The aim of this workshop was to meet external and internal speakers to learn about drug discovery. 
USA (West Virginia)

October 2011

- Participant: Science: Becoming The Messenger-Division of Science \& Research: This workshop was sponsored by the National Science Foundation and its main goal was to build communication skills between researchers in science and the public audience.

USA (West Virginia)

June 2010

- Participant: Write Winning Grants: The aim of this workshop was to train faculty, post-doctoral fellows, and graduate students how to develop an irresistible fundable idea.

France (Dijon)

June 2010

- Participant: The workshop's aim was to introduce the field of materials bioencapsulation to early-stage researchers. The training program included lectures and lab demonstrations (spray coating \& drying, release profile testing, emulsification, dripping, and extrusion).

China (Xi'an, Shanghai, Suzhou, and Beijing)

August 2008

- Presenter: The tour was funded by a grant from the National Science Foundation (NSF). The objective of this visit was to strengthen and facilitate an ongoing international collaboration in research and education in advanced biomedical devices that was initiated in 2006.

Jordan (Amman)

April 2006

- Participant: Al-Farah Hospital Assisted Reproduction and In Vitro Fertilization (IVF) Laboratories: technical experience was gained in semen assessment, sperm preparation, oocyte collection, embryo culture and embryo transfer, and intracytoplasmic sperm injection (ICSI).

\section{Presentations}

- Hamza T, Li B. Podium Presentation. Intracellular Staphylococcus aureus: Challenges and Strategies. Sixteenth Annual Resident Research Symposium. Morgantown, West Virginia, May 2012.

- Hamza T, Li B. Poster Presentation. Staphylococcus aureus Internalization and Associated Osteoblast Responses. Orthopaedic Research Society (ORS) Annual Meeting. San Francisco, CA, February 2012.

- Hamza T. Podium Presentation. Interleukin 12: Biological Functions and Potential Clinical Applications. School of Pharmacy Research Day 2011. Morgantown, WV, October 2011.

- Hamza T, Li B. Poster Presentation. Osteoimmunology: The Inflammatory Response of Osteoblasts upon Staphylococcus aureus Internalization. Health Sciences Van Liere Memorial Convocation and Research Day, Morgantown, WV, March 2011.

- $\quad$ Hamza T, Pham D, Dietz M, Tidwell J, Jones A, Clovis N, Smith S, Li B. Poster Presentation. Intracellular Staphylococcus aureus infection: In vivo evidence for 
chronic osteomyelitis disease. Orthopaedic Research Society (ORS) Annual Meeting, Long Beach, CA, January 2011.

- Hamza T, Jiang B, Li B. Poster Presentation. A potential strategy of eradicating intracellular bacteria using antibiotic-delivery nanoparticles. WVNano Initiative Research Symposium, Morgantown, WV, April 2010.

- $\quad$ Regal S, Li H, Hamza T, Knittle S, Li B. Poster Presentation. Could platelet-rich plasma be an effective treatment for bone infections? Health Sciences Van Liere Memorial Convocation and Research Day, Morgantown, WV, April 2010. $\left(1^{\text {st }}\right.$ place award)

- Li H, Hamza T, Li B. Poster Presentation. In vitro antibacterial effects of platelet-rich plasma on bacterial strains related to bone infection. Orthopaedic Research Society (ORS) Annual Meeting, New Orleans, LA, March 2010.

- Hamza T, Li H, Jiang B, Knittle S, Li B. Poster Presentation. Prevention of bone-related infections using drug-loaded nanoparticles. The 21st EPSCoR National Conference (NSF), Washington, DC, October 2009.

- Hamza T, Li H, Ogle H, Li B. Poster Presentation. Cefazolin embedded polypeptide nanofilms is promising for infection prevention: A study on cell responses. WVNano Research Symposium, Morgantown, WV, May 2009.

- Hamza T, Li B. Poster presentation. Self-assembly multifunctional nanocoatings for biomedical applications. Multifunctional Nanomaterials International Symposium, Roanoke, WV, April 2008. ( $1^{\text {st }}$ place award)

- Ogle H, Hamza T, Li B. Poster Presentation. Antibiotic-eluting nanotechnology coatings for potential prevention of device-associated infections. WV Undergraduate Research Day at the Capitol, Charleston, WV, January 2008.

\section{Professional Experience}

- Organizing School of Pharmacy Research Day............................ 2010

- Teaching Arabic As A Second Language.............................2007-2010

\section{Membership in Professional Organizations}

- American Association of Pharmaceutical Scientists

- Orthopaedic Research Society

- The Association of Medical Laboratory Immunologists (AMLI)

- Microbiology Group Members

\section{Personal Strengths and Skills}

Achiever, Inducer, Positive, Restorative, and Social 